\title{
Recovery of nutrients \\ from biogas digestate \\ with biochar and clinoptilolite
}

Nazlı Pelin Kocatürk 


\section{Thesis committee}

\section{Promotors}

Prof. Dr L. Stoumann Jensen

Professor of Soil Fertility and Waste Resource Recycling

Department of Plant and Environmental Sciences

University of Copenhagen, Denmark

Prof. Dr L. Brussaard

Professor of Soil Biology and Biological Soil Quality

Wageningen University

\section{Co-promotors}

Dr. S. Bruun

Associate professor at the Department of Plant and Environmental Sciences

University of Copenhagen, Denmark

Dr. Kor B. Zwart

Senior Scientist

Alterra, Wageningen University and Research Centre

\section{Other members of the committee}

Prof. Dr. R.N.J. Comans, Wageningen University

Prof. Dr. E. Meers, Ghent University, Belgium

Prof. Dr. A. de Neergaard, University of Copenhagen, Denmark

Dr. H.J.M. Visser, Energy Research Centre of the Netherlands

This research was conducted under the auspices of the Ph.D. School of Science of the University of Copenhagen and the C.T. de Wit Graduate School for Production Ecology and Resource Conservation of Wageningen University under the ERASMUS MUNDUS Joint Doctorate Program Agricultural Transformation by Innovation (AgTraIn). 


\title{
Recovery of nutrients \\ from biogas digestate \\ with biochar and clinoptilolite
}

\author{
Nazlı Pelin Kocatürk
}

Thesis

submitted in fulfilment of the requirements for the joint degree of Doctor at Wageningen University and University of Copenhagen by the authority of the Rector Magnificus Prof. Dr A.P.J. Mol, and Head of Ph.D. School of SCIENCE, Prof. Morten Pejrup in the presence of the Thesis Committee appointed by

the Academic Board, Wageningen University, and the Ph.D. School of SCIENCE, University of Copenhagen to be defended in public on Friday 24 June 2016

at 11:00 a.m. in the Aula of Wageningen University. 


\section{N.P. Kocatürk}

Recovery of nutrients from biogas digestate with biochar and clinoptilolite 130 pages.

$\mathrm{PhD}$ thesis, University of Copenhagen, Copenhagen, Denmark

Wageningen University, Wageningen, The Netherlands (2016)

With references, with summaries in English and Danish

ISBN: 978-94-6257-823-4

DOI: $10.18174 / 382569$ 
In memory of my mother Aysel Kocatürk

Annem Aysel Kocatürk'ün değerli anısına adanmıștır 
"Science is the most reliable guide for civilization, for life, for success in the world. "

Mustafa Kemal Atatürk

The Founder of Turkish Republic

"Dünyada her şey için; uygarlık için, hayat için, başarı için en hakiki mürșit ilimdir; fendir. "

Mustafa Kemal Atatürk 


\section{Table of Contents}

Chapter 1 General Introduction 1

Chapter 2 Nutrient recovery from the liquid fraction of digestate by clinoptilolite

Chapter 3 Chemical activation of biochar for enhanced nutrient removal from liquid manure digestate

Chapter 4 Does the combination of biochar and clinoptilolite enhance nutrient recovery from the liquid fraction of biogas digestate?

Chapter 5 Efficiency of digestate-enriched clinoptilolite and biochar as nitrogen fertilisers

Chapter 6 General Discussion 85

Chapter 7 Conclusions and Outlook 97

References 103

Summary 113

Resumé

Acknowledgements

Curriculum Vitae

PE\&RC Training and Education Statement 


\section{Chapter 1 \\ General Introduction}




\subsection{Motivation}

The number of biogas plants has rapidly increased over the last decades (Vázquez-Rowe et al., 2015). This has brought the need to improve techniques to handle digestate, the by-product of anaerobic digestion in biogas plants. Separation of digestate into liquid and solid fractions is often used at centralised biogas plants, which facilitates the subsequent transportation of nutrients (Jensen, 2013a). The liquid fraction of digestate contains nutrients mainly in ionic form which makes it a valuable fertiliser in agricultural crop production systems. The most common practice of utilising the liquid fraction of digestate is direct field application if the biogas plant is in the vicinity (Drosg et al., 2015). However, direct application of digestate may raise practical and environmental problems if the biogas plant is farther away (Fuchs \& Drosg, 2013). Therefore, processes to concentrate nutrients have been proposed aiming not only to treat the liquid fraction of digestate to overcome the problems related to direct application, but also to recover of nutrients of which natural reserves are being depleted such as phosphorus and potassium. In this thesis, the focus is on the evaluation of the use of clinoptilolite and biochar to recover nutrients from the liquid fraction of digestate; and to investigate the further use of these nutrient-enriched materials as fertiliser.

\subsection{Digestate as a source of nutrients}

The focus of waste management has shifted from disposal to minimization, recovery and recycling. Anaerobic digestion as a biological treatment technology applied to manure slurry is becoming widespread. The products from this technology comprise biogas (methane, carbon dioxide and other trace gases), which is a potential energy source, and a nutrient-rich sludge, which can be used as a fertiliser. Thus, the production of biogas as well as the recovery of nutrients makes anaerobic digestion of manure slurry a valuable waste treatment concept (Hartmann \& Ahring, 2006).

Digestates are reported to have decreased organic matter content, decreased total and organic carbon contents, elevated $\mathrm{pH}$, and lower carbon to nitrogen ratios (C:N ratios) compared to undigested manures (Möller \& Müller, 2012). The differences in digestate compared to manure may have both benefits and 
disadvantages when they are applied in the soil as fertiliser (Jensen, 2013a). The characteristics and the fertiliser value of digestate depend on the nutrients present in the feedstock as well as on the operational parameters of the anaerobic digestion process (Drosg et al., 2015). Under anaerobic conditions, organic forms of nitrogen (N) are converted into ammonium $\left(\mathrm{NH}_{4}-\mathrm{N}\right)$ due to mineralisation during the digestion. Feedstocks with a high degradability such as poultry and pig manures may result in over 80\% $\mathrm{NH}_{4}-\mathrm{N}$ (Sørensen \& Jensen, 2013). Following land application, nitrogen can be taken up directly by plants as $\mathrm{NH}_{4}-\mathrm{N}$ or as nitrate $\left(\mathrm{NO}_{3}\right.$ N) following nitrification, a process which occurs very rapidly in most soils. However, excessive application or inefficient utilisation of $\mathrm{N}$ by crops may result in risk of $\mathrm{NO}_{3}-\mathrm{N}$ leaching and therefore $\mathrm{N}$ losses.

\subsection{Benefits and challenges related to direct land application of digestate}

\section{Benefits of direct application of digestate}

During anaerobic digestion, the nutrient content of the waste (animal manure) is mostly conserved, hence digestate contains a broad range of nutrients such as $\mathrm{N}$, phosphorus (P), potassium (K), magnesium (Mg), sulphur (S) and trace elements (Møller et al., 2009). Therefore digestate can serve as an organic fertiliser which can replace inorganic fertilisers (Möller \& Müller, 2012). Nitrogen is often the growth limiting factor for crops (Walsh et al., 2012) and the form of $\mathrm{N}$ is important for plant availability. Digestate has a higher content of plant-available $\mathrm{N}$ than undigested manure due to the increase in ammonium content during the anaerobic digestion process, (Jensen, 2013a). It has been reported that the application of digestate as fertiliser has benefits over undigested slurry (Möller \& Müller, 2012; Vaneeckhaute et al., 2013). Additionally, the replacement of inorganic fertilisers with digestate has the potential to reduce dependence on inorganic fertiliser and so the energy demand for their production, and also the economic costs associated with their use (Walsh et al., 2012).

\section{Environmental challenges}

Direct application of digestate may result in air and water pollution due to nutrient losses in the environment, especially via ammonia emission and leaching 
and runoff of N and P (Velthof et al., 2015). Digestate contains ammonium which is the form of $\mathrm{N}$ that can readily be adsorbed in the soil. Leaching of ammonium is usually very low except in sandy soils with low cation exchange capacity (CEC). However, ammonium can be converted to nitrate through nitrification within a few days. Nitrate cannot be adsorbed in the soil and is, therefore, prone to leaching (Sørensen \& Jensen, 2013). Leaching of $\mathrm{N}$ can contribute to pollution of groundwater and surface waters (Sørensen \& Jensen, 2013; EPA, 2016). Emission of ammonia, nitrous oxide $\left(\mathrm{N}_{2} \mathrm{O}\right)$ and malodorous gases may occur which cause unpleasant odours during storage and after field application (Feilberg \& Sommer, 2013; Velthof et al., 2015). In addition to odour problems, use of digestate may contribute to soil pollution via deposition of ammonia and nitrogen oxides (Zarebska et al., 2015).

Leaching of $\mathrm{P}$ holds the risk of eutrophication in sensitive areas. The liquid fraction of digestate mainly contains the soluble, ionic from of $\mathrm{P}$, orthophosphate, which is prone to losses shortly after field application (Sørensen \& Jensen, 2013). More effective use of $\mathrm{P}$ is necessary because of environmental concerns and benefits. Phosphorus is an important nutrient for agricultural production, an essential element for all living species, and a non-renewable resource on a human time scale (van Dijk et al., 2016).

Potassium in digestate can potentially be lost by runoff and leaching. Potassium losses are not considered an environmental problem as most $\mathrm{K}$ in the liquid fraction of digestate is present in ionic form, $\mathrm{K}^{+}$, which can be adsorbed on negatively charged soil particles after field application. However, losses should be minimized as $\mathrm{K}$ is a valuable plant nutrient (Sørensen \& Jensen, 2013).

Although most plant nutrients that are in the ionic form can be adsorbed in the soil, they can also be quickly leached after field application of liquid fraction of digestate by macropore flow or lost by surface runoff (Sørensen \& Jensen, 2013).

\section{Practical challenges}

In the European Union (EU) the annual biogas production increased by $106 \%$ from 2006 to 2011, predominantly in countries such as Germany, Belgium and Italy (Vázquez-Rowe et al., 2015). The recent growth in number of biogas plants, hence, digestate produced, has led to restrictions in several EU countries, not only in the allowed nutrient input per hectare on agricultural land, but also in the fertiliser 
application periods to minimize nutrient leaching (Paavola \& Rintala, 2008; Drosg et al., 2015). Therefore, adequate digestate storage capacity is required, to be able to synchronize application with crop demand. Furthermore, the high volumes of digestate to be applied on agricultural land often lead to logistic problems (Ghafoori \& Flynn, 2007; Møller et al., 2009; Rehl \& Müller, 2011). Transportation of digestate to wider application areas is necessary to prevent overloading of the receiving land with nutrients in excess of crop demand. Management and utilisation of the untreated or liquid fraction of digestate presents a challenge in areas with very high animal densities or no cropping land suitable for digestate fertilisation (Zarebska et al., 2015).

\subsection{Treatment of digestate}

Restrictions on manure and digestate application in areas with high livestock density require further treatment of manure and digestate. Another important motivation for treatment of manures and digestate is the recovery of nutrients whose natural reserves are being depleted such as phosphorus and potassium (Lebuf et al., 2013; Drosg et al., 2015). Phosphate-rich rocks used for P fertiliser production are projected to become exhausted within the next few hundred years (van Dijk et al., 2016).

Mechanical separation is usually the first treatment step for manure, digestate from anaerobic digestion of manure and other biowastes (Jensen, 2013b). Mechanical separation of digestate can be implemented with several techniques such as screw presses, decanting centrifuges, etc. This results in a solid fraction rich in organic $\mathrm{N}$ and $\mathrm{P}$, and a liquid fraction with low $\mathrm{P}$, but higher mineral $\mathrm{N}$ and $\mathrm{K}$ contents (Møller et al., 2002; Figure 1.1).

Separated solids can directly be applied due to lower transportation costs and decreased storage volume than liquid digestate (Teglia et al., 2011a; Fuchs \& Drosg, 2013). On the other hand, separated solids can be further stabilised through composting to be used as a soil amendment (Teglia et al., 2011b) or can be thermally dried (Pantelopoulos et al., 2016). Combustion/thermal gasification, ash extraction and pyrolysis can also be applied for further treatment of solid digestates (Jensen, 2013b; Christel et al., 2014). 


\begin{tabular}{|c|c|c|}
\hline \multirow[b]{3}{*}{ Dry Matter } & \multirow{2}{*}{\multicolumn{2}{|c|}{$\square$ Solid fraction }} \\
\hline & & \\
\hline & $40-50 \%$ & $50-60 \%$ \\
\hline Total N & $65-75 \%$ & $25-35 \%$ \\
\hline Ammonium & $70-80 \%$ & $20-30 \%$ \\
\hline Total P & $35-45 \%$ & $55-65 \%$ \\
\hline Potassium & $70-80 \%$ & $20-30 \%$ \\
\hline Carbon & $30-40 \%$ & $60-70 \%$ \\
\hline
\end{tabular}

Figure 1.1 Distribution of dry matter and nutrients in liquid and solid fraction of digestate after separation (Adapted from Fuchs \& Drosg, 2013).

Further treatment methods for the liquid fraction of digestate with the intention of reducing volume and recovering nutrients are summarized in Figure 1.2. Increasing nutrient concentrations can be achieved by $\mathrm{NH}_{3}$ stripping, or through membrane technologies such as ultrafiltration or reverse osmosis. Another way to recover nutrients is by chemical precipitation with magnesium ammonium phosphate (struvite) or calcium phosphates (Lebuf et al., 2013; Sigurnjak et al., 2016). As ammonium is almost always in excess, magnesium oxide and phosphoric acid are added to the liquid fraction of digestate (Drosg et al., 2015).

Sorption processes such as ion exchange can also be applied to concentrate nutrients from the liquid fraction of digestate. However, ion exchange is only marginally applied in practice, usually for final ammonium removal after membrane processes (Drosg et al., 2015). Some researchers studied removal of ammonium and phosphorus from treated pig production and pre-treated dairy wastewaters by ion exchange (Sánchez et al., 1995; Milan et al., 1997; Henriksen et al., 1998; Nguyen \& Tanner, 1998) or as an additional $\mathrm{N}$ 


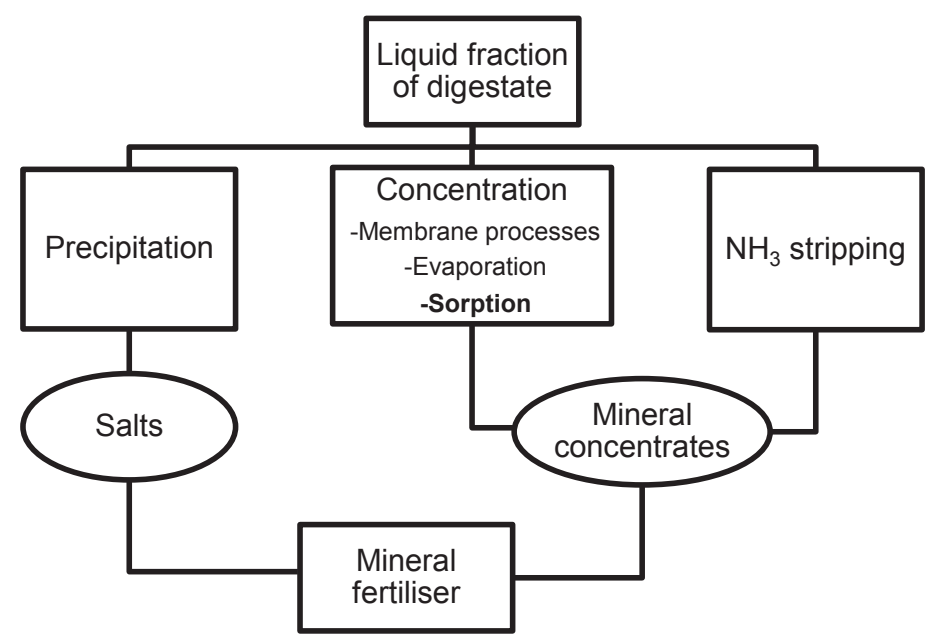

Figure 1.2 Overview of different options for processing liquid fraction of digestate and for final products obtained from these processes (Adapted from Jensen, 2013).

removal process after membrane separation or evaporation (Guo et al., 2007; Fuchs \& Drosg, 2013). However, none of these studies reported ion exchange from digestate or the liquid fraction, which has a much higher ammonium concentration compared to treated pig production and dairy wastewaters.

The recovered nutrients in precipitates and mineral concentrates can be directly applied to land. The residues of the treated liquids may further be treated at a wastewater treatment plant to be eventually discharged (Drosg et al., 2015).

Aforementioned methods can be considered as promising techniques in terms of obtaining high nutrient separation efficiencies from digestate. However, the operational cost of the processes should be taken into consideration in terms of chemicals and energy. It should also be noted that the final product of recovery processes should be plant available and environmentally acceptable in terms of field application. Therefore, economical, agricultural and environmental aspects should be considered at the same time when selecting a treatment method. 


\subsection{Clinoptilolite as a sorbent}

Clinoptilolite, a natural zeolite, is a cation exchanger which belongs to the heulandite group. It has a three-dimensional framework of silicon and aluminium tetrahedra, with the chemical formula $\mathrm{Na}_{6}\left[\left(\mathrm{Al}_{2} \mathrm{O}_{3}\right)\left(\mathrm{SiO}_{2}\right)_{30}\right] \cdot 24 \mathrm{H}_{2} \mathrm{O}$ (Inglezakis, 2005). The CEC of clinoptilolite is constituted by the replacement of $\mathrm{Si}^{4+}$ by $\mathrm{Al}^{3+}$ which causes a negative charge which is balanced by mono- or di- valent cations such as sodium, calcium, potassium, and ammonium, which are exchangeable with other cations (Hedström, 2008).

Clinoptilolite has a high selectivity for ammonium and potassium which is the result of its selective nature towards cations with the selectivity ranking given by Ames (1960) as $\mathrm{Cs}^{+}>\mathrm{Rb}^{+}>\mathrm{K}^{+}>\mathrm{NH}_{4}{ }^{+}>\mathrm{Ba}^{2+}>\mathrm{Sr}^{2+}>\mathrm{Na}^{+}>\mathrm{Ca}^{2+}>\mathrm{Fe}^{3+}>\mathrm{Al}^{3+}>\mathrm{Mg}^{2+}>$ $\mathrm{Li}^{+}$. Clinoptilolite has been found to be efficient at removing orthophosphate from aqueous solutions (Milan et al., 1997; Ganrot et al., 2007; Allar \& Beler-Baykal, 2013; Lin et al., 2015), even though orthophosphate is an anion and cannot be removed through ion exchange by clinoptilolite. Orthophosphate removal occurs via physical adsorption on $\mathrm{Al}^{3+}$ sites of clinoptilolite (Sakadevan \& Bavor, 1998; Ganrot et al., 2008).

Clinoptilolite has been extensively used for industrial treatment to remove heavy metals (Erdem et al., 2004; Günay et al., 2007; Kocasoy \& Sahin, 2007) and domestic wastewater treatment, especially for ammonium removal (Beler-Baykal et al., 1996; Beler Baykal \& Guven, 1997; Nguyen \& Tanner, 1998; Hedström, 2008). It has been used for nutrient recovery from human urine with high efficiencies (Ganrot et al., 2007, 2008; Beler Baykal et al., 2009; Kocatürk \& Baykal, 2012; Allar \& Beler Baykal, 2015). As a natural mineral, it can be regarded as an easily available and reasonably-priced product since there are many deposits around the world (Inglezakis, 2005).

One possible route to recover nutrients from the liquid fraction of digestate can be by processing with clinoptilolite. Since the liquid fraction of digestate contains nutrients (particularly $\mathrm{N}$ and $\mathrm{K}$ ) predominantly in ionic forms, ion exchange and adsorption technologies can potentially be applied to recover and concentrate valuable nutrients from the liquid fraction of digestate. The final product (nutrientenriched clinoptilolite) could subsequently be used as a slow-release fertiliser for agricultural purposes. 


\subsection{Biochar as a sorbent}

Biochar is a relatively-new term for the solid product obtained by pyrolysis of biomass under complete or partial exclusion of oxygen (Lehmann \& Joseph, 2015). International Biochar Initiative (IBI, 2016) defines biochar as: 'A solid material obtained from thermochemical conversion of biomass in an oxygen-limited environment'. Biochar can be used for a range of applications, as an agent for soil improvement, improved resource use efficiency, remediation and/or protection against particular environmental pollution and greenhouse gas mitigation. In addition, to be recognized as biochar, the material has to pass a number of material property definitions that relate both to its quality (e.g., $\mathrm{H}: \mathrm{C}_{\text {org }}$ ratios relate to the degree of charring and therefore mineralisation in soil) and its safety (e.g., heavy metal and other contaminant content). Shackley et al. (2010) define biochar as: "a porous carbonaceous solid, produced by thermochemical conversion of organic materials in an oxygen depleted atmosphere which has physicochemical properties suitable for the safe and long-term storage of carbon in the environment and, potentially, soil improvement". As it can be deduced from the definitions of biochar, the potential biochar applications have been reported as carbon sequestration, soil fertility improvement, pollution remediation, and agricultural by-product and waste recycling (Ahmad et al., 2014).

The physical and structural characteristics of biochar are dependent on both the characteristics of the original biomass feedstock and those of the pyrolysis process such as pyrolysis temperature and heating rate (Chia et al., 2015). These parameters affect the elemental composition of biochar as well as the surface area and CEC, which both influence the nutrient retention properties of biochar. In general, biochars produced by slow pyrolysis show greater N, S, available P, Ca, Mg, surface area and CEC as compared to biochars produced with fast pyrolysis (Ippolito et al., 2015). Increasing pyrolysis temperature usually results in decreasing biochar yield but increasing biochar total $\mathrm{C}, \mathrm{K}, \mathrm{Mg}$ and ash content, $\mathrm{pH}$ and surface area, and decreasing CEC (Mukherjee et al., 2011; Ippolito et al., 2015).

Cation retention by biochar is explained by electrostatic adsorption to negatively-charged oxygen-containing surface functional groups (Wang et al., 2015a). Newly produced biochars are known to have a low ability to adsorb cations due to the presence of fewer oxygen-containing functional groups (Cheng et al., 
2014). Therefore chemical oxidation (or activation) of biochar has been proposed to increase the sorption ability of biochar (Xue et al., 2012).

Biochar has been proposed as a sorbent for removing organic and inorganic contaminants from various types of wastewaters (Ahmad et al., 2014). Biochar has also been discussed as a potential material to recover nutrients from liquid wastes with high nutrient concentrations, such as dairy manure and ruminant urine (Taghizadeh-Toosi et al., 2012a; Sarkhot et al., 2013). Therefore biochar might be used as a sorbent to recover and concentrate valuable nutrients from the liquid fraction of digestate.

\subsection{Objectives}

The overall objective of this thesis is to investigate the use of clinoptilolite and biochar to recover plant nutrients from the liquid fraction of digestate resulting from anaerobic digestion of animal manure, and to investigate the plant-availability of the recovered form of nutrients.

The specific objectives are to:

- Determine the effects of preconditioning of clinoptilolite and initial loading ratio on the removal efficiency of plant nutrients from the liquid fraction of digestate (Chapter 2).

- Determine the effect of chemical activation of biochar on nutrient removal efficiency from the liquid fraction of digestate (Chapter 3).

- Determine the effects of initial loading ratio on the nutrient removal efficiency of biochar; and the effect of clinoptilolite and biochar combinations on the nutrient removal from the liquid fraction of digestate (Chapter 4).

- Quantify the plant growth promotion, nitrogen uptake and fertiliser efficiency of nutrient-enriched biochar and clinoptilolite (Chapter 5).

\subsection{Thesis outline and experimental approach}

Following the General Introduction (Chapter 1), I investigated the use of clinoptilolite as a sorbent to recover nutrients from the liquid fraction of digestate in Chapter 2. Clinoptilolite has been used for decades to remove ammonium from 
wastewaters (Hedström, 2008) and more recently to recover nutrients from human urine (Kocatürk \& Baykal, 2012; Allar \& Beler Baykal, 2015). In this chapter, I studied the effects of preconditioning of clinoptilolite on the removal efficiency of nutrients from the liquid fraction of digestate. I conducted experiments where both a synthetic solution and the liquid fraction of digestate are brought into contact with clinoptilolite, preconditioned at various concentrations of sodium chloride. In addition, I determined the effect of initial loading ratio in column experiments on the nutrient-removal efficiency from the liquid fraction of digestate.

In Chapter 3, I studied the chemical activation of biochar by treating the biochar with deionised water and hydrogen peroxide, sulfuric acid and sodium hydroxide solutions. Biochar has been suggested as a sorbent for ammonium (TaghizadehToosi et al., 2012a; Hale et al., 2013; Gai et al., 2014; Carey et al., 2015; Cui et al., 2016), orthophosphate (Hollister et al., 2013; Sarkhot et al., 2013; Xu et al., 2014) and organic contaminants (Ahmad et al., 2014; Mohan et al., 2014; Wang et al., 2015 b) removal from various wastewaters. Chemical activation of biochar has been shown to increase the oxygen-containing functional groups (Xue et al., 2012; Wang et al., 2015a) which affects the cation sorption on biochar, and orthophosphate removal due to cation bridge bonding (Lin et al., 2012; Qian et al., 2013). I investigated the effects of activation on oxygen-containing functional groups and ammonium, orthophosphate and potassium removal from the liquid fraction of digestate.

In Chapter 4, I studied the use of biochar, and the combination of biochar with clinoptilolite for nutrient recovery from liquid fraction digestate in column experiments. I investigated the effects of initial loading ratio of biochar on the removal efficiency of ammonium, potassium, orthophosphate and organic matter from the liquid fraction of digestate. In the second part of the experimental work in this chapter, I investigated the effects of combinations of clinoptilolite and biochar on the nutrient removal efficiency as compared to clinoptilolite and biochar alone.

In Chapter 5, I tested nutrient enriched biochar and clinoptilolite as nitrogen fertiliser. I investigate the ability of biochar and clinoptilolite enriched with digestate nutrients to supply $\mathrm{N}$ to plants. I conducted a pot experiment in the greenhouse (Figure 1.3) using the double-pot technique (Janssen, 1990) with 


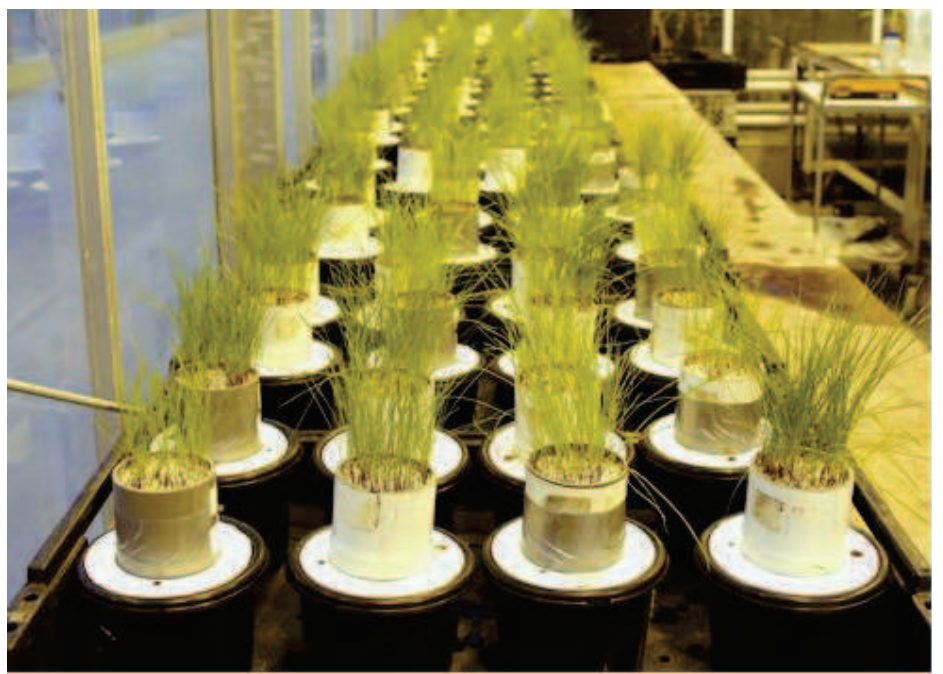

Figure 1.3 Pot experiment using the double pot technique.

ryegrass to test the effect of nutrient-enriched clinoptilolite and biochar, including the effect of initial loading ratio, by determining plant biomass growth and N uptake.

In the General Discussion (Chapter 6), I synthesised and integrated the main findings of my research in light of the literature and discussed their implications.

I conclude this thesis with a general conclusion in Chapter 7 (Conclusions and Outlook) with a reflection on the findings of this thesis in the context of practical applicability of biochar and clinoptilolite for digestate treatment. 


\title{
Chapter 2 \\ Nutrient recovery from the liquid fraction of digestate by clinoptilolite
}

\author{
N.Pelin Kocatürk \\ Kor Zwart \\ Sander Bruun \\ Lars Stoumann Jensen
}

This chapter is under review. 


\begin{abstract}
The direct application of the liquid fraction of biogas digestate to the agricultural fields as a fertiliser may result in practical and environmental problems. Concentrating nutrients onto clinoptilolite and subsequently using clinoptilolite as a fertiliser could be an alternative solution for the management of nutrients in the liquid fraction of digestate. In this study, we investigated the use of clinoptilolite to recover ammonium, potassium and orthophosphate from the liquid fraction of digestate by determining the optimal preconditioning of clinoptilolite and the optimal initial nutrient-to-clinoptilolite loading ratio for highest nutrient removal efficiency.

Preconditioning of clinoptilolite had no significant effect on the total ammonium and potassium removal from the liquid fraction of digestate.

An increase in the initial loading ratio significantly increased nutrient concentrations on the clinoptilolite, but decreased nutrient removal efficiencies from the liquid fraction of digestate: removal efficiencies ranged from $40 \%$ to $89 \%$ for ammonium, 37 to $78 \%$ for potassium and 64 to $80 \%$ for orthophosphate at various initial loading ratios.

Overall, the increase in the concentration of nutrients on the clinoptilolite was rather low, however nutrients could be removed from the liquid fraction of digestate with high removal efficiencies, and this indicated that the use of clinoptilolite could be a solution for improved management and utilisation of the liquid fractions of digestate.
\end{abstract}




\subsection{Introduction}

Digestate from the anaerobic digestion of manure and other organic wastes has a nutrient content which typically is favorable for use as a crop fertiliser, with direct land application often being the most cost-effective solution (Rico et al., 2011; Fuchs \& Drosg, 2013). However, digestate is not an easy by-product to handle due to its high water content and consequently its large volume and low nutrient concentration. In many European Union countries, manure and digestate-spreading periods on agricultural land are restricted in order to minimize nutrient leaching and run-off, and therefore a large storage capacity for manure and digestate is needed. Storage is expensive and the transportation of large volumes of water is ineffective from both a logistical and economic point of view (Paavola \& Rintala, 2008; Rehl \& Müller, 2011). Moreover, environmental problems such as gaseous emissions of malodors, ammonia and greenhouse gases as well as nutrient runoff to streams and waterways may occur when digestate is applied to agricultural land (Hjorth et al., 2009). Processing of manure and digestate may potentially overcome practical and environmental problems related to their direct application on land by reducing their environmental impacts, and improve the fertilising efficiency of manure and digestate (Fuchs \& Drosg, 2013; Zarebska et al., 2015).

One of the processing techniques used is the separation of manure or digestate into liquid and solid fractions before spreading the products on land (Ghafoori \& Flynn, 2007; Hjorth et al., 2010; Teglia et al., 2011a). Separation of liquids and solids will also result in a partial separation of nitrogen $(\mathrm{N})$ and phosphorus $(\mathrm{P})$. The liquid fraction contains the majority of inorganic $\mathrm{N}$ and potassium (K), while $\mathrm{P}$ and organic $\mathrm{N}$ mainly remain in the solid fraction (Møller et al., 2002). However, a certain amount of phosphorus will be in the liquid fraction of the digestate, which still remains a very dilute nutrient solution. Further concentration of these nutrients in the liquid fraction could reduce transportation costs and potentially increase the fertiliser efficiency of the liquid fraction of manure and digestate. Concentration techniques using water evaporation and ammonia stripping consume a great deal of energy and are usually rather costly (Christensen et al., 2013; Fuchs \& Drosg, 2013; Zarebska et al., 2015). Treatment of digestate using an ion exchanger/adsorptive agent may therefore present an attractive alternative.

Clinoptilolite (a natural zeolite) can potentially be used as an adsorptive agent for such purposes as it is a highly selective cation exchanger, especially for 
potassium and ammonium. In a number of studies, ion exchange with clinoptilolite has been shown to be very effective for the removal of ammonium from domestic wastewater (Koon \& Kaufman, 1975; Beler-Baykal et al., 1996; Beler Baykal \& Guven, 1997; Hedström, 2008) and high removal efficiencies for both ammonium and potassium from source-separated human urine have been reported in literature (Ban \& Dave, 2004; Beler Baykal et al., 2009; Kocatürk \& Baykal, 2012). Since the liquid fractions of manure and digestate contain nutrients, particularly nitrogen and potassium, predominantly in ionic forms, ion exchange and adsorption technologies can potentially also be applied to recover and concentrate valuable nutrients from the liquid fraction of manure and digestate. The final product (nutrient enriched clinoptilolite) can be used as a slow release fertiliser for agricultural purposes.

The homoionic state of zeolites has been found to improve their effective exchange capacity and performance in ion exchange applications (Inglezakis, 2005; Inglezakis \& Zorpas, 2012). The homoionic form can be produced by preconditioning clinoptilolite which aims to replace ions from the clinoptilolite surface with ions that can be removed more easily (Inglezakis et al., 2001). Sodium chloride is a widely used agent for preconditioning clinoptilolite (Inglezakis et al., 2001; Lin et al., 2013, 2015) and has been found to be the most efficient preconditioning agent, compared to other salts, for removing ammonium (Koon \& Kaufman, 1975; Milan et al., 1997). This is because sodium ions can be easily exchanged with cations such as ammonium from solutions (Inglezakis et al., 2001; Inglezakis, 2005) as a result of the selective nature of clinoptilolite towards cations with the selectivity ranking given by Ames (Ames, 1960) as $\mathrm{Cs}^{+}>\mathrm{Rb}^{+}>\mathrm{K}^{+}>\mathrm{NH}_{4}{ }^{+}>$ $\mathrm{Ba}^{2+}>\mathrm{Sr}^{2+}>\mathrm{Na}^{+}>\mathrm{Ca}^{2+}>\mathrm{Fe}^{3+}>\mathrm{Al}^{3+}>\mathrm{Mg}^{2+}>\mathrm{Li}^{+}$. Preconditioning has been reported to increase ammonium removal from domestic wastewater or from other solutions (Inglezakis et al., 2001). However these solutions have lower ammonium and organic matter concentrations than the liquid fractions of digestate, and the effects of preconditioning on the nutrient removal from the liquid fraction of digestate have not been reported so far.

Clinoptilolite has also been found to be efficient at removing phosphorus from aqueous solutions (Milan et al., 1997; Ganrot et al., 2007; Allar \& Beler-Baykal, 2013; Lin et al., 2015). Investigations of the effect of the initial ammonium loading ratio (the starting amount of ammonium provided in the system per gram of clinoptilolite) on the removal of ammonium and potassium from human urine with clinoptilolite has shown that initial loading is a significant parameter affecting 
removal efficiency (Beler Baykal et al., 2009). However, the effects of initial loading ratio on the phosphorus removal from liquid solutions have not been reported.

The overall objective of the current study was to test the use of clinoptilolite for the recovery of important plant nutrients from the liquid fraction of digestate resulting from the anaerobic digestion of animal manure. The specific objectives were to determine i) the optimal preconditioning of clinoptilolite and ii) the optimal initial nutrient/clinoptilolite loading ratio for maximum nutrient removal efficiency.

It was hypothesized that clinoptilolite would act as an efficient cation exchanger from the liquid fraction of digestate, that preconditioning would increase its cation exchange capacity and that nutrient removal efficiency would be affected by the initial loading ratio.

\subsection{Materials and Methods}

The clinoptilolite used was from Gördes in the Western Anatolian region of Turkey and has a typical composition (provided by the manufacturer) of 65-72\% $\mathrm{SiO}_{2}, 10-12 \% \mathrm{Al}_{2} \mathrm{O}_{3}$, 0.7-1.9 \% $\mathrm{Fe}_{2} \mathrm{O}_{3}$, 0.1-0.5 \% $\mathrm{Na}_{2} \mathrm{O}, 2.5-3.8 \% \mathrm{~K}_{2} \mathrm{O}, 2.4-3.7 \% \mathrm{CaO}$, $0.9-1.2 \% \mathrm{MgO}, 0-0.08 \% \mathrm{MnO}$ and $0.02-0.05 \% \mathrm{P}_{2} \mathrm{O}_{5}$. The particle size of the clinoptilolite used in the experiments was $1-3 \mathrm{~mm}$.

The liquid fraction of digestate was collected from a centralised biogas plant (Fangel Bioenergy ApS, Odense, Denmark) where digestate is separated into liquid and solid fractions by a decanter centrifuge (Gea Westfalia, AD 1220, Oelde, Germany). The characterization of the liquid fraction of digestate samples (different batches) and synthetic solution (prepared with $\mathrm{NH}_{4} \mathrm{Cl}$ and $\mathrm{KCl}$ ) is shown in Table 2.1. In all experiments, the $\mathrm{pH}$ of the liquid fraction of digestate and synthetic solution was adjusted to 6.5-7.0 using $\mathrm{HCl}(37 \%)$ to prevent ammonia volatilisation.

Table 2.1 Characterization of the liquid fractions of digestate (range indicates concentration variation between liquid fractions used) and synthetic solution used in the experiments.

\begin{tabular}{lll}
\hline Parameters & Liquid fraction of digestate & Synthetic solution \\
\hline $\mathrm{NH}_{4}-\mathrm{N}\left(\mathrm{mg} \mathrm{L}^{-1}\right)$ & $3750-4120$ & 2960 \\
$\mathrm{~K}_{\left(\mathrm{mg} \mathrm{L}^{-1}\right)}$ & $2185-2440$ & 2370 \\
$\mathrm{PO}_{4}-{\mathrm{P}\left(\mathrm{mg} \mathrm{L}^{-1}\right)}_{\mathrm{Ca}\left(\mathrm{mg} \mathrm{L}^{-1}\right)}^{110-125}$ & -- \\
$\mathrm{Mg}\left(\mathrm{mg} \mathrm{L}^{-1}\right)$ & $118-223$ & -- \\
$\mathrm{Na}\left(\mathrm{mg} \mathrm{L}^{-1}\right)$ & $45-81$ & -- \\
$\mathrm{Fe}\left(\mathrm{mg} \mathrm{L}^{-1}\right)$ & $1385-1655$ & -- \\
\hline
\end{tabular}




\section{Effect of preconditioning of clinoptilolite on nutrient removal}

Preconditioning of clinoptilolite was established by loading the clinoptilolite with sodium ions using different concentrations of sodium chloride, i.e. $0.01 \mathrm{M}, 0.1$ $\mathrm{M}$ and $1 \mathrm{M} \mathrm{NaCl}$. Preconditioning of clinoptilolite was performed in Plexiglas columns $2.4 \mathrm{~cm}$ in diameter and $100 \mathrm{~cm}$ long, with $60 \mathrm{~min}$ residence time and a flow rate of $2 \mathrm{~mL} \mathrm{~min}^{-1}$ for 24 hours (Figure 2.1a).

Subsequently, the natural or preconditioned clinoptilolite was mixed with synthetic solution or the liquid fraction of digestate at a ratio of 1:10 clinoptilolite (g) to synthetic solution or liquid fraction of digestate $(\mathrm{mL})$, and shaken for 24 hours in an orbital shaker at $20-25^{\circ} \mathrm{C}$.

\section{Effect of initial ammonium loading ratio on nutrient removal efficiency}

The effect of the initial loading ratio on the ammonium, potassium and orthophosphate removal efficiency was investigated in column experiments in which the liquid fraction of digestate was pumped through a column packed with clinoptilolite. Plexiglas columns were filled with 50-100 g of preconditioned clinoptilolite. The liquid fraction of digestate was fed into the columns by a peristaltic pump (Masterflex L/S Series) at $100 \%$ recycling in the upflow mode for 120 hours (Figure $2.1 \mathrm{~b}$ )
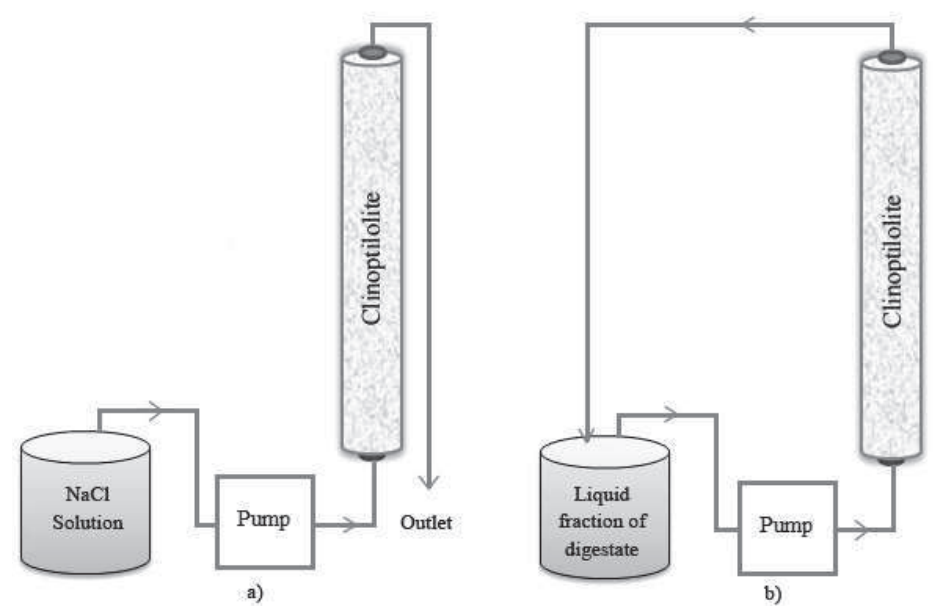

Figure 2.1 Experimental setup for the preconditioning of clinoptilolite (a) and nutrient loading experiments (b). 
Column experiments with various initial ammonium loading ratios were conducted. The experimental conditions are summarized in Table $2.2\left(\mathrm{~L}_{10}-\mathrm{L}_{52}\right.$ designates the different initial ammonium loading ratios). The amount of clinoptilolite used in $\mathrm{L}_{31}$, $\mathrm{L}_{41}, \mathrm{~L}_{52}$ was lower in order to decrease the volume of the liquid fraction of digestate needed to run the experiments.

\section{Analytical Methods}

The ammonium $\left(\mathrm{NH}_{4}-\mathrm{N}\right)$ and orthophosphate $\left(\mathrm{PO}_{4}-\mathrm{P}\right)$ concentrations were measured by flow injection analysis (FIAstar 5000) according to ISO 11732 (International Organization for Standardization, 2005) and ISO 15681-1 (International Organization for Standardization, 2003) respectively. Potassium was analyzed according to Standard Methods using a flame photometer (Perkin Elmer 3300).

\section{Statistical Analyses}

One-way analysis of variance was performed to test the effect of preconditioning of clinoptilolite on nutrient removal. The effect of the initial ammonium loading ratio on nutrient removal efficiency was analyzed by Pearson's product-moment correlation test using the statistical software R version 3.1.0 (R Core Team, 2015).

Table 2.2 Experimental conditions used in the nutrient loading experiments.

\begin{tabular}{llllll}
\hline Designation & $\begin{array}{l}\text { Initial } \mathrm{NH}_{4}-\mathrm{N} \\
\text { loading ratio } \\
\text { (mg NH4 } \\
\text { clinoptilolite) }\end{array}$ & $\begin{array}{l}\text { Digestate } \\
\text { volume } \\
(\mathrm{mL})\end{array}$ & $\begin{array}{l}\text { Amount of } \\
\text { clinoptilolit } \\
\mathrm{e} \\
(\mathrm{g})\end{array}$ & $\begin{array}{l}\text { Packed } \\
\text { height } \\
(\mathrm{cm})\end{array}$ & $\begin{array}{l}\text { Residence } \\
\text { time } \\
(\mathrm{min})\end{array}$ \\
\hline $\mathrm{L}_{10}$ & 10.1 & 270 & 100 & 27 & 60 \\
$\mathrm{~L}_{15}$ & 15.2 & 405 & 100 & 27 & 60 \\
$\mathrm{~L}_{20}$ & 20.2 & 540 & 100 & 27 & 60 \\
$\mathrm{~L}_{31}$ & 30.9 & 405 & 50 & 14 & 60 \\
$\mathrm{~L}_{41}$ & 41.3 & 540 & 50 & 14 & 60 \\
$\mathrm{~L}_{52}$ & 51.6 & 680 & 50 & 14 & 60 \\
\hline
\end{tabular}




\subsection{Results and Discussion}

\section{Effect of preconditioning of clinoptilolite on nutrient removal}

The ammonium concentration of the synthetic solution in the batch experiments decreased more rapidly with preconditioned clinoptilolite than with natural clinoptilolite (Figure 2.2a), indicating a higher ion exchange capability after preconditioning. Clinoptilolite preconditioned with $1 \mathrm{M} \mathrm{NaCl}$ showed the highest ammonium ion exchange rate, but the differences between preconditioning treatments were relatively small after 24 hours. Similarly, Lin et al. (2013) reported a faster ammonium ion exchange rate in synthetic solutions with modified zeolite (modified with $2 \mathrm{M} \mathrm{NaCl}$ ), as compared to natural zeolite. Ammonium ion exchange using the liquid fraction of digestate gave comparable results, but with a smaller effect from the prior preconditioning of clinoptilolite (Figure 2.2b).

Clinoptilolite preconditioned with $1 \mathrm{M} \mathrm{NaCl}$ also showed the highest ion exchange rate for potassium in synthetic solution (Figure 2.3a), which was similar to the results in the liquid fraction of digestate (Figure 2.3b). For potassium, the effects of preconditioning were greater than for ammonium in the liquid fraction of digestate.
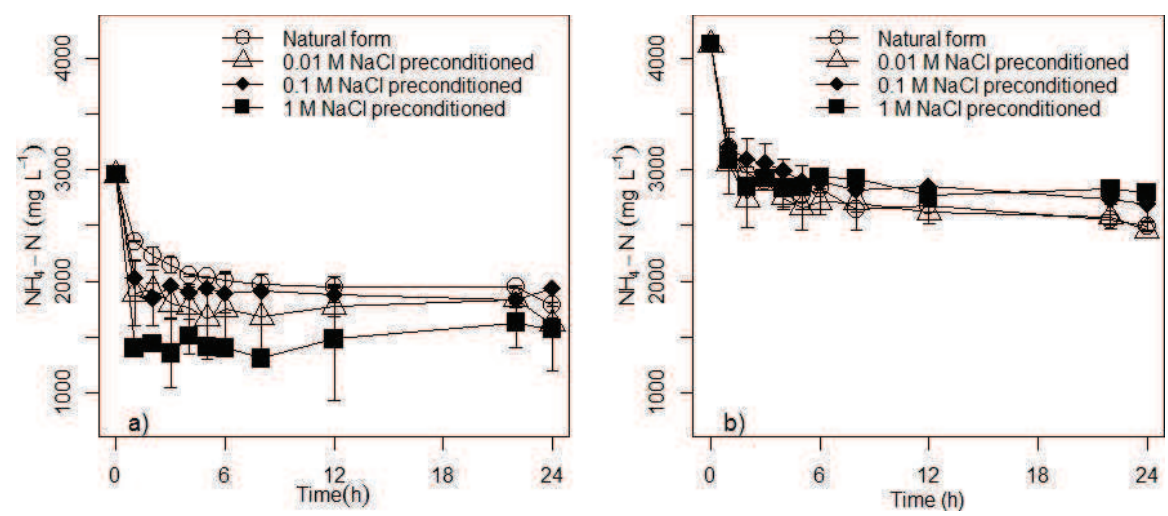

Figure 2.2 Ammonium concentration in batch experiments where clinoptilolite was in contact with synthetic solution (a) and the liquid fraction of digestate (b) after different preconditionings of clinoptilolite. Error bars indicate standard deviation $(n=2)$. 

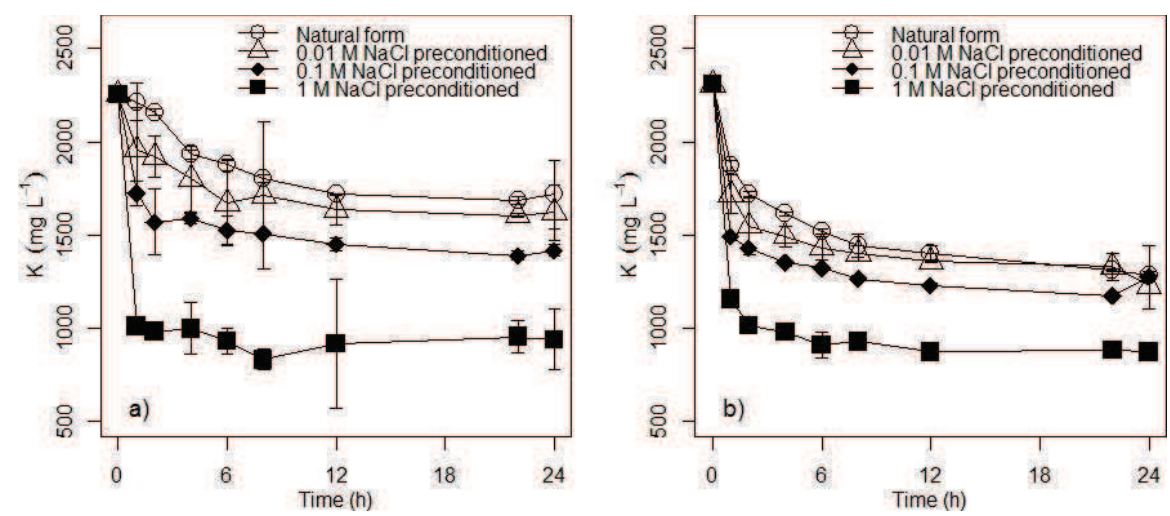

Figure 2.3 Potassium concentration in batch experiments where clinoptilolite was in contact with synthetic solution (a) and the liquid fraction of digestate (b) after different preconditionings of clinoptilolite. Error bars indicate standard deviation $(\mathrm{n}=2)$.

Based on the changes in the concentrations of ammonium and potassium in the liquid, it was possible to calculate the total amount of ammonium and potassium removed per gram of clinoptilolite (Table 2.3). In the synthetic solution, this amount

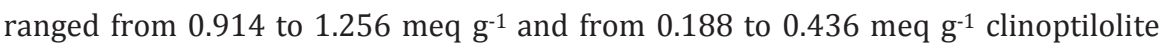
for ammonium and potassium, respectively. For the liquid fraction of digestate it ranged from 1.166 to $1.427 \mathrm{meq} \mathrm{g}^{-1}$ and 0.333 to 0.468 meq g $^{-1}$ for ammonium and potassium respectively. In our study we found a lower ammonium removal from the synthetic solution compared to liquid fraction of digestate. This was somewhat an unexpected result due to the existence of cations such as $\mathrm{Ca}^{2+}, \mathrm{Na}^{+}, \mathrm{Mg}^{2+}$ in the liquid fraction of digestate which are known to compete with ammonium and hence decrease the ammonium removal by clinoptilolite (Nguyen \& Tanner, 1998).

Table 2.3 Specific ammonium and potassium removal achieved with batch experiments with synthetic solution and the liquid fraction of digestate $(n=2)$.

\begin{tabular}{|c|c|c|c|c|c|c|}
\hline \multirow{3}{*}{$\begin{array}{l}\text { Pre- } \\
\text { conditioned } \\
\text { with }\end{array}$} & \multicolumn{3}{|c|}{ Synthetic solution } & \multicolumn{3}{|c|}{ Liquid fraction of digestate } \\
\hline & $\mathrm{NH}_{4}-\mathrm{N}$ & $\mathrm{K}$ & Total & $\mathrm{NH}_{4}-\mathrm{N}$ & $\mathrm{K}$ & Total \\
\hline & \multicolumn{3}{|c|}{ meq $\mathrm{g}^{-1}$ clinoptilolite } & \multicolumn{3}{|c|}{ meq g-1 clinoptilolite } \\
\hline Natural form & $0.979 \pm 0.017$ & $0.188 \pm 0.032$ & $1.167 \pm 0.049$ & $1.390 \pm 0.028$ & $0.333 \pm 0.003$ & $1.723 \pm 0.025$ \\
\hline $0.01 \mathrm{M} \mathrm{NaCl}$ & $1.160 \pm 0.053$ & $0.221 \pm 0.019$ & $1.380 \pm 0.034$ & $1.427 \pm 0.017$ & $0.351 \pm 0.005$ & $1.777 \pm 0.011$ \\
\hline $0.1 \mathrm{M} \mathrm{NaCl}$ & $0.914 \pm 0.003$ & $0.284 \pm 0.004$ & $1.196 \pm 0.000$ & $1.222 \pm 0.096$ & $0.378 \pm 0.000$ & $1.600 \pm 0.096$ \\
\hline $1 \mathrm{M} \mathrm{NaCl}$ & $1.256 \pm 0.163$ & $0.436 \pm 0.026$ & $1.691 \pm 0.188$ & $1.166 \pm 0.044$ & $0.468 \pm 0.002$ & $1.634 \pm 0.046$ \\
\hline
\end{tabular}


The difference between the results for the liquid fraction of digestate and synthetic solution might be attributed to the difference in initial ammonium concentrations. The liquid fraction of digestate had a higher ammonium concentration $44120 \mathrm{mg}$ $\mathrm{NH}_{4}-\mathrm{N} \mathrm{L}^{-1}$ ) than synthetic solution (2960 mg $\mathrm{NH}_{4}-\mathrm{N} \mathrm{L}^{-1}$ ) so that there were more $\mathrm{NH}_{4}{ }^{+}$cations available for exchange which resulted in a higher ammonium removal per gram of clinoptilolite. Another explanation could be that the organic matter and suspended solids in the liquid fraction of digestate may affect the surface charge density and provide more cation exchangeable sites for ammonium and potassium (Nguyen \& Tanner, 1998; Jorgensen \& Weatherley, 2003).

We found that the ammonium removal using preconditioned clinoptilolite from the synthetic solution and the liquid fraction of digestate was not significantly different from natural form of zeolite. For potassium alone, the greatest removal by far from both the synthetic solution $(p=0.005)$ and the liquid fraction of digestate $(\mathrm{p}<0.001)$ was obtained for clinoptilolite preconditioned with $1 \mathrm{M} \mathrm{NaCl}$.

Our results indicated that preconditioning of clinoptilolite with $\mathrm{NaCl}$ had no significant effect on total ammonium and potassium removal from the synthetic solution and the liquid fraction of digestate. The results regarding preconditioning in the literature are contrasting. Inglezakis et al. (2001) found that preconditioning of clinoptilolite using $\mathrm{NaCl}$ concentrations above $0.4 \mathrm{M}$ had no effect on the exchange capacity for ammonium. This was explained by the fact that at $0.4 \mathrm{M} \mathrm{NaCl}$, clinoptilolite was saturated with sodium ions and increasing it further would not increase the number of exchanged ions. Semmens \& Martin (1988) reported that the total exchange capacity was not affected by preconditioning, and only the composition of the exchanging ions differed between the natural and preconditioned clinoptilolite samples. Lin et al. (2013) reported $\mathrm{Na}^{+}$was the cation which dominated cation exchange with ammonium when the initial ammonium concentration was less than $500 \mathrm{mg} \mathrm{L}^{-1}$, but $\mathrm{Ca}^{2+}$ dominated cation exchange at 1000 mg $\mathrm{L}^{-1}$ initial ammonium concentration. They reported increasing ammonium removal at $1000 \mathrm{mg} \mathrm{L}^{-1}$ initial ammonium concentration when clinoptilolite was preconditioned with $\mathrm{NaCl}$. But they also reported increasing ammonium removal with natural (untreated) clinoptilolite at an initial concentration of $4000 \mathrm{mg} \mathrm{L}^{-1}$, as compared to $1000 \mathrm{mg} \mathrm{L}^{-1}$ initial ammonium concentration. An explanation for the lack of an effect of preconditioning could be that both the synthetic solution and the liquid fraction of digestate had a high ammonium concentration (around 3000 to more than $4000 \mathrm{mg} \mathrm{NH}_{4}-\mathrm{N} \mathrm{L}^{-1}$ ) in the solution and this resulted in a very large 
difference between the solid and liquid phase. Therefore a large difference between the concentration gradient in the solid phase and in the liquid phase can cause most of the exchangeable cations on clinoptilolite surface to be replaced by ammonium to a similar degree in both natural form of clinoptilolite and preconditioned clinoptilolite. Further studies to explore the effects of preconditioning at different initial ammonium concentrations could be useful.

Total ammonium and potassium removal ranged between 1.167 and 1.691 meq $\mathrm{g}^{-1}$ clinoptilolite for the synthetic solution and between 1.600 and $1.777 \mathrm{meq} \mathrm{g}^{-1}$ clinoptilolite for the liquid fraction of digestate. Our results were comparable with the total exchange capacities reported in the literature. Koon \& Kaufman (1975) reported a total exchange capacity of clinoptilolite between 1.6 and 2.0 meq g-1, Semmens \& Martin (1988) reported a total exchange capacity between 1.98 and $2.07 \mathrm{meq} \mathrm{g}^{-1}$ for ammonium and potassium ions together.

\section{Effect of the initial ammonium loading ratio on nutrient removal efficiency}

In the column loading experiments, a higher decrease in ammonium concentration was observed with smaller initial loading ratios (Figure 2.4a), with $\mathrm{L}_{10}$ showing the highest and $\mathrm{L}_{52}$ the lowest ammonium removal from the liquid fraction of digestate. Similarly, lower initial loading ratios resulted in a greater decrease in potassium concentration in the liquid fraction of digestate (Figure 2.4b).

These results were in accordance with literature, e.g. Beler Baykal et al. (2009) investigated the removal of ammonium and potassium from source-separated human urine and found that increasing loading ratios resulted in higher ammonium and potassium concentrations remaining in the urine solution.

In contrast to ammonium and potassium, the removal of orthophosphate did not differ between loading ratios (Figure 2.4c). This might be due to different removal mechanisms responsible for the removal of anions. Ammonium and potassium are removed from the liquid primarily through ion exchange, however orthophosphate is an anion and therefore likely to be removed by adsorption. Clinoptilolite has been reported to adsorb considerable amount of phosphates (Sakadevan \& Bavor, 1998; Ganrot et al., 2007; Kocatürk \& Baykal, 2012) and Ban \& Dave (2004) reported that clinoptilolite-rich zeolite itself worked as $\mathrm{P}$ adsorbent. Other mechanisms for $\mathrm{P}$ removal could be precipitation and filtration since a visible color change was 

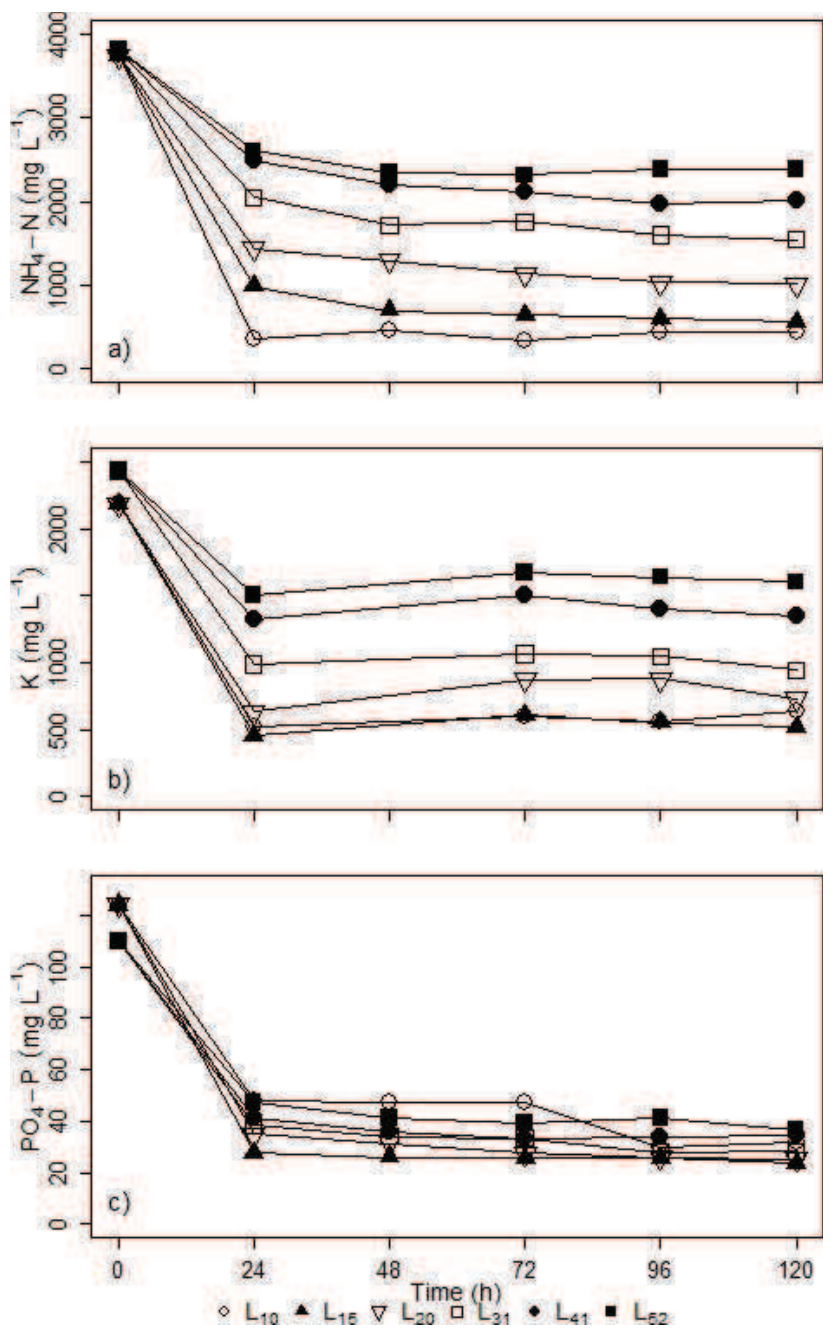

Figure 2.4 Ammonium (a), potassium (b) and orthophosphate (c) concentration changes in the liquid fraction of digestate in the column nutrient loading at different initial ammonium loading ratios (Lx: signifies an ammonium loading ratio of $\mathrm{X} \mathrm{mg} \mathrm{NH}_{4}-\mathrm{N} \mathrm{g}^{-1}$ clinoptilolite).

observed in all samples, however we have not conducted further analyses to support this explanation. Further studies are needed for understanding the orthophosphate removal mechanisms from liquid fraction of digestate, which was not our objective in this study. 

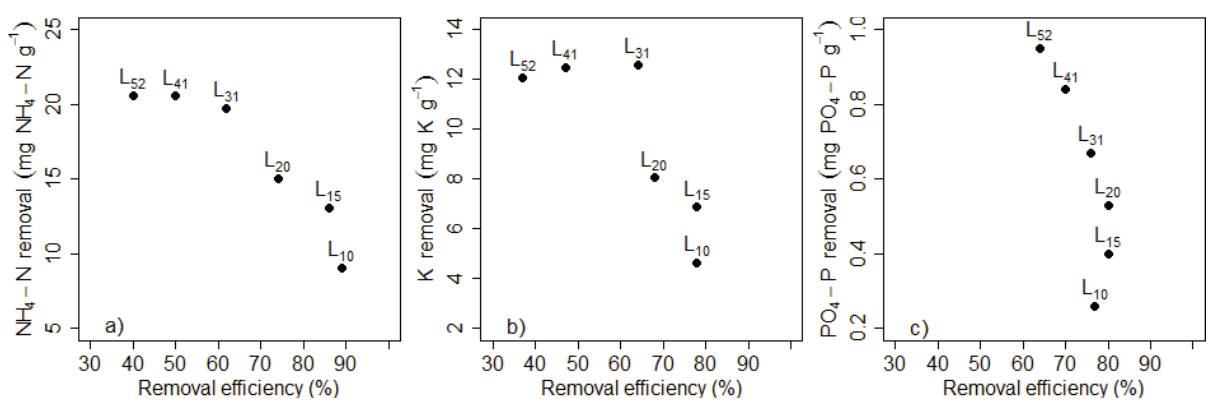

Figure 2.5 Relationship between ammonium (a), potassium (b) and orthophosphate (c) removal per gram of clinoptilolite and the corresponding removal efficiencies for the different initial loading ratios.

Ammonium removal efficiencies ranged from $40 \%$ to $89 \%$ (Figure $2.5 \mathrm{a}$ ) and the highest removal efficiency was achieved with the lowest loading ratio, $\mathrm{L}_{10}$, where the amount of $\mathrm{NH}_{4}-\mathrm{N}$ removed per g clinoptilolite was $9.1 \mathrm{mg} \mathrm{NH}-\mathrm{N} \mathrm{g}^{-1}$. The highest ammonium removal per g clinoptilolite was $20.58 \mathrm{mg} \mathrm{NH}_{4}-\mathrm{N} \mathrm{g}^{-1}$ with the highest initial loading ratio in $L_{52}$, although the ammonium removal efficiency was only 40 \%. Lin et al. (2013) reported an ammonium removal $17.3 \mathrm{mg} \mathrm{N}$ per g clinoptilolite in an experiment with a synthetic wastewater with $1000 \mathrm{mg} \mathrm{NH}_{4}-\mathrm{N} \mathrm{L}^{-1}$ initial concentration. Karadag et al. (2006) found $20.37 \mathrm{mg} \mathrm{N}$ per g clinoptilolite removal from sanitary landfill leachate with $3750 \mathrm{mg} \mathrm{NH}_{4}-\mathrm{N} \mathrm{L}^{-1}$ initial concentration. Beler Baykal et al. (2009) reported an ammonium removal of $18.7 \mathrm{NH}_{4}-\mathrm{N}$ per $\mathrm{g}$ clinoptilolite from human urine with initial ammonium concentration up to 6950 mg $\mathrm{NH}_{4}-\mathrm{N} \mathrm{L}^{-1}$.

Potassium removal efficiencies decreased with increasing loading ratios, and the highest removal efficiency was $78 \%$ for both $\mathrm{L}_{10}$ and $\mathrm{L}_{15}$ (Figure $2.5 \mathrm{~b}$ ). The highest potassium removal per g clinoptilolite was $12.57 \mathrm{mg} \mathrm{K} \mathrm{g}^{-1}$ obtained with the highest initial loading ratio $\mathrm{L}_{52}$, but the efficiency decreased to $37 \%$. Similarly, Beler Baykal et al. (2009) reported decreasing removal efficiencies with increasing loading ratios when clinoptilolite was used to remove potassium from human urine.

Orthophosphate removal efficiencies ranged from 64 to $80 \%$ and similar removal efficiencies were observed for all the loading ratios up to $\mathrm{L}_{31}$ (Figure 2.5c). However a further increase in loading ratios, i.e. $\mathrm{L}_{41}, \mathrm{~L}_{52}$, led to a decrease in P04-P removal efficiencies. Kocatürk \& Baykal (2012) investigated $\mathrm{PO}_{4}-\mathrm{P}$ removal from diluted urine solutions and found more than $90 \%$ orthophosphate removal 


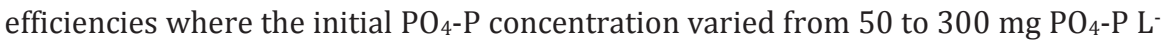
1. $\mathrm{P}$ adsorption capacities reported varying from $0.090 \mathrm{~g}^{-1}$ to $1.33 \mathrm{mg} \mathrm{P} \mathrm{g}^{-1}$ clinoptilolite (Allar \& Beler-Baykal, 2013; Lin et al., 2015). Sakadevan \& Bavor (1998) reported a $\mathrm{P}$ adsorption of $2.15 \mathrm{mg} \mathrm{P} \mathrm{g}^{-1}$ for clinoptilolite-rich zeolite from a pure solution, which is much higher than the value in the present study. The difference between their results and the results in the present study might be attributed to different experimental conditions since the liquid solutions, the amount of clinoptilolite and the experimental setups used in the two studies were completely different from each other. They found more than $50 \% \mathrm{P}$ removal when the initial $\mathrm{P}$ concentration in the solution was below $200 \mathrm{mg} \mathrm{P} \mathrm{L}^{-1}$, while the removal efficiency was less than $30 \%$ for solutions with an initial P concentration above 200 mg P L-1. Milan et al. (1997) reported 20-35\% $\mathrm{PO}_{4}-\mathrm{P}$ removal from anaerobically

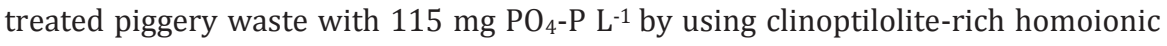
zeolites. In the present study the highest orthophosphate removal per $\mathrm{g}$ clinoptilolite was $0.95 \mathrm{mg} \mathrm{PO}_{4}-\mathrm{P} \mathrm{g}^{-1}$ with the lowest removal efficiency, which might mean that further adsorption could have been possible with a higher orthophosphate concentration in the liquid fraction of digestate.

Overall, the initial loading ratio had a significant effect on removal efficiency for both ammonium and potassium removal $(\mathrm{p}<0.001)$ and for orthophosphate removal $(\mathrm{p}=0.012)$, and increasing loading ratios led to decreasing removal efficiencies $(r=-0.99, r=-0.98, r=-0.91$ for ammonium, potassium and orthophosphate respectively). The removal efficiencies were as high as $86 \%, 78 \%$ and $80 \%$ for ammonium, potassium and orthophosphate respectively up to the $\mathrm{L}_{15}$ loading ratio. For ammonium and potassium, our results were in accordance with Beler Baykal et al. (2009) who reported that increases in the initial loading ratio lead to higher surface concentrations (i.e. amount of ammonium or potassium removed per g clinoptilolite) on the clinoptilolite but result in significant reductions in removal efficiencies.

Although high removal efficiencies can be obtained using clinoptilolite, leading to low ammonium, phosphate and potassium concentrations in the treated digestate, the increase in the concentration of nutrients from the liquid fraction of digestate into the loaded clinoptilolite appears to be relatively modest. $300 \mathrm{~kg}$ of clinoptilolite would be needed to process 1 ton of liquid fraction of digestate by using $\mathrm{L}_{15}$ loading if the $\mathrm{NH}_{4}-\mathrm{N}$ concentration of the liquid fraction of digestate were $3900 \mathrm{mg} \mathrm{L}^{-1}$, and $13 \mathrm{mg} \mathrm{NH}_{4}-\mathrm{N}$ could be removed per g clinoptilolite. Therefore the 
reduction in weight appears to be on the low side, with only a reduction factor of 3 4 as compared to the untreated liquid fraction of digestate. In order to make the treatment process economically attractive, a greater increase in concentration or weight reduction would normally be required, but the economy depends on both the cost of the ion exchanger/adsorbent and transportation, as well as the fertiliser properties of the nutrient bound to clinoptilolite, which may be more stable and easier to manage (to store, distribute and apply to soil).

Another important aspect is the remaining ammonium and orthophosphate concentrations in the liquid fraction of digestate, if the remaining liquid is to be disposed after nutrient recovery. Although we observed high removal efficiencies, the remaining concentrations in the liquid were between 435 and $2383 \mathrm{mg} \mathrm{NH}_{4}-\mathrm{N} \mathrm{L}^{-}$ 1 for ammonium and between 32 and $37 \mathrm{mg} \mathrm{PO}_{4}-\mathrm{P} \mathrm{L}^{-1}$ for orthophosphate, which are still high from the pollution prevention point of view. Allar \& Beler Baykal (2015) studied further treatment of the treated human urine with clinoptilolite by stagewise operation (operating a new column after finalising the previous column)of clinoptilolite columns. They found that stagewise operation resulted in reduced residual concentration in the liquid but provided only limited improvement in terms of nutrient recovery. Stagewise operation can be considered for obtaining lower nutrient concentrations and higher removal efficiencies compared to one step operation also for nutrient recovery from the liquid fraction of digestate.

\subsection{Concluding remarks}

Preconditioning of clinoptilolite before application in a column system for the treatment of digestate only has a minor effect on total ammonium and potassium removal. Preconditioning is a resource-demanding process and is therefore unlikely to be economically relevant for such systems.

Increases in the initial loading leads to higher nutrient removal per $\mathrm{g}$ clinoptilolite (higher nutrient concentration on clinoptilolite), but results in reductions in removal efficiencies.

Our study demonstrated that nutrients (in our study: N, P and K) can be removed from the liquid fraction of digestate with high removal efficiencies. Therefore, loading clinoptilolite may be a viable option for the management of nutrients from the liquid fraction of digestate. However, the value of the loaded clinoptilolite depends on its suitability and efficacy as a fertiliser for plants. In 
column systems we could only increase the concentration of the nutrients on clinoptilolite with a factor of 3-4 by weight as compared to the untreated liquid fraction of digestate. This means that savings on nutrient transportation are limited. However, loading of clinoptilolite with digestate may be an attractive option in situations where the clinoptilolite is available cheaply, and where its value as a soil amendment to improve soil properties, e.g. in poor soils, is high.

\section{Acknowledgements}

This work has been conducted as a part of a $\mathrm{PhD}$ thesis project supported by Agricultural Transformation by Innovation (AgTraIn) Erasmus Mundus Joint Doctoral Programme. The authors would also like to thank Rota Mining Co. for providing clinoptilolite samples. The first author would like to thank Lijbert Brussaard for his valuable comments to improve the manuscript, and Johannes Schumacher for his guidance and help with data analysis. 


\title{
Chapter 3 \\ Chemical activation of biochar for enhanced nutrient removal from liquid manure digestate
}

\author{
N.Pelin Kocatürk \\ Georgios Bekiaris \\ Clément Peltre \\ Kor Zwart \\ Lars Stoumann Jensen \\ Sander Bruun
}

This chapter is under review. 


\begin{abstract}
Nutrient sorption to biochar has been suggested as a means of recovering and handling nutrients from liquid waste streams, with several studies proposing activation of biochar as a way of improving its ability for nutrient sorption. This study examined the effects of biochar activation with various chemical agents, i.e. sulfuric acid, sodium hydroxide and hydrogen peroxide, on surface properties and biochar's ability to remove nutrients from the liquid fraction of digestate. Ammonium removal from the liquid fraction of digestate with untreated biochar was found to be $4.74 \mathrm{mg} \mathrm{NH} 4 \mathrm{~N} \mathrm{~g}^{-1}$, increasing to $10.40 \mathrm{mg} \mathrm{NH}_{4}-\mathrm{N} \mathrm{g}^{-1}$ with $\mathrm{NaOH}-$ activated biochar. Potassium was released from untreated biochar into the liquid fraction of digestate, and only minor potassium removal, $1.22 \mathrm{mg} \mathrm{K} \mathrm{g}^{-1}$, was achieved after $\mathrm{H}_{2} \mathrm{SO}_{4}$ activation. Activation with $\mathrm{H}_{2} \mathrm{SO}_{4}$ increased orthophosphate removal from 1.38 to $2.02 \mathrm{mg} \mathrm{PO}_{4}-\mathrm{P} \mathrm{g}^{-1}$. A significant positive correlation was found between orthophosphate removal and the carboxyl functional groups, as evidenced by FTIR photoacoustic spectroscopy. However, ammonium removal was not related to any oxygen-containing functional groups of biochar, probably because other mechanisms were dominant. In conclusion, activation of biochar can increase nutrient removal from the liquid fraction of digestate, but effects differ between elements.
\end{abstract}




\subsection{Introduction}

Europe's capacity for biogas production has been rapidly increasing in recent years (Fuchs \& Drosg, 2013). This also means that a large amount of digestate, the nutrient-rich effluent from the anaerobic digestion of waste feedstocks, is produced. Often the digestate is separated into a liquid fraction and a solid fraction. The solid fraction can be transported to places where the nutrients and organic matter are needed. The liquid fraction also has a potential value as a fertiliser due to its contents of dissolved nutrients. However the high water content of the liquid fraction of digestate means that it is relatively expensive to store and transport (Zarebska et al., 2015). It is therefore desirable to develop methods that can be used to concentrate or remove the nutrients from the liquid fraction.

Biochar is a carbon-rich product resulting from the thermal degradation of organic material in the absence of air (pyrolysis), and is promoted as a soil amendment (Lehmann \& Joseph, 2015). Biochar has been proposed as a sorbent for removing organic and inorganic contaminants from various types of wastewaters (Ahmad et al., 2014). The potential of biochar to recover nutrients from liquid wastes with high nutrient concentrations, such as dairy manure and ruminant urine, has also been discussed in the literature (Taghizadeh-Toosi et al., 2012; Sarkhot et al., 2013).

It has been suggested that the removal of ammonium by biochar is mainly controlled by interactions between ammonium ions and oxygen-containing functional groups, such as carboxylates or carboxylic acids, on the biochar surface (Wang et al., 2015a; Cui et al., 2016). Several studies have suggested that pyrolysis temperature is an important parameter affecting biochar properties (Ahmad et al., 2014; Lehmann \& Joseph, 2015). Increasing pyrolysis temperatures results in the removal of oxygen-containing functional groups and produces high aromaticity and low polarity biochars, which may negatively affect ammonium sorption to biochar (Gai et al., 2014). Newly produced biochars are also known to have a low ability to adsorb cations due to the presence of fewer oxygen-containing functional groups (Cheng et al., 2014).

Biochar's ability to remove orthophosphate has been attributed to bridge bonding with polyvalent cations. $\mathrm{Ca}^{2+}, \mathrm{Mg}^{2+}, \mathrm{Al}^{3+}$ and $\mathrm{Fe}^{3+}$ ions can act as a bridge to connect negatively-charged functional groups on the biochar surface with orthophosphate (Lin et al., 2012; Qian et al., 2013). 
Chemical activation of biochar has been shown to increase the oxygencontaining functional groups (Xue et al., 2012). Therefore, it was hypothesised that the chemical activation of biochar results in an increasing number of oxygencontaining functional groups and that the biochar has a greater sorption ability for ammonium, potassium and orthophosphate compared to untreated biochar.

The overall objective of this study was to investigate the effect of various activation procedures for biochar on its ability to remove nutrients from the liquid fraction of digestate. The specific objectives were to determine i) the effect of chemical activation on the oxygen-containing functional groups of biochar and ii) the effect of activation on ammonium, potassium and orthophosphate removal from the liquid fraction of digestate.

\subsection{Materials and Methods}

\section{Activation of Biochar}

Wood biochar was used in the experiments, produced by the slow pyrolysis of holm oak at $650{ }^{\circ} \mathrm{C}$ (Proininso Inc. Málaga, Spain). Biochar samples had an ash content of $11.3 \%$ (dry basis) and a composition of $76.5 \%$ C, $1.4 \% \mathrm{H}, 0.8 \% \mathrm{~N}, 7 \%$ 0, $0.2 \%$ P, $0.6 \%$ K, $0.04 \% \mathrm{Na}, 5 \% \mathrm{Ca}, 0.3 \% \mathrm{Mg}, 0.05 \% \mathrm{Fe}, 0.14 \% \mathrm{Al}$ (Ross, 2016). The particle size of the biochar samples was 1-4 mm. Activation of biochar was performed by treating the biochar with deionised water and different concentrations of the $\mathrm{H}_{2} \mathrm{O}_{2}, \mathrm{H}_{2} \mathrm{SO}_{4}$ and $\mathrm{NaOH}$ solutions, i.e. $1 \mathrm{M}$ and $3 \mathrm{M}$, as well as different temperatures i.e. $20{ }^{\circ} \mathrm{C}$ and $80{ }^{\circ} \mathrm{C}$, with a solid-to-liquid ratio of 1:20. Activation was conducted in conical flasks that were stirred for $24 \mathrm{~h}$ with a magnetic stirrer.

Activated biochars were rinsed twice with $500 \mathrm{~mL}$ deionised water and dried at $70 \stackrel{\circ}{\circ}$ for $24 \mathrm{~h}$. Dry biochar samples, except for the untreated biochar (no rinsing and no $\mathrm{pH}$ adjustment applied to untreated biochar samples), were transferred into beakers to adjust pH. $1 \mathrm{M} \mathrm{H}_{2} \mathrm{SO}_{4}$ and $1 \mathrm{M} \mathrm{NaOH}$ were used to adjust the $\mathrm{pH}$ of the activated biochar and water mixture to between 6 and 7. Biochars were dried at room temperature for $24 \mathrm{~h}$ and then at $70^{\circ} \mathrm{C}$ for a further $24 \mathrm{~h}$ prior to the sorption experiments. 


\section{Sorption experiments}

Sorption experiments were conducted by contacting untreated and activated biochars with a synthetic solution of minerals and the liquid fraction of digestate separately. Table 3.1 gives an overview of all the treatments. The synthetic solution was prepared as a solution of $\mathrm{NH}_{4} \mathrm{Cl}, \mathrm{KCl}$ and $\mathrm{Na}_{2} \mathrm{HPO}_{4}$ salts. The liquid fraction of digestate was collected from a centralised biogas plant (Fangel Bioenergy ApS, Odense, Denmark) where digestate is separated into liquid and solid fractions by a decanter centrifuge (Gea Westfalia, AD 1220, Oelde, Germany). The characterisation of the synthetic solutions and liquid fractions of digestate is presented in Table 3.2; the synthetic solution was made up to resemble digestate ammonium, phosphate and potassium concentrations. The $\mathrm{pH}$ of the synthetic solution and liquid fraction of digestate was adjusted to 6.5-7 using $\mathrm{HCl}(37 \%)$ prior to contact with biochars to prevent ammonia volatilisation. The sorption experiments were conducted by adding $2.5 \mathrm{~g}$ of the untreated or activated biochar to a conical flask with $50 \mathrm{~mL}$ synthetic solution and liquid fraction of digestate and shaking the flasks on a laboratory shaker at $150 \mathrm{rpm}$ for $48 \mathrm{~h}$.

Table 3.1 Overview of the treatments.

\begin{tabular}{|c|c|c|c|}
\hline Biochar type & Abbreviation & $\begin{array}{l}\text { Concentration } \\
\text { of the activation } \\
\text { agent }\left(\mathrm{mol} \mathrm{L}^{-1}\right)\end{array}$ & $\begin{array}{l}\text { Activation } \\
\text { temperature } \\
\left({ }^{\circ} \mathrm{C}\right)\end{array}$ \\
\hline Untreated & $\mathrm{U}-\mathrm{BC}$ & $\mathrm{n} / \mathrm{a}$ & $\mathrm{n} / \mathrm{a}$ \\
\hline De-ionised water activated & DW-BC & $\mathrm{n} / \mathrm{a}$ & 20 \\
\hline \multirow[t]{4}{*}{ Sulfuric acid activated } & $\mathrm{H}_{2} \mathrm{SO}_{4}-\mathrm{L} 20-\mathrm{BC}$ & 1 & 20 \\
\hline & $\mathrm{H}_{2} \mathrm{SO}_{4}-\mathrm{H} 20-\mathrm{BC}$ & 3 & 20 \\
\hline & $\mathrm{H}_{2} \mathrm{SO}_{4}-\mathrm{L} 80-\mathrm{BC}$ & 1 & 80 \\
\hline & $\mathrm{H}_{2} \mathrm{SO}_{4}-\mathrm{L} 80-\mathrm{BC}$ & 3 & 80 \\
\hline \multirow[t]{4}{*}{ Sodium hydroxide activated } & $\mathrm{NaOH}-\mathrm{L} 20-\mathrm{BC}$ & 1 & 20 \\
\hline & $\mathrm{NaOH}-\mathrm{H} 20-\mathrm{BC}$ & 3 & 20 \\
\hline & $\mathrm{NaOH}-\mathrm{L} 80-\mathrm{BC}$ & 1 & 80 \\
\hline & $\mathrm{NaOH}-\mathrm{L} 80-\mathrm{BC}$ & 3 & 80 \\
\hline \multirow[t]{2}{*}{ Hydrogen peroxide activated } & $\mathrm{H}_{2} \mathrm{O}_{2}-\mathrm{L} 20-\mathrm{BC}$ & 1 & 20 \\
\hline & $\mathrm{H}_{2} \mathrm{O}_{2}-\mathrm{H} 20-\mathrm{BC}$ & 3 & 20 \\
\hline
\end{tabular}


Table 3.2 Characterisation of the synthetic solutions and the liquid fractions of digestate (range indicates concentration variation).

\begin{tabular}{lll}
\hline Parameter & $\begin{array}{l}\text { Synthetic } \\
\text { solutions }\end{array}$ & $\begin{array}{l}\text { Liquid fractions } \\
\text { of digestate }\end{array}$ \\
\hline $\mathrm{NH}_{4}-\mathrm{N}\left(\mathrm{mg} \mathrm{L}^{-1}\right)$ & $3339-3448$ & $4094-4384$ \\
$\mathrm{~K}\left(\mathrm{mg} \mathrm{L}^{-1}\right)$ & $2406-2511$ & $1795-2035$ \\
$\mathrm{PO}_{4}-\mathrm{P}\left(\mathrm{mg} \mathrm{L}^{-1}\right)$ & $147-159$ & $104-115$ \\
$\mathrm{Ca}\left(\mathrm{mg} \mathrm{L}^{-1}\right)$ & $\mathrm{n} / \mathrm{a}$ & $228-300$ \\
$\mathrm{Mg}\left(\mathrm{mg} \mathrm{L}^{-1}\right)$ & $\mathrm{n} / \mathrm{a}$ & $58-64$ \\
$\mathrm{Na}\left(\mathrm{mg} \mathrm{L}^{-1}\right)$ & $\mathrm{n} / \mathrm{a}$ & $1100-1320$ \\
$\mathrm{Fe}\left(\mathrm{mg} \mathrm{L}^{-1}\right)$ & $\mathrm{n} / \mathrm{a}$ & $55-86$ \\
$\mathrm{pH}$ & $6.96-7.23$ & $7.64-8.72$ \\
\hline
\end{tabular}

\section{Analytical methods}

Ammonium $\left(\mathrm{NH}_{4}-\mathrm{N}\right)$ and orthophosphate $\left(\mathrm{PO}_{4}-\mathrm{P}\right)$ concentrations were measured by flow injection analysis (FIAstar 5000) according to ISO 11732 (2005) and ISO 15681-1 (2003), respectively. Potassium was analysed according to Standard Methods (2005) using a flame photometer (Perkin Elmer 3300).

\section{Fourier Transform-Infrared Spectroscopy (FTIR) analysis}

The FTIR-PAS spectra of the untreated and activated biochars were recorded on a Nicolet 6700 spectrometer (ThermoScientific, USA) equipped with a PA-301 photoacoustic detector (Gasera Ltd, Finland), as described previously by Bekiaris et al. (in preparation). Briefly, a small quantity of biochar was placed in a cup with $\varnothing$ of $10 \mathrm{~mm}$. The sample chamber was purged with helium prior to measurement in order to decrease the effect of moisture evaporation from the sample and increase the signal-to-noise $(\mathrm{S} / \mathrm{N})$ ratio. Activated charcoal (SigmaAldrich Denmark ApS, CAS number: 7440-44-0) was used to record the background, which was subtracted from the sample spectra to remove the effect of ambient $\mathrm{CO}_{2}$ and moisture. For each sample, 128 scans in the mid-infrared region between 4000 and $600 \mathrm{~cm}^{-1}$ were recorded and averaged. Fityk 0.9.8 software (Wojdyr, 2010) was used for peak deconvolution of the region of interest between 1900 and $900 \mathrm{~cm}^{-1}$. 


\section{Statistical analysis}

Statistical analyses were conducted using the statistical package $\mathrm{R}$, version 3.2.2 (The R Project, 2015). Data from the sorption experiments were analysed using a one-way analysis of variance (ANOVA) procedure for ammonium, potassium and orthophosphate removal separately, and Tukey's honestly significant difference (HSD) test was conducted to investigate differences between various activation conditions at the $\mathrm{P}<0.05$ level.

A Pearson product-moment correlation test was performed to investigate the correlation between the area of deconvoluted peaks and ammonium and orthophosphate removal separately.

\subsection{Results and Discussion}

\section{Sorption experiments}

\section{Ammonium removal}

Figure 3.1a shows that activation had a significant effect on ammonium removal compared to untreated biochar $(\mathrm{p}<0.001)$. The removal using $\mathrm{H}_{2} \mathrm{SO}_{4}-\mathrm{H} 80-\mathrm{BC}$ $(\mathrm{p}=0.026), \mathrm{NaOH}-\mathrm{L} 20$ ( $\mathrm{p}=0.017), \mathrm{NaOH}-\mathrm{L} 80(\mathrm{p}=0.001), \mathrm{NaOH}-\mathrm{H} 80(\mathrm{p}=0.006)$ and $\mathrm{H}_{2} \mathrm{O}_{2}$-L20-BC ( $\left.\mathrm{p}=0.008\right)$ was significantly different from that of the untreated biochar. The highest $\mathrm{NH}_{4}-\mathrm{N}$ removal from synthetic solutions was found with $\mathrm{NaOH}-$ L80-BC at $3.95 \mathrm{mg} \mathrm{g}^{-1}$ biochar, and this was significantly different from U-BC, DWBC, $\mathrm{H}_{2} \mathrm{SO}_{4}$-L80-BC, $\mathrm{H}_{2} \mathrm{O}_{2}$-L20-BC and $\mathrm{H}_{2} \mathrm{O}_{2}$-H20-BC. The lowest ammonium removal was found with $\mathrm{H}_{2} \mathrm{O}_{2}$-L20, which resulted in a negative removal (i.e. release).

Our results showed that activation of biochar with deionised water and hydrogen peroxide did not improve ammonium removal compared to untreated biochar. Similarly, Gai et al. (2014) reported a decrease in biochar's ability to remove ammonium after being washed in deionised water. Wang et al. (2015) found that the ammonium adsorption capacity of biochar did not change after activation with $\mathrm{H}_{2} \mathrm{O}_{2}$ unless the $\mathrm{pH}$ of activated biochar was adjusted from 3.7 to 7. Adjusting the $\mathrm{pH}$ of biochar prior to sorption resulted in an increase in adsorption capacity. In the present study, the final $\mathrm{pH}$ in synthetic solutions 

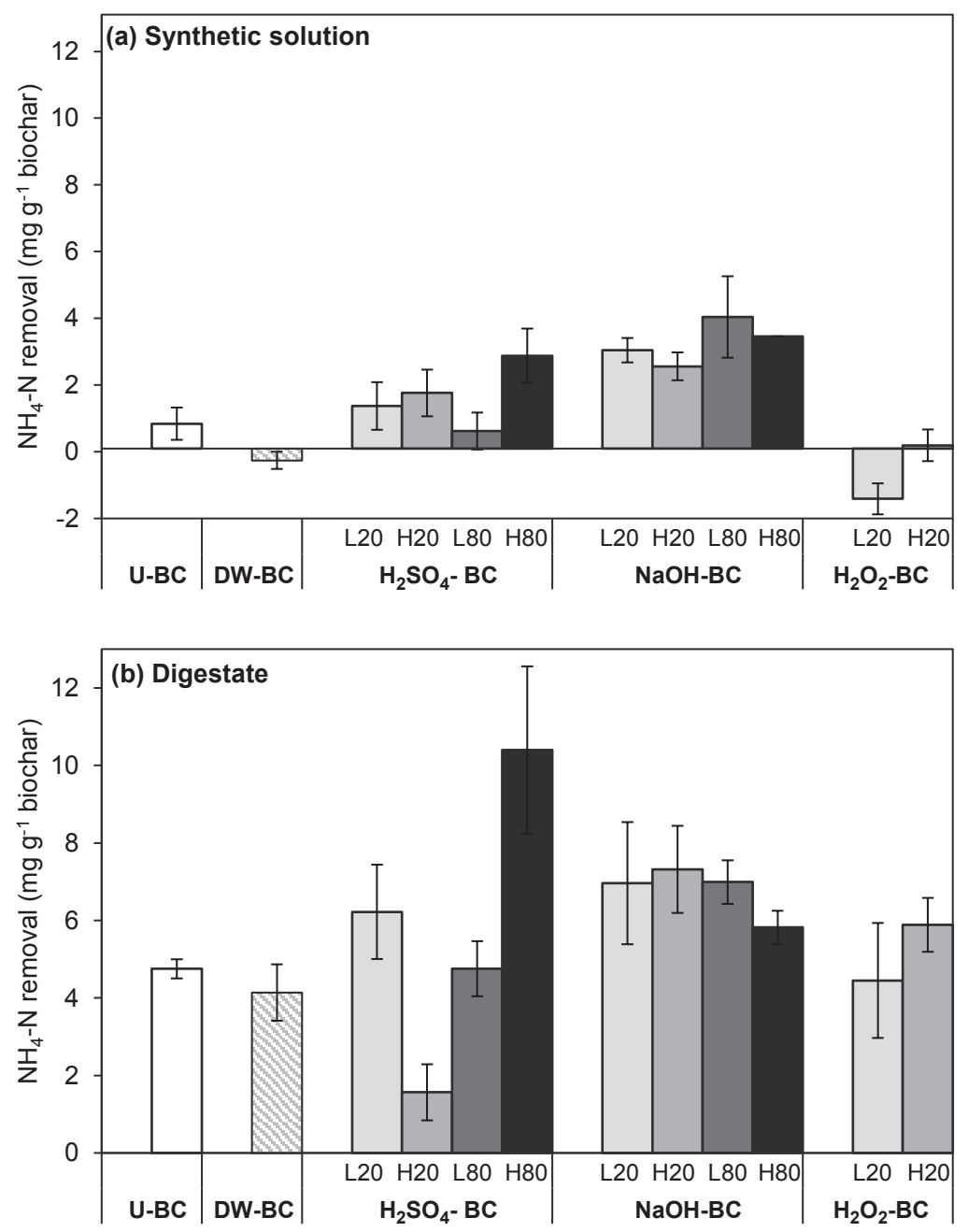

Figure 3.1 Ammonium removal per g biochar from (a) synthetic solution and (b) the liquid fraction of digestate with untreated biochar and as a result of various activation procedures. Error bars indicate standard error $(\mathrm{n}=3)$.

after $48 \mathrm{~h}$ of contact with $\mathrm{H}_{2} \mathrm{O}_{2}$-activated biochar was between $7.62 \pm 0.19$ and $7.77 \pm 0.06$ (Table 3.3), but no increase in ammonium removal was observed.

The removal of ammonium from synthetic solutions by untreated biochar has previously been studied and several mechanisms discussed in the literature. Cation 
exchange was used as one possible mechanism to explain ammonium removal (Sarkhot et al., 2013; Gai et al., 2014; Cui et al., 2016). Sarkhot et al. (2013) observed the release of $\mathrm{Ca}^{+}$ions and Cui et al. (2016) reported that $\mathrm{Mg}^{2+}$ and $\mathrm{Ca}^{2+}$ were released into the liquid solutions whereas $\mathrm{NH}_{4}{ }^{+}$was removed, therefore concluding that these cations play an important role in the sorption of ammonium. $\mathrm{K}^{+}$release from biochar (Figure 3.2a) was observed, which could be due to cation exchange with $\mathrm{NH}_{4}{ }^{+}$in the synthetic solution. In all the treatments except the acid treatment, ammonia volatilisation may also have contributed to ammonium removal from synthetic solutions as the final pH ranged from $7.62 \pm 0.19$ to $8.67 \pm 0.05$ (Table 3.3). In this $\mathrm{pH}$ range struvite $\left(\mathrm{MgNH}_{4} \mathrm{PO}_{4} .6 \mathrm{H}_{2} \mathrm{O}\right)$ precipitation may also be responsible for ammonium removal (De Graaff et al., 2011). However no further measurements were conducted to explain which mechanism was dominant for ammonium removal.

A higher ammonium removal by acid and base-treated chars could be explained by cation exchange: cations in biochar were replaced with $\mathrm{H}^{+}$and $\mathrm{Na}^{+}$ions as a result of $\mathrm{H}_{2} \mathrm{SO}_{4}$ and $\mathrm{NaOH}$ treatments, and thereby $\mathrm{H}^{+}$and $\mathrm{Na}^{+}$could easily be exchanged with $\mathrm{NH}_{4}{ }^{+}$ions, since $\mathrm{NH}_{4}{ }^{+}$is more competitive than the aforementioned ions (Cui et al., 2016).

Table 3.3 Final pH in synthetic solutions and the liquid fraction of digestates after $48 \mathrm{~h}$ contact with untreated or activated biochars.

\begin{tabular}{|c|c|c|}
\hline Treatment & $\begin{array}{l}\mathrm{pH} \\
\text { (synthetic } \\
\text { solution) }\end{array}$ & $\begin{array}{l}\mathrm{pH} \\
\text { (digestate) }\end{array}$ \\
\hline U-BC & $7.89 \pm 0.07$ & $8.58 \pm 0.08$ \\
\hline DW-BC & $7.83 \pm 0.05$ & $8.52 \pm 0.16$ \\
\hline $\mathrm{H}_{2} \mathrm{SO}_{4}-\mathrm{L} 20-\mathrm{BC}$ & $5.23 \pm 0.05$ & $7.65 \pm 0.48$ \\
\hline $\mathrm{H}_{2} \mathrm{SO}_{4}-\mathrm{H} 20-\mathrm{BC}$ & $3.46 \pm 0.15$ & $7.54 \pm 0.45$ \\
\hline $\mathrm{H}_{2} \mathrm{SO}_{4}-\mathrm{L} 80-\mathrm{BC}$ & $3.17 \pm 0.08$ & $7.42 \pm 0.16$ \\
\hline $\mathrm{H}_{2} \mathrm{SO}_{4}-\mathrm{L} 80-\mathrm{BC}$ & $2.14 \pm 0.05$ & $8.17 \pm 0.16$ \\
\hline $\mathrm{NaOH}-\mathrm{L} 20-\mathrm{BC}$ & $\mathrm{n} / \mathrm{a}$ & $8.67 \pm 0.05$ \\
\hline $\mathrm{NaOH}-\mathrm{H} 20-\mathrm{BC}$ & $8.47 \pm 0.13$ & $8.87 \pm 0.18$ \\
\hline $\mathrm{NaOH}-\mathrm{L} 80-\mathrm{BC}$ & $\mathrm{n} / \mathrm{a}$ & $8.47 \pm 0.13$ \\
\hline NaOH-L80-BC & $8.67 \pm 0.05$ & $8.32 \pm 0.14$ \\
\hline $\mathrm{H}_{2} \mathrm{O}_{2}-\mathrm{L} 20-\mathrm{BC}$ & $7.62 \pm 0.19$ & $8.3 \pm 0.23$ \\
\hline $\mathrm{H}_{2} \mathrm{O}_{2}-\mathrm{H} 20-\mathrm{BC}$ & $7.77 \pm 0.06$ & $8.06 \pm 0.44$ \\
\hline
\end{tabular}


Activation of biochar significantly affected ammonium removal $(\mathrm{p}<0.001)$ from the liquid fraction of digestate (Figure 3.1b). Removal with $\mathrm{H}_{2} \mathrm{SO}_{4}-\mathrm{H} 20-\mathrm{BC}$ $(\mathrm{p}=0.012), \mathrm{H}_{2} \mathrm{SO}_{4}-\mathrm{H} 80-\mathrm{BC}(\mathrm{p}<0.001)$ and $\mathrm{NaOH}-\mathrm{H} 20-\mathrm{BC}(\mathrm{p}=0.039)$ resulted in a significantly different removal compared to untreated biochar. The highest $\mathrm{NH}_{4}-\mathrm{N}$ removal from the liquid fraction of digestate was observed in $\mathrm{H}_{2} \mathrm{SO}_{4}-\mathrm{H} 80$ - $\mathrm{BC}$ with a removal of $10.4 \mathrm{mg} \mathrm{g}^{-1}$ biochar and this was significantly different from $\mathrm{U}-\mathrm{BC}, \mathrm{DW}-$ BC, $\mathrm{H}_{2} \mathrm{O}_{2}$-L20-BC, $\mathrm{H}_{2} \mathrm{O}_{2}$-H20-BC, NaOH-H80-BC, $\mathrm{H}_{2} \mathrm{SO}_{4}$-H20-BC and $\mathrm{H}_{2} \mathrm{SO}_{4}$-L80-BC. $\mathrm{H}_{2} \mathrm{SO}_{4}-\mathrm{H} 20-\mathrm{BC}$ resulted in the lowest $\mathrm{NH}_{4}-\mathrm{N}$ removal from the liquid fraction of digestate with $1.57 \mathrm{mg} \mathrm{g}^{-1}$ biochar.

In the liquid fraction of digestate, higher ammonium removal compared to synthetic solution was observed. This could be attributed to the presence of organic matter in the liquid fraction of digestate, which increases ammonium removal by coadsorption with dissolved organic molecules. Similarly Sarkhot et al. (2013) found higher ammonium removal from manure compared to pure solution. Lehmann et al. (2002) reported increased ammonium adsorption on biochar with the presence of soluble organic matter. Both studies explain this increase in ammonium adsorption by the presence of organic matter and thereby co-adsorption of ammonium and dissolved organic matter. Another explanation for higher ammonium removal could be struvite $\left(\mathrm{MgNH}_{4} \mathrm{PO}_{4} \cdot 6 \mathrm{H}_{2} \mathrm{O}\right)$ precipitation due to higher concentrations of magnesium in the liquid fraction of digestate. Cui et al. (2016) reported the formation of struvite when biochar is used to remove ammonium from liquid solutions.

\section{Potassium removal}

Potassium removal from synthetic solution was significantly affected by the activation of biochar (Figure 3.2a) and $\mathrm{K}$ removal in activated biochars was significantly different compared to the untreated biochar $(\mathrm{p}<0.001)$. The highest $\mathrm{K}$ removal was observed in $\mathrm{H}_{2} \mathrm{SO}_{4}$-H80-BC, NaOH-L20-BC and $\mathrm{H}_{2} \mathrm{SO}_{4}$-L80-BC with $1.22,1.06$ and $0.87 \mathrm{mg} \mathrm{K} \mathrm{g}^{-1}$ biochar removal respectively. Negative values were found with U-BC, DW-BC, DW-BC, $\mathrm{H}_{2} \mathrm{O}_{2}-\mathrm{L} 20-\mathrm{BC}, \mathrm{H}_{2} \mathrm{O}_{2}-\mathrm{H} 20-\mathrm{BC}$ and $\mathrm{NaOH}-\mathrm{H} 80-\mathrm{BC}$, indicating that $\mathrm{K}$ was released into the synthetic solution. Figure $3.2 \mathrm{~b}$ shows that potassium removal from the liquid fraction of digestate was also affected and $\mathrm{K}$ removal in activated biochars was significantly different compared to the untreated biochar $(\mathrm{p}<0.001)$. The highest $\mathrm{K}$ removal was found with $\mathrm{H}_{2} \mathrm{SO}_{4}-\mathrm{H} 80-\mathrm{BC}, \mathrm{H}_{2} \mathrm{SO}_{4}$ L80-BC and NaOH-H80-BC with 2.10, 1.21 and $0.53 \mathrm{mg} \mathrm{K} \mathrm{g}^{-1}$ biochar removal 
respectively, and K release into the liquid fraction of digestate was observed after all the other treatments.

The highest potassium release was observed from untreated biochar which was not washed prior to the sorption experiments. This was probably the reason why it released higher amounts of potassium compared to the deionised water and
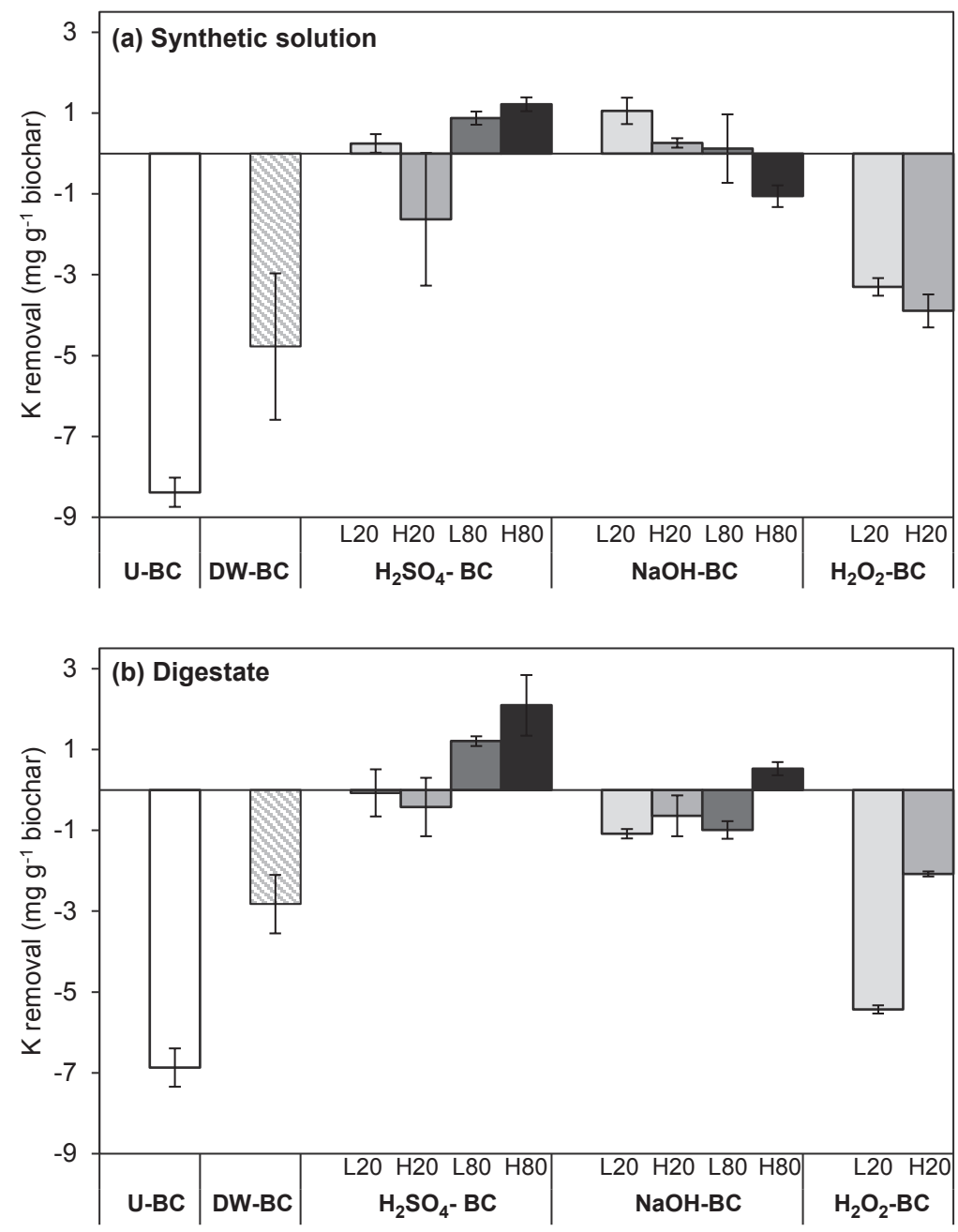

Figure 3.2 Potassium removal per g biochar from (a) synthetic solution and (b) the liquid fraction of digestate with untreated biochar and as a result of various activation procedures. Error bars indicate standard error $(n=3)$. 
peroxide-treated chars. Potassium release from wood biochar was also observed by (Angst \& Sohi, 2013), who studied K release from hardwood biochar with water extraction, and found complete extraction of $\mathrm{K}$, up to $4.48 \mathrm{mg} \mathrm{K} \mathrm{g}^{-1}$ release. Wu et al. (2011) reported that $90 \%$ of potassium in wood biochar could be released in water. As discussed previously, cations in biochar, including potassium, are likely to have been replaced with $\mathrm{H}^{+}$and $\mathrm{Na}^{+}$ions as a result of the $\mathrm{H}_{2} \mathrm{SO} 4$ and $\mathrm{NaOH}$ treatments. Once $\mathrm{K}$ was removed from the biochar, biochar could exchange $\mathrm{H}^{+}$and $\mathrm{Na}^{+}$ions with $\mathrm{K}^{+}$in the solution and in the liquid fraction of digestate, and this could be the reason for the potassium removal with most of the $\mathrm{H}_{2} \mathrm{SO}_{4}$ and $\mathrm{NaOH}$-treated biochars. Asada et al. (2006) found that a higher amount of potassium was released from untreated charcoal than from $\mathrm{H}_{2} \mathrm{SO}_{4}$-treated charcoal, concluding that sulfuric acid treatment removes minerals.

However, even though the ability for potassium adsorption can be obtained by $\mathrm{H}_{2} \mathrm{SO}_{4}$ and $\mathrm{NaOH}$ activation, the adsorption capacity is rather low and will also result in biochar potassium being present in the activation media, which subsequently cannot be reused to activate new biochar samples.

\section{Orthophosphate removal}

Figure 3.3a shows that activation of biochar had a significant, but rather differentiated effect on orthophosphate removal from the synthetic solutions ( $\mathrm{p}<0.001) . \mathrm{PO}_{4}-\mathrm{P}$ removal was highest with DW-BC $\left(1.91 \mathrm{mg} \mathrm{g}^{-1}\right.$ biochar) and this was significantly different from all the other treatments. All $\mathrm{H}_{2} \mathrm{SO}_{4}$-activated biochars showed dramatically reduced $\mathrm{PO}_{4}-\mathrm{P}$ removal, which was significantly lower than the other treatments in synthetic solutions.

In the literature, several possible mechanisms for phosphate removal from liquid solutions by biochar have been proposed, including phosphate adsorption to $\mathrm{MgO}$ on the biochar surface (Yao et al., 2011), precipitation reactions between phosphate and $\mathrm{Ca}^{+}$and $\mathrm{Mg}^{+}$ions in biochar (Wang et al., 2015), anion exchange with surface hydroxyl groups (Sarkhot et al., 2013) and electrostatic interaction of the phosphate anions with charged hydroxide surfaces (Chen et al., 2011). The results of the present study showed that untreated and activated biochars could remove orthophosphate, except for the biochars activated with sulfuric acid. This could be due to the low equilibrium $\mathrm{pH}$ in the synthetic solution that was in contact with acid treated biochar. All other solutions had a final $\mathrm{pH}$ of between 7.62 and 8.67 (Table 
3.3), which allows precipitation reactions for hydroxyapatite $\left(\mathrm{Ca}_{5} \mathrm{OH}\left(\mathrm{PO}_{4}\right)_{3}\right)$ and struvite $\left(\mathrm{MgNH}_{4} \mathrm{PO}_{4} 6 \mathrm{H}_{2} \mathrm{O}\right)$ in the presence of $\mathrm{Ca}^{+}$and $\mathrm{Mg}^{+}$ions (De Graaff et al., 2011). In contrast, the final $\mathrm{pH}$ of the synthetic solution contacted with $\mathrm{H}_{2} \mathrm{SO}_{4}$ treated chars varied between 2.16 and 5.23 and therefore the hydroxyapatite and struvite precipitation reactions would be limited. Furthermore, it is likely that the acid treatment of biochar removes most of the $\mathrm{Ca}^{+}$and $\mathrm{Mg}^{+}$ions together with $\mathrm{Fe}^{3+}$ and $\mathrm{Al}^{3+}$ in the biochar, which may contribute to cation bridging in all the other treatments (Lin et al., 2012; Qian et al., 2013).
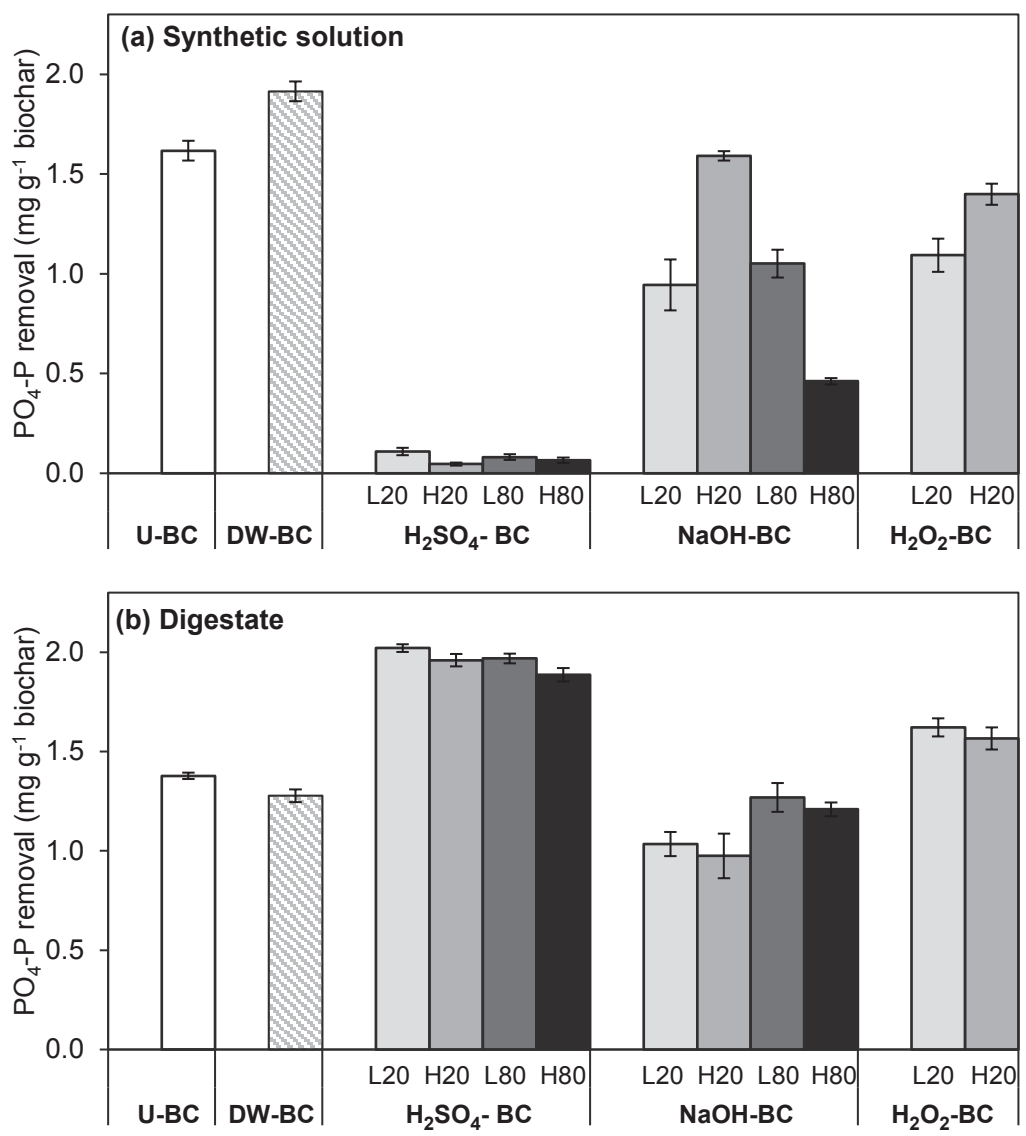

Figure 3.3 Orthophosphate removal per g biochar from (a) synthetic solution and (b) the liquid fraction of digestate with untreated biochar and as a result of various activation procedures. Error bars indicate standard error $(n=3)$. 
For the liquid fraction of digestate, all treatments resulted in a significantly different removal of orthophosphate from $U$-BC $(\mathrm{p}<0.001)$, except for $\mathrm{DW}-\mathrm{BC}$ and $\mathrm{NaOH}-\mathrm{L} 80-\mathrm{BC}$ (Figure 3.3b). In contrast to the results in the synthetic solution, $\mathrm{H}_{2} \mathrm{SO}_{4}$-activated biochars resulted in the highest $\mathrm{PO}_{4}$ - $\mathrm{P}$ removal with up to $2.02 \mathrm{mg}$ $\mathrm{PO}_{4}-\mathrm{P} \mathrm{g}^{-1}$ removal. The very different removal from synthetic solution and the liquid fraction of digestate for the $\mathrm{H}_{2} \mathrm{SO}_{4}$ treatment may be attributed to the difference in $\mathrm{pH}$ between the two solutions. All liquid digestates had a final $\mathrm{pH}$ (at the end of the sorption experiment) of between 7.42 and 8.87 (Table 3.3), which would be within a suitable pH range for hydroxyapatite and struvite precipitation (De Graaff et al., 2011). Moreover, cation bridging of divalent and trivalent cations (which were not likely to be present in acid-treated biochar, but would be present in the digestate) with orthophosphate may explain the differences in orthophosphate removal between the synthetic solution and the liquid fraction of digestate (Lin et al., 2012; Qian et al., 2013).

\section{Functional groups on the biochar surface}

According to Cui et al. (2016), oxygen-containing functional groups play an important role in the sorption of ammonium since ammonium can form surface complexes with carbonyl and carboxyl groups. However, FTIR-PA spectra from the differently activated biochars only revealed visible differences between the spectrum of the biochar activated with $\mathrm{H}_{2} \mathrm{SO}_{4}$ and the other biochars (Supplementary Figure 3.1). Deconvolution of the spectrum in the region between 1800 and $900 \mathrm{~cm}^{-1}$, where oxygen-containing functional groups occur, was used to resolve the overlapping peaks and separate peaks related to oxygen-containing bonds. The results can be found in Supplementary Figure 3.2 and Table 3.4.

Deconvoluted peaks corresponding to the vibration of oxygen-containing functional groups were observed at $1710 \mathrm{~cm}^{-1}$ ( $\mathrm{C}=0$ stretching from carboxylic acids), $1590 \mathrm{~cm}^{-1}$ (symmetric and asymmetric $\mathrm{C}=0$ stretching vibration of carboxyl groups), 1420-1390 $\mathrm{cm}^{-1}$ (symmetric and asymmetric C-O stretching vibration of carboxyl groups), $1270 \mathrm{~cm}^{-1}$ (aromatic CO- and phenolic -OH 


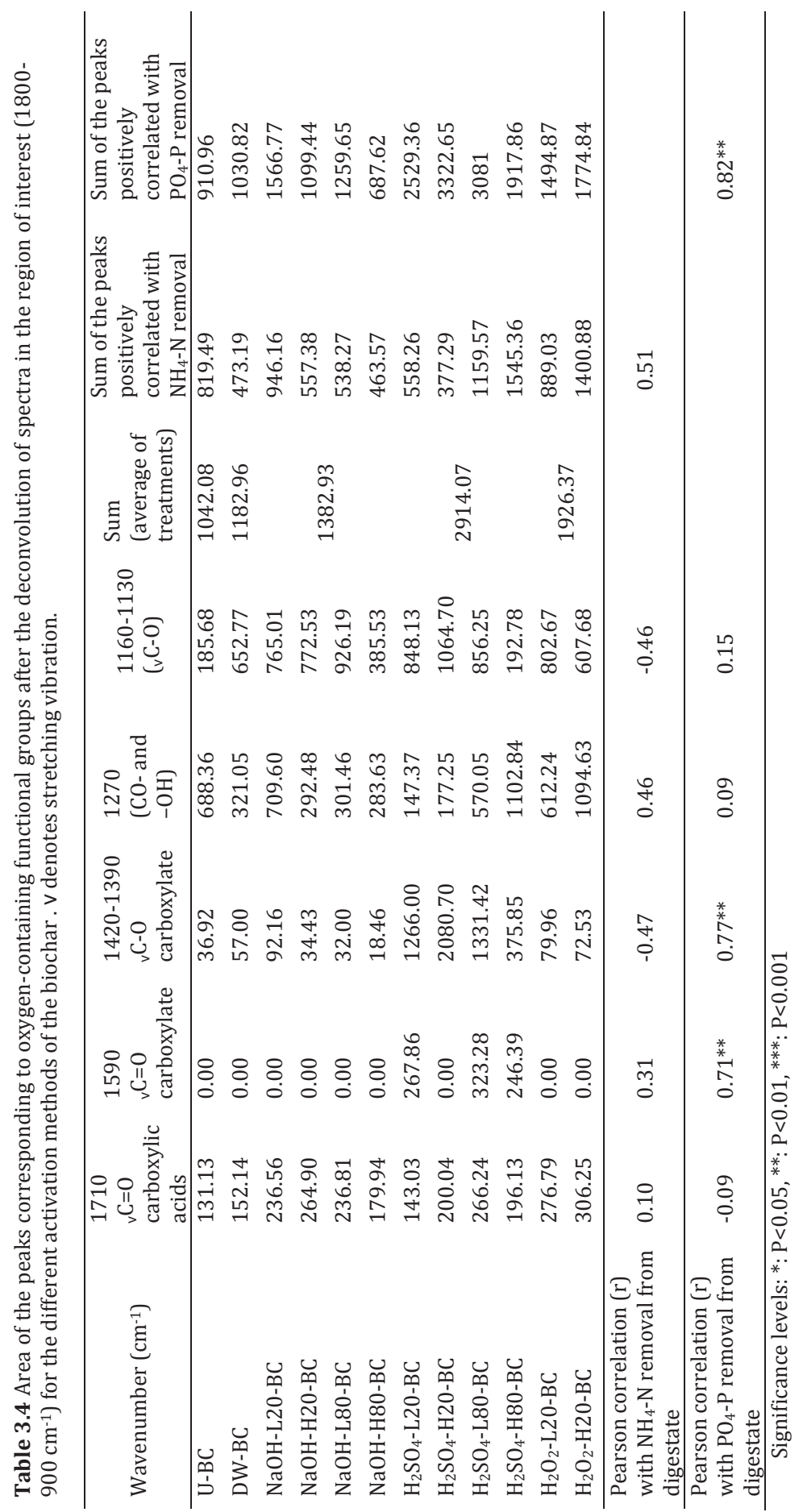


groups) and $1160-1130 \mathrm{~cm}^{-1}$ (C-O stretching vibrations of oxygenated functional groups of cellulose) (Cheng et al., 2008; Cui et al., 2016).

The sum of the area of the peaks corresponding to the oxygen-containing functional groups revealed that activated biochars contained more oxygencontaining functional groups than untreated biochars or deionised water-treated biochars (U-BC and DW-BC respectively) (Table 3.4). The greatest increase was observed after $\mathrm{H}_{2} \mathrm{SO}_{4}$ activation, followed by $\mathrm{H}_{2} \mathrm{O}_{2}$ and $\mathrm{NaOH}$ activation. This followed the removal of $\mathrm{PO}_{4}-\mathrm{P}$ from the liquid fraction of digestate, while it appeared that in the case of $\mathrm{NH}_{4}-\mathrm{N}$ removal the biochars activated with $\mathrm{NaOH}$ removed more $\mathrm{NH}_{4}-\mathrm{N}$ than the biochars activated with $\mathrm{H}_{2} \mathrm{O}_{2}$. However, as described earlier, $\mathrm{NH}_{4}-\mathrm{N}$ can also be removed from the digestate due to cation exchange, coadsorption with organic matter, precipitation in the form of struvite and ammonia volatilisation, which means that this is not related to the oxygen-containing functional groups of the biochar.

The correlation between the area of each peak and the removal of $\mathrm{NH}_{4}-\mathrm{N}$ and $\mathrm{PO}_{4}-\mathrm{P}$ from the liquid digestate after the addition of biochar revealed that none of the peaks ascribed to oxygen-containing bonds were significantly correlated with $\mathrm{NH}_{4}$ $\mathrm{N}$ removal (Table 3.4). Again, removal of $\mathrm{NH}_{4}-\mathrm{N}$ may be through other mechanisms such as cation exchange, co-adsorption with organic matter, precipitation in the form of struvite and ammonia volatilisation, therefore the amount of $\mathrm{NH}_{4}$ that can be adsorbed to oxygen-containing surface groups of biochar may be limited. However, peaks at $1590 \mathrm{~cm}^{-1}$ and $1420-1390 \mathrm{~cm}^{-1}$ ascribed to carboxylate groups were significantly positively correlated with $\mathrm{PO}_{4}-\mathrm{P}$ removal. The sum of the area of all peaks positively correlated with $\mathrm{PO}_{4}-\mathrm{P}$ removal, including carboxylate peaks together with peaks at $1270 \mathrm{~cm}^{-1}$ (aromatic CO- and phenolic -OH groups) and $1160-1130 \mathrm{~cm}^{-1}$ (C-O stretching vibrations of oxygenated functional groups of cellulose), was found to be significantly correlated with $\mathrm{PO}_{4}-\mathrm{P}$ removal $(\mathrm{r}=0.82)$. The peak corresponding to carboxylic acids at $1710 \mathrm{~cm}^{-1}$ was not correlated with $\mathrm{PO}_{4}-\mathrm{P}$ removal. Peaks corresponding to carboxyl groups could reflect the presence of the carboxylate ion COO- once it was in contact with the liquid fraction of digestate. The positive correlation between carboxyl peaks and $\mathrm{PO}_{4}$-P removal suggested that the formation of cation bridges between carboxylate ion and orthophosphate was an important mechanism for $\mathrm{PO}_{4}-\mathrm{P}$ removal from liquid fraction of digestate. Again, the formation of cation bridges could be due to the presence of polyvalent cations such 
as $\mathrm{Ca}^{2+}, \mathrm{Mg}^{2+} \mathrm{Al}^{3+}$ and $\mathrm{Fe}^{3+}$ in biochar and in the liquid fraction of digestate (Lin et al., 2012; Qian et al., 2013).

\subsection{Conclusions}

Our results showed that wood biochar could remove ammonium and orthophosphate from the liquid fraction of digestate and that removals were somewhat improved by chemical activation of biochar with sulfuric acid, sodium hydroxide and hydrogen peroxide. Potassium removal was not possible with untreated, deionised water-treated and $\mathrm{H}_{2} \mathrm{O}_{2}$-activated biochar since they released potassium into the liquid fraction of digestate. However chemical activation of biochar with $\mathrm{NaOH}$ and $\mathrm{H}_{2} \mathrm{SO}_{4}$ enabled potassium removal from the liquid fraction of digestate, but resulted in biochar potassium being present in the activation media, which could not then be reused

A strong positive correlation was found between orthophosphate removal and the carboxyl functional groups, which might be due to cation bridging between carboxylate ions and orthophosphate.

Ammonium removal was not related to any oxygen-containing functional groups of biochar and other mechanisms are probably dominant in ammonium removal, such as cation exchange, co-adsorption with organic matter and struvite precipitation. Further investigations might be useful to understand fully the mechanisms behind nutrient removal by biochar and its relationship with the surface functional groups.

\section{Acknowledgement}

This work has been conducted as part of a $\mathrm{PhD}$ thesis project supported by the Agricultural Transformation by Innovation (AgTraIn) Erasmus Mundus Joint Doctorate Programme funded by the Education, Audiovisual and Culture Executive Agency (EACEA). We gratefully acknowledge the provision of biochar samples from the EU FP-7 FertiPlus Project (grant no. 289853). We also thank Andrew Ross for providing the data on biochar samples. The first author would like to thank Bjarne W. Strobel for discussions about the results, Helle Sørensen for discussions about statistical analyses and Lijbert Brussaard for his valuable comments on the manuscript. 


\section{Supplementary Figures}

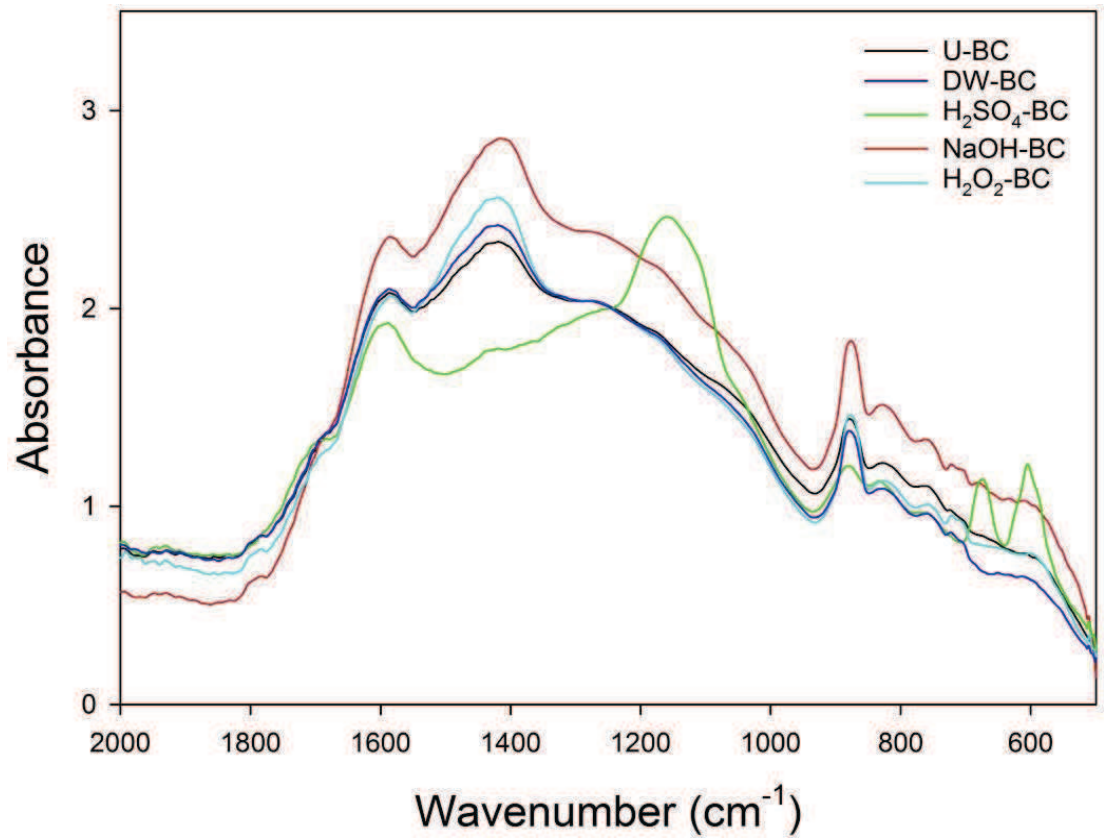

Supplementary Figure 3.1 Averaged FTIR-PA spectra across the different activations of the biochars. 


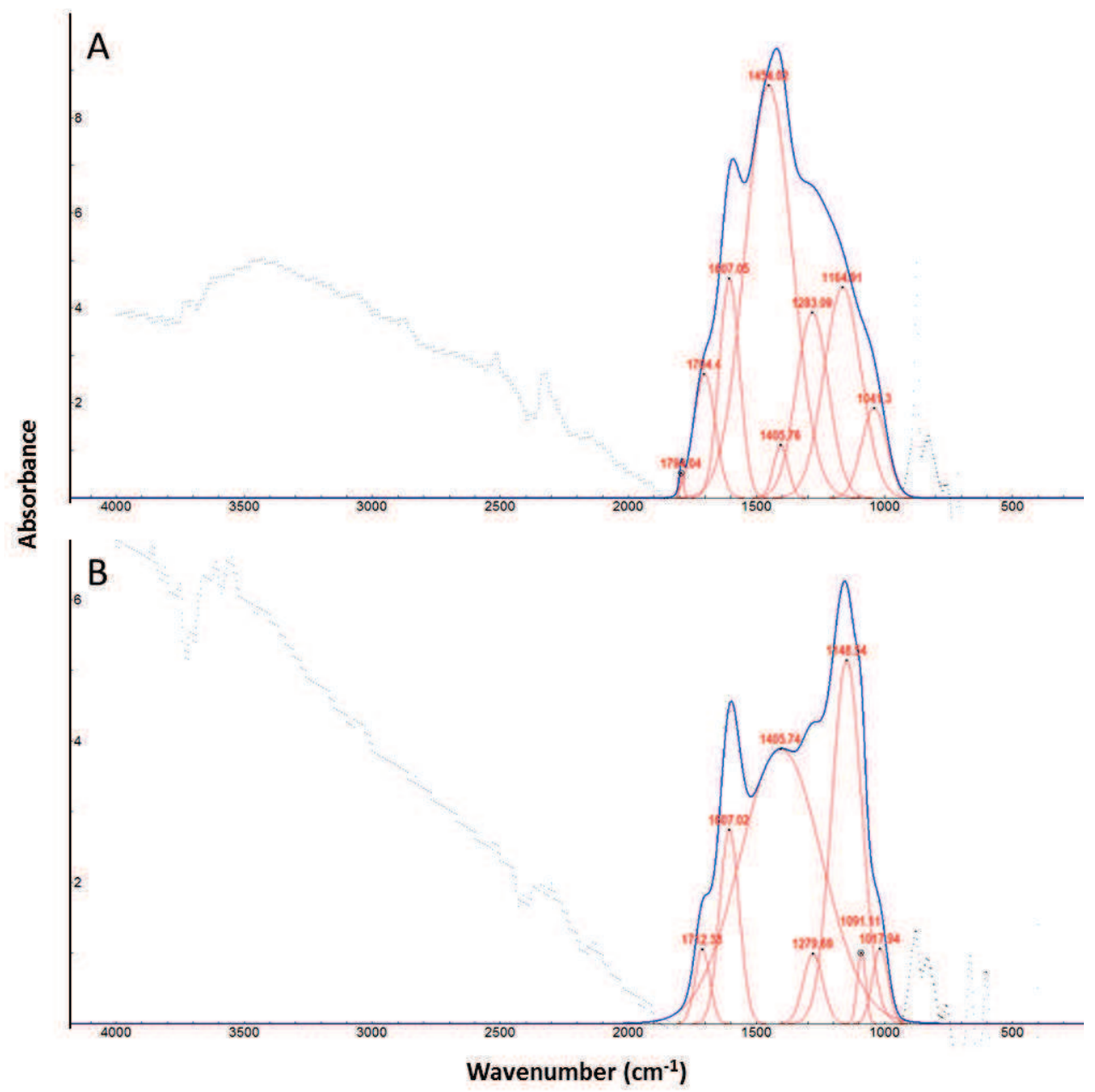

Supplementary Figure 3.2 An example of peak deconvolution of the region of interest (1800$900 \mathrm{~cm}^{-1}$ ) for the biochar activated with (A) $1 \mathrm{M} \mathrm{H}_{2} \mathrm{O}_{2}$ at $20{ }^{\circ} \mathrm{C}$ and (B) $1 \mathrm{M} \mathrm{H}_{2} \mathrm{SO}_{4}$ at $20{ }^{\circ} \mathrm{C}$. 


\title{
Chapter 4 \\ Does the combination of biochar and clinoptilolite enhance nutrient recovery from the liquid fraction of biogas digestate?
}

\author{
N. Pelin Kocatürk \\ Kor Zwart \\ Lijbert Brussaard \\ Sander Bruun \\ Lars Stoumann Jensen
}

This chapter is under review. 


\begin{abstract}
Concentrating nutrients on sorbents such as biochar and clinoptilolite and subsequently using the nutrient-enriched sorbents as a fertiliser could be an alternative way to manage nutrients in the liquid fraction of digestate. In this study, we investigated the use of biochar and clinoptilolite columns in removing ammonium, potassium, orthophosphate and dissolved organic carbon (DOC) from the liquid fraction of digestate. Our objectives were to investigate the effect of the initial loading ratio between liquid and biochar on nutrient removal, and to investigate the effect of combining biochar with clinoptilolite on nutrient and DOC removal efficiency.

Increasing the initial loading ratios increased nutrient concentrations on biochar to $8.61 \mathrm{mg} \mathrm{NH}_{4}-\mathrm{N} \mathrm{g}^{-1}, 1.95 \mathrm{mg} \mathrm{PO}_{4}-\mathrm{P} \mathrm{g}^{-1}$ and $13.01 \mathrm{mg}$ DOC g-1. However, an increase in the initial loading ratio resulted in decreasing removal efficiencies. Potassium removal was not possible since biochar released potassium into the liquid fraction of digestate.

The combination of biochar and clinoptilolite resulted in improved ammonium, potassium and DOC removal efficiencies compared to biochar alone, but did not significantly change $\mathrm{PO}_{4}$-P removal efficiencies. Removal efficiencies with combined sorbents were up to $67 \%$ for ammonium, $58 \%$ for DOC and $58 \%$ for potassium. Clinoptilolite alone showed higher removal efficiencies compared to biochar alone, and combining clinoptilolite with biochar only improved total P removal efficiency.

Nutrient removal from the liquid fraction of digestate with clinoptilolite and biochar may be an option for concentrating nutrients from the liquid fraction of digestate when both sorbents are available at a low cost.
\end{abstract}

Keywords: biochar; clinoptilolite; nutrient recovery; sorption; liquid fraction of digestate. 


\subsection{Introduction}

Management solutions for digestate are becoming increasingly important with the rising number of biogas plants in which animal manure is anaerobically digested with or without the addition of other types of organic waste or bioenergy crops. In regions that have a nutrient surplus due to intensive animal production, mechanical separation is often used to facilitate the redistribution of nutrient surpluses to other regions (Møller, 2000; Paavola \& Rintala, 2008; Jørgensen \& Jensen, 2009). Mechanical separation can also be valid for large-scale, centralised biogas plants where the solid fraction of mechanically separated digestate can be transported more easily and economically to regions with lower animal densities and no nutrient surplus (Møller, 2000; Møller et al., 2007). This still leaves the voluminous liquid fraction of digestate, and the most common practice is to apply it directly to agricultural fields where it may serve as a fertiliser due to its high content of plantavailable nutrients (Hjorth et al., 2010; Fuchs \& Drosg, 2013). However, nutrient balancing in the soil is important to avoid nutrient runoff to streams and waterways and protect groundwater resources and in Europe nutrient loads must remain within certain legal limits (Fuchs \& Drosg, 2013). Hence long-distance transportation and storage of large volumes of liquid manure or digestate is usually necessary, which can be problematic due to high transportation costs and large storage capacity requirements (Rehl \& Müller, 2011; Fuchs \& Drosg, 2013; Zarebska et al., 2015).

The recovery and concentration of nutrients from the liquid fraction of digestate by using sorbent materials could therefore potentially offer one solution for reducing practical and environmental issues. Sorbent materials enriched in nutrients can be considered to be nutrient carriers, which can subsequently be used as a fertiliser in agricultural fields. Biochar has been suggested as a sorbent for the removal of ammonium (Mukherjee et al., 2011; Hale et al., 2013; Hollister et al., 2013; Sarkhot et al., 2013; Hina et al., 2014; Wang et al., 2015a) and phosphate (Yao et al., 2013; Zeng et al., 2013; Wang et al., 2015c) from various wastewaters. Biochar has also attracted growing interest as an effective sorbent for removing organic contaminants due to its porous structure and large surface area (Chen et al., 2011; Ahmad et al., 2014; Mohan et al., 2014; Oh \& Seo, 2015; Wang et al., 2015b). Clinoptilolite, a natural zeolite mineral, is a well-known sorbent (cation exchanger), especially in the removal of ammonium from wastewater (Koon \& Kaufman, 1975; 
Beler-Baykal et al., 1996; Beler Baykal \& Guven, 1997; Hedström, 2008). Several studies have described the use of clinoptilolite for ammonium, potassium and orthophosphate recovery with high efficiencies from source-separated human urine (Ganrot et al., 2007, 2008; Beler Baykal et al., 2009; Beler-Baykal et al., 2011; Kocatürk \& Baykal, 2012; Allar \& Beler Baykal, 2015) and the liquid fraction of digestate (Kocatürk et al.).

The initial loading ratio (the initial amount of ammonium $\mathrm{N}$ in the liquid divided by the amount of sorbent in the system) is reported to be an important design parameter, which influences the nutrient removal efficiency in sorption systems with clinoptilolite (Kocatürk et al.; Beler Baykal et al., 2009). However, as yet there have been no studies that report on the effect of the initial loading ratio on the nutrient removal efficiency of biochar.

Combining biochar and clinoptilolite may represent a complementary solution for nutrient recovery from the liquid fraction of digestate, considering the specialised nature of biochar for ammonium, phosphate and organic matter adsorption and clinoptilolite's efficiency as a cation exchanger with high selectivity for ammonium and potassium. We hypothesised that: i) biochar adsorbs nutrients, i.e. ammonium, potassium and orthophosphate, and organic matter from the liquid fraction of digestate, and nutrient removal efficiency is affected by the initial loading ratio, ii) combining clinoptilolite and biochar provides greater complementary sorption which can remove nutrients and organic matter from the liquid fraction of digestate more efficiently than either one of them alone.

The objectives of our study were to investigate: i) the effect of the initial loading ratio of biochar on the removal efficiency of ammonium, potassium, orthophosphate and organic matter from the liquid fraction of digestate, ii) the effect of the combination of clinoptilolite and biochar on nutrient removal efficiency as compared to clinoptilolite and biochar alone.

\subsection{Materials and Methods}

Wood biochar was used in the experiments, which was produced by slow pyrolysis of holm oak at $650{ }^{\circ} \mathrm{C}$ and at atmospheric pressure (Proininso Inc. Málaga, Spain). Biochar samples had a composition of $76.5 \% \mathrm{C}, 1.4 \% \mathrm{H}, 0.8 \% \mathrm{~N}, 7 \%$ 0, 0.2 $\%$ P, $0.6 \% \mathrm{~K}, 0.04 \% \mathrm{Na}, 5$ \% Ca, $0.3 \% \mathrm{Mg}, 0.05 \% \mathrm{Fe}, 0.14 \% \mathrm{Al}$ (Ross, 2016) and a particle size of 1-4 mm. 
The clinoptilolite was from Gördes, Turkey and had a typical composition of 65$72 \% \mathrm{SiO}_{2}, 10-12 \% \mathrm{Al}_{2} \mathrm{O}_{3}, 0.7-1.9 \% \mathrm{Fe}_{2} \mathrm{O}_{3}, 0.1-0.5 \% \mathrm{Na}_{2} \mathrm{O}, 2.5-3.8 \% \mathrm{~K}_{2} \mathrm{O}, 2.4-3.7 \%$ $\mathrm{CaO}, 0.9-1.2 \% \mathrm{MgO}, 0-0.08 \% \mathrm{MnO}$ and $0.02-0.05 \% \mathrm{P}_{2} \mathrm{O}_{5}$ (data provided by the manufacturer, Rota Mining Co.). The particle size of the clinoptilolite was 1-3 mm. The properties of the biochar and clinoptilolite samples are given in Table 4.1. pH and specific surface area analyses of clinoptilolite and biochar were performed by a commercial laboratory (Eurofins, Germany). The cation exchange capacity (CEC) of clinoptilolite was provided by the manufacturer, while CEC of biochar was provided by (Dijk, 2015).

The liquid fraction of digestate was collected from a centralised biogas plant (Morsø Bioenergi ApS, Redsted, Denmark) where pig and cattle slurry as the main feedstock and various food wastes as the co-substrate are anaerobically digested and separated into liquid and solid fractions by a Gea Westfalia (UCA

501-00-02) decanter centrifuge. Table 4.2 shows the characterisation of the liquid fraction of digestate. In all the experiments, the $\mathrm{pH}$ of the liquid fraction of digestate was adjusted to 6.5-7.0 using $\mathrm{HCl}(37 \%)$ to prevent ammonia volatilisation.

Table 4.1 Properties of biochar and clinoptilolite samples

\begin{tabular}{llll}
\hline Sorbent & $\begin{array}{l}\text { Cation exchange capacity } \\
\left(\mathrm{cmol}_{\mathrm{c}} \mathrm{kg}^{-1}\right)\end{array}$ & $\begin{array}{l}\text { Surface area }\left(\mathrm{m}^{2}\right. \\
\mathrm{g}-1)\end{array}$ & $\mathrm{pH}$ \\
\hline Biochar & 42.3 & 166 & 8.2 \\
Clinoptilolite & $150-210$ & 35.5 & 8.5 \\
\hline
\end{tabular}

Table 4.2 Characterisation of the liquid fractions of digestate used in the study (range indicates concentration variation between two batches of the digestate liquids used).

\begin{tabular}{|c|c|}
\hline Parameter & Concentration \\
\hline $\mathrm{NH}_{4}-\mathrm{N}\left(\mathrm{mg} \mathrm{L}^{-1}\right)$ & $3195-4207$ \\
\hline $\mathrm{K}\left(\mathrm{mg} \mathrm{L}^{-1}\right)$ & $1337-2850$ \\
\hline $\mathrm{PO}_{4}-\mathrm{P}\left(\mathrm{mg} \mathrm{L}^{-1}\right)$ & $113-206$ \\
\hline Total N (mg L-1) & $4268-4507$ \\
\hline Total P (mg L-1) & $292-315$ \\
\hline Dissolved organic carbon $\left(\mathrm{mg} \mathrm{L}^{-1}\right)$ & $1418-2910$ \\
\hline $\mathrm{Ca}\left(\mathrm{mg} \mathrm{L}^{-1}\right)$ & $322-445$ \\
\hline $\operatorname{Mg}\left(\mathrm{mg} \mathrm{L}^{-1}\right)$ & $61-87$ \\
\hline $\mathrm{Na}\left(\mathrm{mg} \mathrm{L}^{-1}\right)$ & $1412-1800$ \\
\hline $\mathrm{Fe}\left(\mathrm{mg} \mathrm{L}^{-1}\right)$ & $45-108$ \\
\hline $\mathrm{pH}$ & $8.46-8-84$ \\
\hline
\end{tabular}




\section{Effect of the initial loading ratio on nutrient and organic matter removal}

We conducted column experiments with biochar to investigate the effect of the initial loading ratio on $\mathrm{NH}_{4}{ }^{+}, \mathrm{PO}_{4}^{3-}, \mathrm{K}^{+}$and DOC removal. The liquid fraction of digestate was pumped through Plexiglas columns $(100 \mathrm{~cm}$ height and $2.4 \mathrm{~cm}$ diameter) packed with $120 \mathrm{~g}$ biochar. A peristaltic pump (Masterflex L/S Series) was used to pump the liquid fraction of digestate at $100 \%$ recycling in the upflow mode at 1 bed volume per hour for 72 hours.

Column experiments were conducted in two replicates, with various initial ammonium loading ratios, i.e. 10, 15, 20, 30, 40, $80 \mathrm{mg} \mathrm{NH}_{4}-\mathrm{N} \mathrm{g}^{-1}$ biochar designated as L10, L15, L20, L30, L40, L80 respectively. The volume of the liquid fraction of digestate in the feed tank was dependent on the initial loading ratio and the ammonium concentration in the liquid fraction of digestate, and varied between 300 and $2800 \mathrm{~mL}$ to achieve the desired loading ratios. A $5 \mathrm{~mL}$ sample volume was taken from the feed tank every 24 hours.

\section{Nutrient removal by combining biochar and clinoptilolite}

Column experiments were conducted to investigate the effect of combining biochar with clinoptilolite by comparing removal efficiency in columns with biochar and clinoptilolite alone. We also investigated the effect of sequencing or mixing the sorbents in combined systems on nutrient removal efficiency. The tested columns were biochar alone (B), clinoptilolite alone (C), biochar and clinoptilolite homogenously mixed in one column (M), a biochar column followed by a clinoptilolite column (BC) and a clinoptilolite column followed by a biochar column (CB). The liquid fraction of digestate was pumped through Plexiglas columns (25 and $50 \mathrm{~cm}$ height, $2.4 \mathrm{~cm}$ diameter) packed with clinoptilolite and/or biochar. The amount of sorbent added to the columns and the volume of the liquid fraction of digestate in the feed tank was based on the initial loading ratio and ammonium concentration in the liquid fraction of digestate. An overview of the experimental setup is shown in Figure 4.1 and the experimental conditions are summarised in Table 4.3. Column experiments were run at $100 \%$ recycling in the upflow mode for 72 hours in three replicates. A $10 \mathrm{~mL}$ sample volume was taken from the feed tank every 24 hours. 


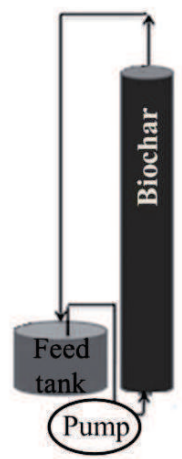

(a)

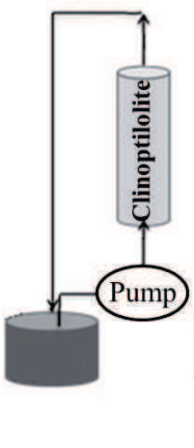

(b)

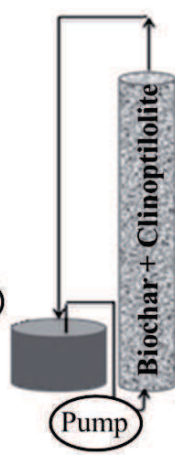

(c)

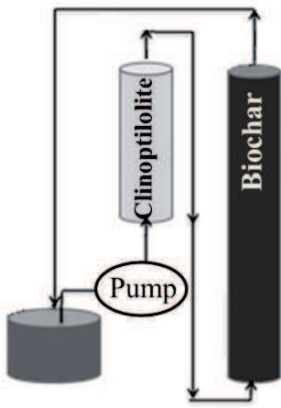

(d)

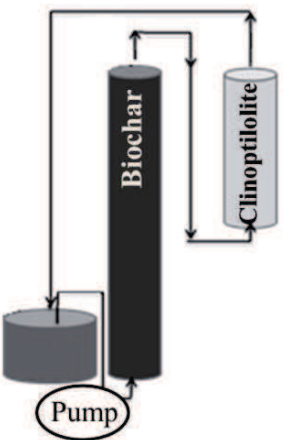

(e)

Figure 4.1 Experimental setup for a) biochar-alone column (B), b) clinoptilolite-alone column (C), c) biochar and clinoptilolite homogenously mixed in one column (M), d) biochar column followed by a clinoptilolite column (BC) and e) clinoptilolite column followed by a biochar column (CB).

\section{Analyses}

Samples from the different experimental setups were analysed for $\mathrm{NH}_{4}-\mathrm{N}, \mathrm{PO}_{4}-\mathrm{P}$ and $\mathrm{K}$ in different laboratories using different instruments. The ammonium (NH4-N) and orthophosphate (PO4-P) concentrations were measured on a flow injection analyser (FIAstar 5000) and a segmented flow analyser according to ISO 11732 (International Organization for Standardization, 2005) and ISO 15681-1 (International Organization for Standardization, 2003) respectively for samples

Table 4.3 Experimental conditions used in the nutrient loading experiments with biochar-alone column (B), clinoptilolite-alone column (C), biochar and clinoptilolite homogenously mixed in one column (M), biochar column followed by a clinoptilolite column (BC), clinoptilolite column followed by a biochar column (CB).

\begin{tabular}{llllll}
\hline Designation & $\begin{array}{l}\text { Initial } \\
\text { loading ratio }\end{array}$ & $\begin{array}{l}\text { Amount of } \\
\text { clinoptilolite }(\mathrm{g})\end{array}$ & $\begin{array}{l}\text { Amount of } \\
\text { biochar }(\mathrm{g})\end{array}$ & $\begin{array}{l}\text { Bed height } \\
(\mathrm{cm})\end{array}$ & $\begin{array}{l}\text { Digestate } \\
\text { volume }(\mathrm{mL})\end{array}$ \\
\hline $\mathrm{B}$ & $1^{\mathrm{a}}$ & $\mathrm{n} / \mathrm{a}$ & 60 & 50 & 450 \\
$\mathrm{C}$ & $1^{\mathrm{b}}$ & 60 & $\mathrm{n} / \mathrm{a}$ & 17 & 450 \\
$\mathrm{M}$ & $15^{\mathrm{c}}$ & 45 & 45 & 50 & 338 \\
$\mathrm{BC}$ & $1^{\mathrm{c}}$ & 60 & 60 & 50,17 & 450 \\
$\mathrm{CB}$ & $1^{\mathrm{c}}$ & 60 & 60 & 17,50 & 450 \\
\hline
\end{tabular}

a initial loading ratio is $15 \mathrm{mg} \mathrm{NH}_{4}-\mathrm{N} \mathrm{g}^{-1}$ biochar

b initial loading ratio is $15 \mathrm{mg} \mathrm{NH}_{4}-\mathrm{N} \mathrm{g}^{-1}$ clinoptilolite

c initial loading ratio for the combined columns is chosen as $15 \mathrm{mg} \mathrm{NH}_{4}-\mathrm{N} \mathrm{g}^{-1}$ clinoptilolite and the same amount of biochar has been added to the system 
from the 'effect of initial loading ratio on nutrient removal' and 'nutrient removal by combining biochar and clinoptilolite' experiments. Potassium was analysed using a flame photometer (Perkin Elmer 3300) and inductively coupled plasma atomic emission spectroscopy according to Standard Methods and for the same set of samples.

Dissolved carbon (DC) and dissolved inorganic carbon (DIC) were measured in all samples by a segmented flow analyser according to Dutch Standards (Dutch Standards, 1997). Dissolved organic carbon (DOC) was calculated as the difference between DC and DIC (DOC = DC - DIC). Total N and total P were analysed after digesting samples in a mixture of sulphuric acid, salicylic acid and $\mathrm{Se}$, to which $\mathrm{H}_{2} \mathrm{O}_{2}$ was added, and were colorimetrically determined by a segmented flow analyser according to (Novozamsky et al., 1984; International Organization for Standardization, 2003, 2005).

The removal was determined for each sampling occasion as:

$$
\boldsymbol{R}_{x}=\frac{C_{x}-C_{(x+1)}}{M} \times V_{x}
$$

where $\mathrm{R}_{\mathrm{x}}$ is the amount of sorbate removed from the solution by the sorbent (mg g${ }^{1}$ ) between sampling occasion $x$ and $x+1, C_{x}$ is the concentration (mg L-1) of the sorbate on sampling occasion $x, V_{x}$ is the volume (L) of the aqueous solution (digestate) on sampling occasion $x$ and M (g) is the mass of the sorbent. The total removal at the end of the experiment was calculated as:

$$
\mathbf{R}=\sum_{x=1}^{x=n} R_{x}
$$

where $\mathrm{R}$ is the total amount of sorbate removed from the solution by the sorbent at the end of the experiment $\left(\mathrm{mg} \mathrm{g}^{-1}\right)$, and $n$ is the total number of sampling occasions. Removal efficiency (RE) was determined as:

$$
\operatorname{RE}(\%)=\frac{R}{C_{0} V_{0}} \times 100
$$

where RE is the removal efficiency (\%), $\mathrm{R}$ is the total removal of the sorbate, $C_{0}$ is the initial concentration of the sorbate and $V_{0}$ is the initial volume of the liquid fraction of digestate. 


\section{Statistical analyses}

Statistical analyses were conducted using the statistical package R, version 3.2.2 (The R Project, 2015). Data from the experiments on nutrient removal by biochar were analysed using a one-way analysis of variance (ANOVA) procedure for independent samples to test for statistically significant differences $(p<0.05)$. We performed a Pearson product-moment correlation test to investigate the correlation between the initial loading ratio and $\mathrm{NH}_{4}-\mathrm{N}$ removal, $\mathrm{NH}_{4}-\mathrm{N}$ removal efficiency, $\mathrm{PO}_{4}$ $\mathrm{P}$ removal, $\mathrm{PO}_{4}-\mathrm{P}$ removal efficiency, DOC removal and DOC removal efficiency separately.

For nutrient removal in the combining biochar and clinoptilolite experiment, Tukey's Honest Significant Difference (HSD) test was conducted to investigate differences between biochar, clinoptilolite and various combined column systems at the $\mathrm{P}<0.05$ level.

\subsection{Results and Discussion}

\section{Effect of the initial loading ratio on nutrient and organic matter removal}

Figure 4.2a shows the change in ammonium concentration over time as a result of various loading ratios. A higher decrease in ammonium concentration was observed with lower initial loading ratios. Ammonium removal by biochar (Figure $4.2 \mathrm{~b})$ was significantly affected by the initial loading ratio $(\mathrm{p}=0.014)$. L80 resulted in the highest ammonium removal with $8.61 \mathrm{mg} \mathrm{NH}_{4}-\mathrm{N} \mathrm{g}^{-1}$ biochar. An increase was observed in $\mathrm{NH}_{4}-\mathrm{N}$ removal with rising initial loading ratios, and this observation was supported by a correlation test which showed a strong positive linear correlation between the initial loading ratio and $\mathrm{NH}_{4}-\mathrm{N}$ removal $(\mathrm{r}=0.86, \mathrm{p}<0.001)$.

Several potential mechanisms for ammonium removal by biochar from liquid solutions have been proposed: cation exchange with cations such as $\mathrm{Ca}^{2+}, \mathrm{Mg}^{2+}, \mathrm{K}^{+}$, $\mathrm{Na}^{+}$in biochar (Hale et al., 2013; Sarkhot et al., 2013; Zeng et al., 2013; Cui et al., 2016), chemical reactions with (oxygen-containing) surface functional groups (Kizito et al., 2015; Wang et al., 2015a, 2015c; Cui et al., 2016), surface areadependent 

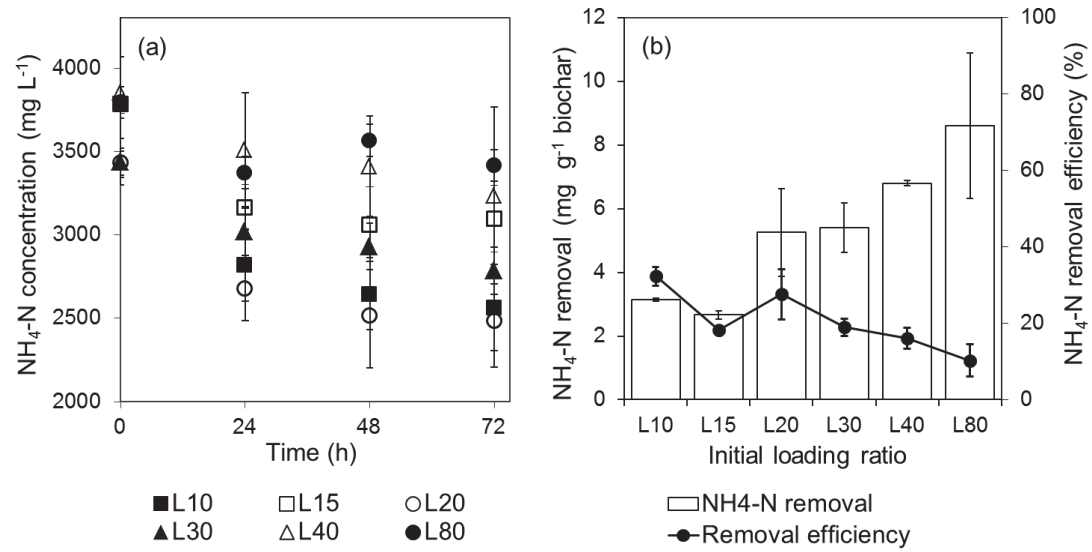

Figure 4.2 Ammonium concentration changes over time during removal in a column with biochar for different loading ratios (a), $\mathrm{NH}_{4}-\mathrm{N}$ removal per g biochar and $\mathrm{NH}_{4}-\mathrm{N}$ removal efficiency as a result of various initial loading ratios (b). L10-L80 signifies initial loading ratios between 10 and $80 \mathrm{mg} \mathrm{NH}_{4}-\mathrm{N} \mathrm{g}^{-1}$ biochar. Error bars indicate standard deviations $(\mathrm{n}=2)$.

physical diffusion and physical entrapment of $\mathrm{NH}_{4}{ }^{+}$in biochar pores (Clough et al., 2013; Kizito et al., 2015), co-adsorption with soluble organic matter (Lehmann et al., 2002; Sarkhot et al., 2013) and struvite $\left(\mathrm{MgNH}_{4} \mathrm{PO}_{4} \cdot 6 \mathrm{H}_{2} \mathrm{O}\right)$ precipitation on biochar (Cui et al., 2016). Lehmann et al. (2002) attribute ammonium adsorption to the coadsorption with soluble organic matter. They found that the addition of extracted DOC from manure increases ammonium adsorption. Nutrient sorption with biochar has not previously been studied in column systems, but there are several studies that report ammonium removal in batch studies, mostly from synthetic solutions. Reported values for the amount of ammonium removal per g vary between 0.10 and $5.40 \mathrm{mg} \mathrm{g}^{-1}$ from synthetic solutions with wood biochar (Hollister et al., 2013; Hina et al., 2014; Jassal et al., 2015; Wang et al., 2015a, 2015c). Few studies have reported ammonium removal from manure or manure digestates, which usually have a higher ammonium concentration and organic matter content than synthetic solutions. Sarkhot et al. (2013) found ammonium removal of $5.30 \mathrm{mg} \mathrm{NH} \mathrm{NH} \mathrm{g}^{-1}$, whereas Kizito et al. (2015) found ammonium removal of $44.64 \mathrm{mg} \mathrm{NH}_{4}-\mathrm{N} \mathrm{g}^{-1}$, both of which are higher than that reported for synthetic solutions. Our results were in the range of the results reported, except for the results presented by Takaya et al. (2016). They reported an ammonium removal of $114.4 \mathrm{mg} \mathrm{g}^{-1}$ from synthetic solutions with holm oak wood biochar pyrolysed at $650{ }^{\circ} \mathrm{C}$ (the same biochar as that 
used in this study), which is very high compared with our results and with other studies in the literature.

Ammonium removal efficiency (Figure 4.2b) varied between $10 \%$ and $32 \%$ and was significantly affected by different initial loading ratios ( $p=0.007)$. The highest removal efficiency was observed at the lowest loading ratio (L10), with increasing loading ratio generally resulting in decreasing removal efficiencies. This observation was supported by a correlation test that indicated a negative correlation between initial loading ratio and ammonium removal efficiency $(r=-0.76, p=0.003)$. Overall, our results showed that the removal of ammonium by biochar was possible but limited. The highest removal was achieved with L80, but its removal efficiency was the lowest, just $10 \%$ at this loading ratio. Even with the L10 loading ratio the efficiency was only $32 \%$. In the literature, ammonium removal efficiencies range between $7 \%$ and $33 \%$ from synthetic solutions (Sarkhot et al., 2013; Hina et al., 2014) and $18 \%$ and $60 \%$ from manure products (Sarkhot et al., 2013; Kizito et al., 2015). Our results for digestate were therefore lower than the efficiencies previously reported; however, removal efficiency is dependent on the initial loading ratio and these studies have not reported the initial loading ratios, hence our results may not be comparable.

DOC removal per g biochar was significantly affected by the initial loading ratio (Figure 4.3, $\mathrm{p}<0.001$ ). The highest initial loading ratio resulted in the highest DOC removal with $13.0 \mathrm{mg}$ DOC g-1 biochar. Similarly to the ammonium results, DOC removal increased significantly with increasing initial loading ratios, and a correlation test showed a strong positive correlation between initial loading ratio and DOC removal $(r=0.93, p<0.001)$. In previous studies, biochar has been shown to be an efficient sorbent for removing various organic compounds due to its high surface area and microporosity (Ahmad et al., 2014), but we have not found any studies that have reported DOC removal with biochar. Xing et al. (2008) studied DOC sorption with granular activated carbon from biologically treated sewage effluents that had a DOC concentration of $55 \mathrm{mg} \mathrm{L}^{-1}$. They applied various amounts of activated carbon and found that increasing the dosage of activated carbon from $0.25 \mathrm{~g}$ to $5 \mathrm{~g}$ in $1 \mathrm{~L}$ wastewater results in a decrease in the amount of DOC removed, which is a similar observation to ours.

We found DOC removal efficiencies ranging from $25 \%$ to $68 \%$, and decreasing significantly with an increasing initial loading ratio $(\mathrm{p}=0.004)$. There was a strong negative correlation between initial loading ratio and DOC removal 


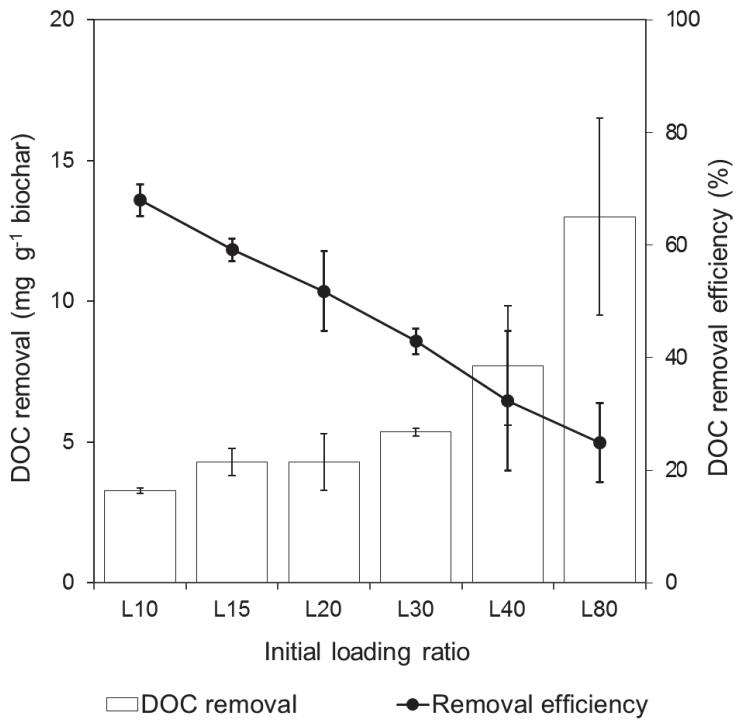

Figure 4.3 Dissolved organic carbon (DOC) removal per g biochar and DOC removal efficiency for different initial loading ratios. L10-L80 signifies initial loading ratios between 10 and $80 \mathrm{mg}$ $\mathrm{NH}_{4}-\mathrm{N} \mathrm{g}^{-1}$ biochar. Error bars indicate standard deviations ( $\left.\mathrm{n}=2\right)$.

efficiency $(\mathrm{r}=-0.86, \mathrm{p}<0.001)$. Xing et al. (2008) also reported that DOC removal efficiency fell from $82 \%$ to $48 \%$ with a decreasing dosage, which corresponds to an increasing initial loading ratio in our study.

Orthophosphate concentration declined over time at all initial loading ratios (Figure 4.4a). The highest final $\mathrm{PO}_{4}-\mathrm{P}$ concentration at the end of the experiments was observed with the highest loading ratio (L80). Orthophosphate removal was significantly affected by the initial loading ratio ( $p=0.02$, Figure $4.4 \mathrm{~b}$ ). The highest

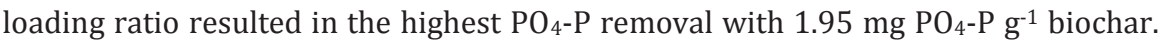
There was a strong positive correlation between initial loading ratio and $\mathrm{PO}_{4}-\mathrm{P}$ removal $(\mathrm{r}=0.89, \mathrm{p}<0.001)$. Our results for orthophosphate removal were in line with other studies, which reported up to 

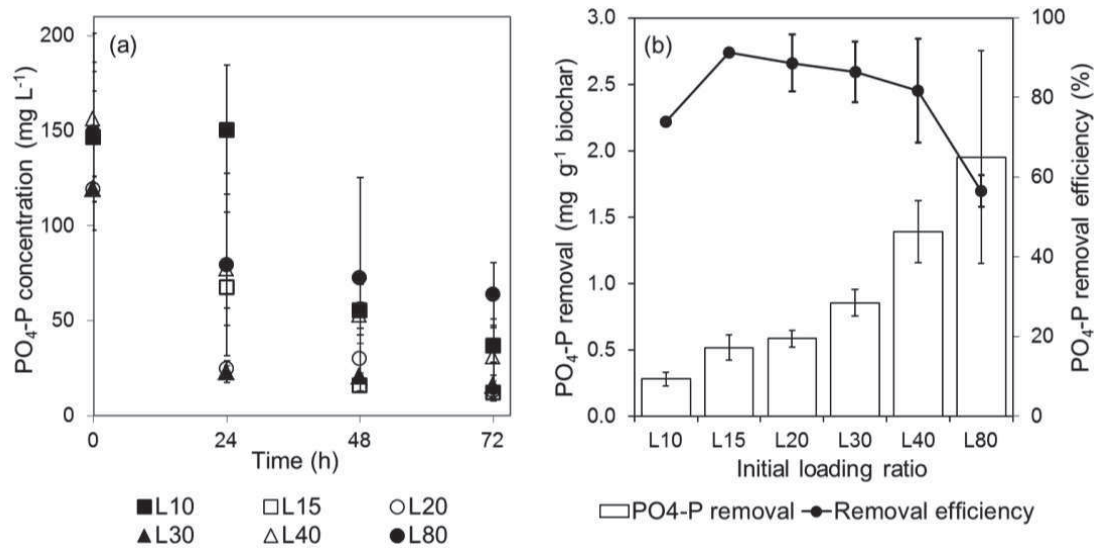

Figure 4.4 Orthophosphate concentration changes over time during removal in a column with biochar for different loading ratios (a), $\mathrm{PO}_{4}$ - $\mathrm{P}$ removal per $\mathrm{g}$ biochar and $\mathrm{PO}_{4}-\mathrm{P}$ removal efficiency as a result of various initial loading ratios (b). L10-L80 signifies initial loading ratios between 10 and $80 \mathrm{mg} \mathrm{NH}_{4}-\mathrm{N} \mathrm{g}^{-1}$ biochar. Error bars indicate standard deviations ( $\left.\mathrm{n}=2\right)$.

approximately $1.0 \mathrm{mg} \mathrm{PO}_{4}-\mathrm{P} \mathrm{g}^{-1}$ removal from synthetic solutions and dairy manure (Chen et al., 2011; Hale et al., 2013; Hollister et al., 2013; Sarkhot et al., 2013). However, the removal in our experiments was low compared with Wang et al. (2015c) and Takaya et al. (2016) who used oak wood

biochar and reported orthophosphate removal of 10.1 and $15.1 \mathrm{PO}_{4}-\mathrm{P} \mathrm{g}{ }^{-1}$ biochar respectively.

Orthophosphate removal efficiency ranged from $57 \%$ to $91 \%$ and decreased significantly with an increasing initial loading ratio $(\mathrm{p}=0.02$, Figure $4.4 \mathrm{~b})$. There was a strong negative correlation between initial loading ratio and $\mathrm{PO}_{4}-\mathrm{P}$ removal efficiency ( $\mathrm{r}=-0.72, \mathrm{p}=0.008$ ). Our results for orthophosphate removal efficiency were in line with other studies which reported removal efficiencies of between $38 \%$ and $95 \%$ (Sarkhot et al., 2013; Zeng et al., 2013). We did not investigate the mechanisms involved in orthophosphate removal by biochar, but potential mechanisms suggested for orthophosphate removal from liquid solutions include phosphate adsorption to $\mathrm{MgO}$ on the biochar surface (Yao et al., 2011), precipitation reactions between phosphate and $\mathrm{Ca}^{+}$and $\mathrm{Mg}^{+}$ions (Wang et al., 2015c), anion exchange with surface hydroxyl groups (Sarkhot et al., 2013) and electrostatic interaction of phosphate anions with charged hydroxide surfaces (Chen et al., 2011). In our study, precipitation reactions between phosphate and $\mathrm{Ca}^{+}$and $\mathrm{Mg}^{+}$were 
likely to occur due to the relatively high $\mathrm{pH}$ (8.50-8.65, data not shown) in the liquid fraction of digestate at the end of the experiments.

We observed increasing potassium concentrations (Figure 4.5) in the feed tank at all initial loading ratios, which indicated potassium release from the biochar regardless of the loading ratio. The potassium concentration at the end of the experiment was highest with the lowest initial loading ratio (L10).

Potassium release from wood biochar was also observed by Angst \& Sohi (2013), and they reported up to $4.48 \mathrm{mg} \mathrm{K} \mathrm{g-1} \mathrm{release.} \mathrm{Wu} \mathrm{et} \mathrm{al.} \mathrm{(2011)} \mathrm{reported} \mathrm{that} 90 \%$ of potassium in wood biochar is released in water. However, in a study on activation of biochar, Kocatürk et al. showed that chemical activation of biochars with H2SO4 and $\mathrm{NaOH}$ enables potassium removal from the liquid fraction of digestate. Thus raw, untreated biochar cannot be used alone as a sorbent for potassium.

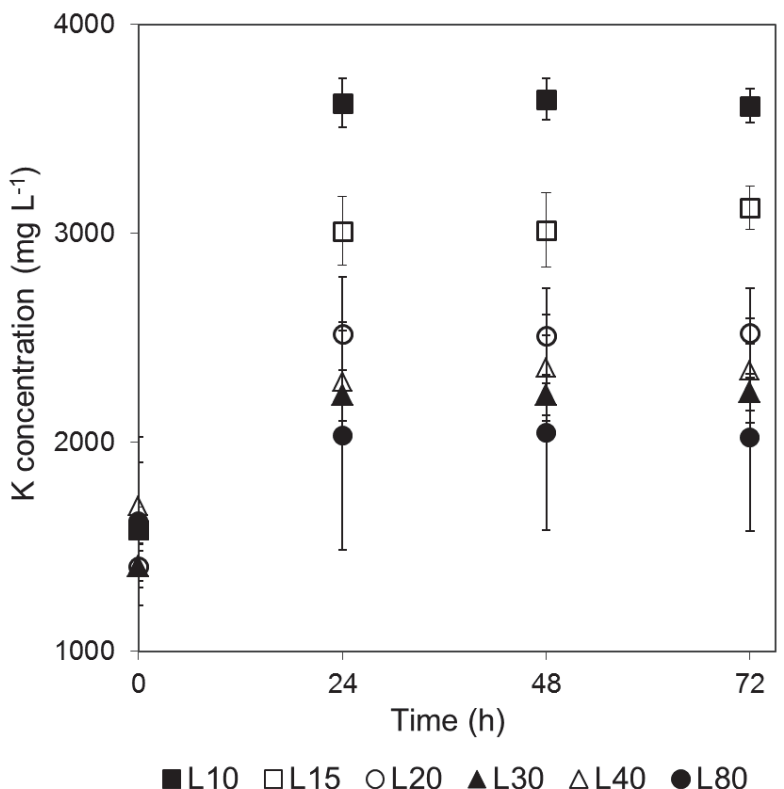

Figure 4.5 Potassium concentration changes in time as a result of various initial loading ratios. L10-L80 signifies initial loading ratios between 10 and $80 \mathrm{mg} \mathrm{NH}_{4}-\mathrm{N} \mathrm{g}^{-1}$ biochar. Error bars indicate standard deviations $(\mathrm{n}=2)$. 


\section{Nutrient removal by combining biochar and clinoptilolite}

We observed the lowest ammonium removal efficiency in the column with biochar alone (Figure 4.6a), whereas higher $\mathrm{NH}_{4}-\mathrm{N}$ removal efficiencies were observed in the column with clinoptilolite alone as well as in the combined column systems. We observed a similar pattern for both total $\mathrm{N}$ (Figure 4.6b) and DOC (Figure 4.6c). This indicated that $\mathrm{NH}_{4}-\mathrm{N}$, total $\mathrm{N}$ and DOC removal by combining biochar with clinoptilolite resulted in improved removal efficiency as compared to columns with biochar alone. This was due to the higher sorption capacity of clinoptilolite for ammonium, total N and DOC. Clinoptilolite is reported to be an efficient sorbent for removing ammonium from the liquid fraction of digestate, with up to $89 \%$ efficiency (Kocatürk et al.). There are studies that have compared the efficiency of biochar and zeolites in removing ammonium, and greater efficiencies have been reported with zeolites than with biochar. Carey et al. (2015) found that base-modified biochar could remove $5.3 \mathrm{mg} \mathrm{NH}_{3}-\mathrm{N}$, whereas clinoptilolite removed

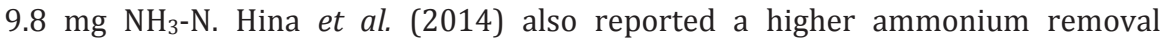
efficiency with zeolite (91\%) compared to biochar (49\%). Halim et al. (2010) compared activated carbon and zeolite in the removal of ammonia from landfill leachate and found approximately $20 \%$ and $80 \% \mathrm{NH}_{3}-\mathrm{N}$ removal efficiency with activated carbon and zeolite respectively. Farkaš et al. (2005) reported that wastewater treatment with activated carbon and subsequent treatment with zeolite resulted in $62 \%$ additional total organic carbon removal compared to activated carbon treatment alone. Ganrot et al. (2007) compared the efficiency of activated carbon and zeolite in removing total $\mathrm{N}$ from human urine and found comparable efficiencies for both sorbents, although they state that activated carbon adsorbs ammonium, but also larger organic molecules containing nitrogen, whereas zeolite mainly removes ammonium. Our results were in line with previous studies and provided clear evidence of the higher efficiency of clinoptilolite in the removal of ammonium, total $\mathrm{N}$ and DOC. Our results also indicated that the efficiency of clinoptilolite in removing ammonium, total $\mathrm{N}$ and DOC could not be improved upon in combined columns. 

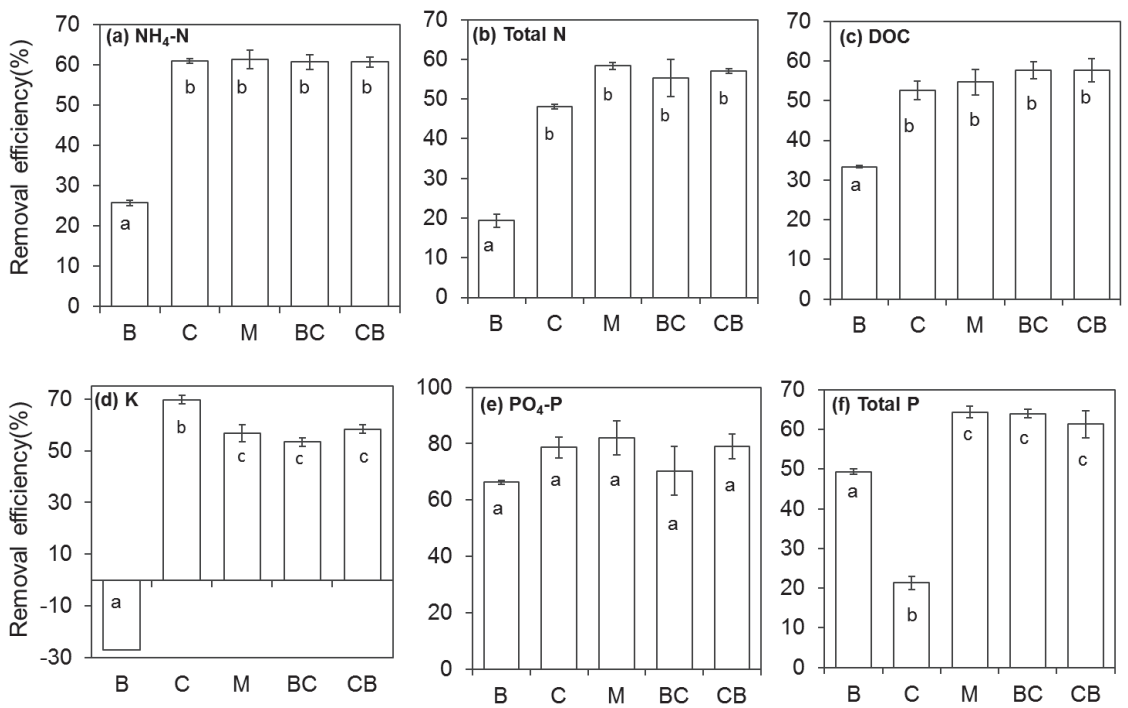

Figure 4.6 Ammonium (a), total nitrogen (b), dissolved organic carbon (c), potassium (d), orthophosphate (e), total phosphorus (f) removal from the liquid fraction of digestate with biochar-alone column (B), clinoptilolite-alone column (C), biochar and clinoptilolite homogenously mixed in one column (M), biochar column followed by a clinoptilolite column (BC), clinoptilolite column followed by a biochar column (CB). Letters inside the bars indicate significant differences $(\mathrm{p}<0.05)$ among various column systems. Error bars indicate standard errors $(n=3)$.

Potassium removal was not possible in the biochar columns as biochar released $\mathrm{K}$ in the liquid fraction of digestate (Figure 4.6d), which was in line with our observations in the experiments with biochar alone. Clinoptilolite on the other hand could remove approximately $70 \%$ of $\mathrm{K}$ in the liquid fraction of digestate. As a result, combining clinoptilolite with biochar resulted in $50 \% \mathrm{~K}$ removal efficiency, which was lower than in the columns with clinoptilolite alone. Clinoptilolite is known as a selective cation exchanger with a higher selectivity for potassium than for ammonium (Koon \& Kaufman, 1975). Beler Baykal et al. (2009) reported up to $90 \%$ potassium removal efficiencies from human urine and Kocatürk et al. reported up to $78 \%$ removal efficiencies from the liquid fraction of digestate using clinoptilolite. Our results showed that biochar cannot be used on its own as a sorbent for potassium and it decreases the potassium removal efficiency of clinoptilolite when they are used in combination. 
Orthophosphate removal efficiency was similar in all columns (Figure 4.6e). Clinoptilolite removed on average $79 \%$ of orthophosphate, which was in line with the results from Kocatürk et al. who reported $80 \%$ orthophosphate removal from the liquid fraction of digestate with clinoptilolite. However, total $\mathrm{P}$ removal efficiency was the lowest in the column with clinoptilolite alone and was higher in the columns with biochar alone (Figure 4.6f). Biochar has a typical solid density ranging from 1.5 to $2.0 \mathrm{~g} \mathrm{~cm}^{-3}$ (Lehmann \& Joseph, 2015) whereas clinoptilolite has a solid density of 2.2 to $2.4 \mathrm{~g} \mathrm{~cm}^{-3}$ (data provided by the manufacturer) and this affects filtration efficiency (Tchobanoglous et al., 2003). The differences between solid densities also created differences in bed volume for the same amount (of weight) of the two materials. Total phosphorus is mainly attached to the particles and higher filtration efficiency and a higher bed volume in the biochar column could be the reason for the difference in total $\mathrm{P}$ removal for biochar and clinoptilolite. Combined columns resulted in the highest total $\mathrm{P}$ removal, indicating improved removal compared to the clinoptilolite and biochar-alone columns, which may also be due to a higher bed volume since combined columns had more sorbent materials compared to clinoptilolite and biochar-alone columns.

Overall, combining biochar with clinoptilolite improved $\mathrm{NH}_{4}-\mathrm{N}$, total $\mathrm{N}, \mathrm{DOC}, \mathrm{K}$ and total $\mathrm{P}$ removal efficiencies and did not change $\mathrm{PO}_{4}-\mathrm{P}$ removal efficiencies compared to columns with biochar alone. As for clinoptilolite, combining it with biochar was only beneficial in improving total $\mathrm{P}$ removal efficiency. We did not observe a significant effect of sequencing or mixing the sorbents in combined systems on the nutrient removal efficiency from the liquid fraction of digestate. Therefore in circulating systems such as our setup, the sequence of adsorbents does not matter.

Nutrient-enriched products from digestates as well as the liquid fraction of digestates need to be concentrated and highly enriched with nutrients if they are to be used as fertilisers (Fuchs \& Drosg, 2013). Kocatürk et al. reported that $300 \mathrm{~kg}$ of clinoptilolite would be needed to process $1 \mathrm{Mg}$ of liquid fraction of digestate (assuming $3900 \mathrm{mg} \mathrm{L}^{-1} \mathrm{NH}_{4}-\mathrm{N}$ concentration) if the column system were designed with a $15 \mathrm{mg} \mathrm{NH} 4-\mathrm{N}$ g clinoptilolite initial loading ratio. A similar calculation for biochar would result in $1466 \mathrm{~kg}$ biochar since the removal was around $2.66 \mathrm{mg} \mathrm{NH}_{4}$ $\mathrm{N} \mathrm{g}^{-1}$, with less than $20 \%$ ammonium removal, whereas clinoptilolite resulted in 13 mg NH $4-\mathrm{N} \mathrm{g}^{-1}$ removal and $86 \%$ ammonium removal at the same initial loading ratio (L15). The concentration of nutrients on biochar is much lower compared to 
clinoptilolite, which may not be economically and practically feasible. Nevertheless, the use of biochar as a sorbent material may still be attractive in regions where biochar is produced for energy recovery and is needed as a soil improver. Another important aspect for selecting a sorbent material for removing nutrients from the liquid fractions of digestate is the effectiveness of the enriched sorbents as a fertiliser (Kocatürk et al.).

\subsection{Conclusions}

Our results indicated that biochar could be used as a sorbent material to remove ammonium, orthophosphate and dissolved organic carbon from the liquid fraction of digestate and concentrate it on its surface. However potassium removal was not possible and biochar even released potassium into the liquid fraction of digestate. Ammonium, orthophosphate and dissolved organic carbon removal increased with increasing initial loading ratios, but removal efficiencies decreased.

Biochar addition in the combined systems did not improve clinoptilolite's efficiency at removing $\mathrm{NH}_{4}-\mathrm{N}, \mathrm{PO}_{4}-\mathrm{P}$, total $\mathrm{N}$ and $\mathrm{DOC}$ except for total $\mathrm{P}$ removal, and resulted in a lower K removal efficiency compared to clinoptilolite-alone columns.

Concentration of nutrients on biochar is limited and occurs at low levels, but may still be an option where large volumes of biochar are available at a low cost. Clinoptilolite presents higher removal efficiencies and a higher concentration of nutrients compared to biochar. Nutrient removal from the liquid fraction of digestate with clinoptilolite and biochar may be an attractive option where they are both available and inexpensive, and where their value as soil improvers is high, e.g. when soils are depleted in nutrients and organic matter.

\section{Acknowledgements}

This work has been conducted as part of a PhD thesis project supported by the Agricultural Transformation by Innovation (AgTraIn) Erasmus Mundus Joint Doctorate Programme funded by the Education, Audiovisual and Culture Executive Agency (EACEA). We gratefully acknowledge the provision of biochar samples from

the EU FP-7 FertiPlus Project (grant no. 289853) and clinoptilolite samples from Rota Mining Co., Turkey. We also thank Andrew Ross and Evert Jan Dijk for providing the data on biochar samples. 


\title{
Chapter 5 \\ Efficiency of digestate-enriched clinoptilolite and biochar as nitrogen fertilisers
}

\author{
N.Pelin Kocatürk \\ Kor Zwart \\ Sander Bruun \\ Lars Stoumann Jensen \\ Helle Sørensen \\ Lijbert Brussaard
}

This chapter is under review. 


\begin{abstract}
Aims: The liquid fraction of biogas digestate can be directly applied in the field as a fertiliser, but this may result in practical and environmental problems. One solution to this could be to concentrate nutrients onto sorbents, which can subsequently be used as a fertiliser. This study investigated the ability of biochar and clinoptilolite enriched with digestate nutrients to supply nitrogen $(\mathrm{N})$ when used as a fertiliser.

Methods: A pot experiment with ryegrass was conducted to test the effect of nutrient-enriched clinoptilolite and biochar, including the effect of initial loading ratio, by determining plant biomass growth and uptake of $\mathrm{N}$.

Results: Nutrient-enriched biochar and clinoptilolite increased plant biomass yield and $\mathrm{N}$ uptake compared to the control (untreated sorbents) treatments. Enriched clinoptilolite resulted in a higher plant biomass yield and $\mathrm{N}$ uptake compared to enriched biochar. Initial loading ratio had a significant effect on plant biomass response and apparent $\mathrm{N}$ recovery (ANR) for enriched clinoptilolite, but for biochar it only affected ANR.

Conclusions: Nitrogen from enriched clinoptilolite and biochar could be taken up by the plants, and clinoptilolite performed more effectively than biochar. Initial loading ratio affected the performance of the sorbents when used as a fertiliser.
\end{abstract}




\subsection{Introduction}

Digestate from anaerobic digestion in biogas plants shows comparable properties to animal slurry, both physically and as a fertiliser. This is the case not only when manure is the only feedstock, but also when additional organic waste feedstock is used for co-fermentation. Digestate is therefore often processed and managed in a similar way to animal slurry. In areas with a high animal density and hence a nutrient surplus compared to crop requirements, mechanical slurry separation can be used as a method to facilitate redistribution of nutrient surpluses to other areas (Møller, 2000; Paavola \& Rintala, 2008; Jørgensen \& Jensen, 2009). The solid fraction resulting from the separation contains most of the dry matter and phosphorus (Hjorth et al., 2009, 2010), but constitutes only 10-25\% of the total mass, so it can be transported more easily and economically to regions with lower animal densities and no nutrient surplus (Møller, 2000; Møller et al., 2007).

The liquid fraction of separated manure and digestate, which has a high water content and low nutrient concentration, can be applied directly to agricultural land in the vicinity of the farm or the biogas plant (Hjorth et al., 2010; Fuchs \& Drosg, 2013). However, in areas with very high animal densities or no cropping land suitable for digestate fertilisation, management and utilisation of the liquid fraction presents a challenge (Zarebska et al., 2015). Transportation of large volumes of liquids is costly and ineffective (Paavola \& Rintala, 2008; Hjorth et al., 2009; Rehl \& Müller, 2011). Furthermore, environmental problems, such as gaseous emissions of malodours, ammonia and greenhouse gases as well as nutrient runoff to streams and waterways, may occur when the liquid fraction of digestate is applied to agricultural land (Hjorth et al., 2009). To overcome such problems, recovery and concentration of nutrients from the liquid fraction may be a desirable option, and one potential method for this could be sorption to a solid carrier. Both inorganic and organic materials have been used successfully for nutrient sorption. Clinoptilolite (a natural zeolite) has been used to remove nutrients from source-separated urine (Ganrot et al., 2007; Beler Baykal et al., 2009; Beler-Baykal et al., 2011; Kocatürk \& Baykal, 2012; Allar \& Beler Baykal, 2015) and several studies have described the adsorption of ammonium and other nutrients to biochar, a carbonaceous product from the pyrolysis of biomass (Eldridge \& ChengRong, 2010; Hale et al., 2013; Sarkhot et al., 2013; Gai et al., 2014; Jassal et al., 2015; Wang et al., 2015c). 
A sorbent should be cost-effective in concentrating nutrients. However, if the product is to be used as a fertiliser, the nutrient-enriched sorbent should also release the nutrients upon application to soil, in order for the nutrients to become plant available. Clinoptilolite acts a slow release fertiliser when added to soil (Perrin et al., 1998; Reháková et al., 2004) since it is able to desorb nutrients following the enrichment step (Kithome et al., 1998; Ganrot et al., 2007; Hedström, 2008; BelerBaykal et al., 2011; Cyrus \& Reddy, 2011). Biochar has also been reported to release nutrients subsequent to enrichment (Hale et al., 2013; Sarkhot et al., 2013; Hina et al., 2014; Jassal et al., 2015; Wang et al., 2015a), but only a few studies report on the performance of enriched biochar as a fertiliser (Taghizadeh-Toosi et al., 2012a, $2012 \mathrm{~b}$ ). For the practical implications of using sorbents to remove nutrients from the liquid fractions of digestate, it is important have knowledge of the effectiveness of the enriched sorbents.

Initial loading ratio, i.e. the ratio of the amount of nutrients to the amount of sorbents, has been described as an important design parameter for ion exchange/adsorption processes which influences the nutrient removal efficiency from the liquid fraction and consequently the degree of enrichment of nutrients on the sorbent material (Kocatürk et al.; Beler Baykal et al., 2009). To the authors' knowledge, the effect of initial loading ratio on the plant availability of $\mathrm{N}$ sorbed to clinoptilolite and biochar has not been investigated when enriched clinoptilolite and biochar are used as fertilisers. This information is important when clinoptilolite and biochar are to be used both for the treatment of the liquid fraction of digestate and as fertilisers following the enrichment process.

The objectives of this study were to assess the effects of digestate nutrientenriched clinoptilolite and biochar on plant growth by measuring biomass yield and nitrogen uptake and by calculating biomass response (BR) and apparent nitrogen recovery (ANR).

We hypothesised that:

- nitrogen sorbed to clinoptilolite and biochar is available to plants and will result in a higher biomass yield and $\mathrm{N}$ uptake compared to the control (untreated clinoptilolite and biochar)

- nitrogen sorbed to clinoptilolite is as available to plants as N sorbed to biochar, and both enriched sorbents will result in similar BR and ANR at the same N application level 
- initial loading ratio and hence the $\mathrm{N}$ enrichment of clinoptilolite and biochar do not affect plant growth, and low and high initial loading ratios will result in similar BR and ANR at the same N application level.

\subsection{Materials and Methods}

\section{Experimental set-up}

We used the double-pot technique (Janssen, 1990), in which plants are grown in a two-tiered pot. The upper compartment contains quartz sand without nutrients, to which only the material to be tested has been added; the lower compartment contains a nutrient solution with all the essential nutrients except the one whose availability is being quantified in the top compartment. At the bottom of the upper compartment, a mesh ( $1 \mathrm{~mm}$ pore size) allows roots to grow through to the bottom compartment. With the double-pot technique, the optimal availability of all nutrients, except the one being tested, can be guaranteed by the nutrient solution in the lower pot (Antil et al., 2009). The difference in growth between plants is a measure of the availability of the tested nutrient in the upper compartment.

In our study, the upper pot $(0.25 \mathrm{~L})$ was filled in two steps. In the first step, a mixture of $200 \mathrm{~g}$ quartz sand $\left(1435 \mathrm{~g} \mathrm{~L}^{-1}\right)$ and the product to be tested (biochar, clinoptilolite or synthetic fertiliser, see Table 5.1) was added. In the second step, a germination layer was created by adding $100 \mathrm{~g}$ quartz sand and ryegrass (Lolium perenne L.) seeds, sown at $1 \mathrm{~cm}$ depth at a rate of $0.40 \mathrm{~g}$ seeds per pot. The quartz sand was inoculated with a solution containing soil micro-organisms, which was prepared by filtering a mixture of $50 \mathrm{~g}$ soil and $2 \mathrm{~L}$ deionised water through a coarse filter paper. Each upper pot was placed on a lower pot $(1 \mathrm{~L})$ containing a nutrient solution, from which $\mathrm{N}$ was omitted. The composition of the nutrient solution in the lower pots was $(\mathrm{mM}) 1 \mathrm{MgSO}_{4}, 0.5 \mathrm{KH}_{2} \mathrm{PO}_{4}, 1.0 \mathrm{~K}_{2} \mathrm{SO}_{4}, 2.0 \mathrm{CaCl}_{2}$, with trace elements (mg L ${ }^{-1}$ ) $0.5 \mathrm{~B}, 0.5 \mathrm{Mn}, 0.05 \mathrm{Zn}, 0.02 \mathrm{Cu}, 0.01 \mathrm{Mo}$, and $5.3 \mathrm{Fe}$ (as Fe-EDTA). The nutrient solutions in the lower pots were changed once a week.

There was a small space between the upper and lower pot in order to prevent direct transport of water and nutrients between the two layers. The upper pots were watered with deionised water three times a week to keep the moisture level corresponding to approximately $60 \%$ of the water-holding capacity of the control treatment (only sand and water). Double pots were allocated at random to trays (eight plants per tray) at the beginning of the experiment, and shifted at random 
between trays every seven days. The experiment was carried out in a greenhouse with four replicates at an average temperature of $17^{\circ} \mathrm{C}$ and an average humidity of $62 \%$.

Aboveground biomass was harvested after 21, 36 and 70 days. On the last date, roots in the lower and upper pots were also harvested. Roots were separated from sand and fertiliser materials by washing with deionised water. The separated roots were dipped into $0.01 \mathrm{M} \mathrm{HCl}$ solution and rinsed again with deionised water. Dry matter yields of aboveground biomass and roots were determined after drying the plant materials at $70{ }^{\circ} \mathrm{C}$ for $72 \mathrm{~h}$. Samples were ground and digested in a mixture of sulphuric acid, salicylic acid and $\mathrm{Se}$, to which $\mathrm{H}_{2} \mathrm{O}_{2}$ was added. Total $\mathrm{N}$ was colorimetrically determined in the digest by a segmented flow analyser (Temminghoff \& Houba, 2004).

Table 5.1 Overview of the treatments.

\begin{tabular}{|c|c|c|c|c|c|}
\hline Treatment & $\begin{array}{l}\text { Abbre } \\
\text { vi- } \\
\text { ation }\end{array}$ & $\begin{array}{l}\text { Initial loading } \\
\text { ratio } \\
\left(\mathrm{mg} \mathrm{NH}_{4}-\mathrm{N} \mathrm{g}^{-1}\right)\end{array}$ & $\begin{array}{l}\text { Total N } \\
\text { content of } \\
\text { sorbent } \\
\left(\mathrm{mg} \mathrm{N} \mathrm{g}^{-1}\right)\end{array}$ & $\begin{array}{l}\mathrm{N} \text { application } \\
\left(\mathrm{mg} \mathrm{N} \text { pot }^{-1}\right)\end{array}$ & $\begin{array}{l}\text { Amount of } \\
\text { sorbent or N } \\
\text { solution applied } \\
\left(\text { g pot }^{-1}\right)\end{array}$ \\
\hline \multicolumn{6}{|l|}{ Biochar } \\
\hline Control & BCon & 0 & 1.68 & 0 & $5.58^{a}$ \\
\hline \multirow[t]{2}{*}{ Low } & BL15 & 10 & 8.07 & 15 & 1.86 \\
\hline & BL45 & & & 45 & 5.58 \\
\hline \multirow[t]{2}{*}{ High } & BH15 & 40 & 9.58 & 15 & 1.57 \\
\hline & BH45 & & & 45 & 4.70 \\
\hline \multicolumn{6}{|l|}{ Clinoptilolite } \\
\hline Control & CCon & 0 & 0.05 & 0 & $5.98^{a}$ \\
\hline \multirow[t]{2}{*}{ Low } & CL15 & 10 & 7.52 & 15 & 1.99 \\
\hline & CL45 & & & 45 & 5.98 \\
\hline \multirow{2}{*}{ High } & CH15 & 52 & 14.73 & 15 & 1.02 \\
\hline & CH45 & & & 45 & 3.05 \\
\hline Reference & & & $\left(\mathrm{mg} \mathrm{N} \mathrm{L}^{-1}\right)$ & & $\left(\mathrm{mL}\right.$ pot $\left.^{-1}\right)$ \\
\hline $\begin{array}{l}\text { Control, } \\
\text { unfertilised }\end{array}$ & SCon & $\mathrm{n} / \mathrm{a}$ & 0 & 0 & 0 \\
\hline Synthetic N & S15 & $\mathrm{n} / \mathrm{a}$ & 2000 & 15 & 25 \\
\hline solution & $\mathrm{S} 45$ & 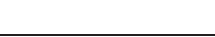 & ${ }_{5}$ & 45 & 75 \\
\hline
\end{tabular}


Biomass yield was calculated as the sum of the aboveground biomass of all three cuts, plus the roots at the final harvest. Total $\mathrm{N}$ uptake was calculated as the sum of $\mathrm{N}$ in all cuts and roots. The root-mass ratio (RMR), which is an indicator of $\mathrm{N}$ availability, was calculated as:

$$
\operatorname{RMR}=\frac{\mathbf{B}_{\mathbf{r}}}{\mathbf{B}_{\mathrm{t}}}
$$

where $B_{r}$ is root biomass and $B_{t}$ is total biomass for each treatment. RMR is bounded between 0 and 1; lower RMR values indicate increasing nitrogen availability due to less biomass allocation to the roots as compared to the leaves (Wilson, 1988; Poorte \& Nagel, 2000; Pérez-Harguindeguy et al., 2013).

\section{Treatments}

Nutrient-enriched clinoptilolite and biochar were produced by adsorption of nutrients $(\mathrm{N}, \mathrm{P}, \mathrm{K})$ from the liquid fraction of digestate. The clinoptilolite used was from Gördes in Turkey with a typical composition of 65-72 \% $\mathrm{SiO}_{2}, 10-12 \% \mathrm{Al}_{2} \mathrm{O}_{3}$, 0.7-1.9 \% $\mathrm{Fe}_{2} \mathrm{O}_{3}$, 0.1-0.5 \% Na $2 \mathrm{O}, 2.5-3.8 \% \mathrm{~K}_{2} \mathrm{O}, 2.4-3.7 \% \mathrm{CaO}, 0.9-1.2 \% \mathrm{MgO}, 0-$ $0.08 \% \mathrm{MnO}$ and $0.02-0.05 \% \mathrm{P}_{2} \mathrm{O}_{5}$ (Rota Mining Co.). The clinoptilolite samples used in the nutrient enrichment procedure had a particle size of $1-3 \mathrm{~mm}$, a pH of 8.5 , with 150-210 $\mathrm{cmol}_{\mathrm{c}} \mathrm{kg}^{-1}$ cation exchange capacity (CEC, data provided by the manufacturer), and $35.5 \mathrm{~m}^{2} \mathrm{~g}^{-1}$ specific surface area (analysed by a commercial lab, Eurofins, Germany). Biochar was produced from holm oak by slow pyrolysis at 650 ${ }^{\circ} \mathrm{C}$ and atmospheric pressure (Proininso Inc. Málaga, Spain) and had an ash content of $11.3 \%$ (dry basis) and a composition of $76.5 \%$ C, $1.4 \% \mathrm{H}, 0.8 \% \mathrm{~N}, 7 \%$ 0, $0.2 \%$ $\mathrm{P}, 0.6 \% \mathrm{~K}, 0.04 \% \mathrm{Na}, 5 \% \mathrm{Ca}, 0.3 \% \mathrm{Mg}, 0.05 \% \mathrm{Fe}, 0.14 \% \mathrm{Al}$ (Ross, 2016). Biochar samples with a particle size of 1-4 mm were used in the enrichment procedure and the samples had a pH of 8.2, $42.3 \mathrm{cmol}_{\mathrm{c}} \mathrm{kg}^{-1} \mathrm{CEC}$ (Dijk, 2015), and $166 \mathrm{~m}^{2} \mathrm{~g}^{-1}$ specific surface area (analysed by Eurofins, Germany).

Sorbent materials were separately brought into contact with the liquid fraction of digestate in Plexiglas columns (50 and $100 \mathrm{~cm}$ length, $2.4 \mathrm{~cm}$ diameter), which resulted in the retention of nutrients on the sorbent materials. The liquid fraction of digestate was from a full-scale biogas plant (Fangel Bioenergy ApS, Odense, Denmark) using pig slurry as the main feedstock with co-digestion of food waste; the liquid fraction was produced by a decanting centrifuge treatment of the digestate. The liquid fraction of digestate was fed into the columns using a 
peristaltic pump at $100 \%$ recycling in the upflow mode for 120 and 72 hours for clinoptilolite and biochar, respectively, to secure a stable ammonium concentration in the feed tank. Two initial loading ratios were applied, namely 10 (low) and 52 (high) $\mathrm{mg} \mathrm{NH}_{4}-\mathrm{N} \mathrm{g}^{-1}$ for clinoptilolite, and 10 (low) and 40 (high) $\mathrm{mg} \mathrm{NH}_{4}-\mathrm{N} \mathrm{g}^{-1}$ for biochar. The $\mathrm{N}$ contents of the biochar and clinoptilolite prior to and after nutrient enrichment are shown in Table 5.1.

Enriched sorbents were mixed with quartz sand at two levels, 15 and $45 \mathrm{mg} \mathrm{N}$ pot $^{-1}$, which corresponded to 150 and $450 \mathrm{~kg}$ of $\mathrm{N}$ per ha respectively. A synthetic $\mathrm{NH}_{4} \mathrm{NO}_{3}$ solution was used as a reference fertiliser and applied at the same $\mathrm{N}$ application levels. Sand mixed with untreated (non-enriched) biochar or clinoptilolite and pure sand (no addition of $\mathrm{N}$ solution, biochar or clinoptilolite) were used as controls.

Untreated biochar and clinoptilolite, used for the control treatments, contained some $\mathrm{N}$, but less than in the nutrient-enriched sorbents in all cases (Table 5.1). The amount of untreated clinoptilolite and biochar applied in the controls was the same as the highest amount of nutrient-enriched biochar and clinoptilolite applied in the experiment.

\section{Statistical analysis}

We tested the effect of enriched sorbents on plant growth by analysing biomass and total N-uptake data separately for each treatment (clinoptilolite, biochar and synthetic solution) with one-way ANOVA tests. Each sub-treatment was compared to the corresponding control, and for each outcome (biomass and $\mathrm{N}$ uptake) the pvalues were adjusted with the Holm method in order to correct for multiple testing.

Biomass and $\mathrm{N}$ uptake data were analysed using linear regression on the amount of applied N. The slopes of the regression models represented the biomass response (BR) and apparent $\mathrm{N}$ recovery (ANR) for each treatment. The effect of different $\mathrm{N}$ applications (enriched biochar, enriched clinoptilolite and synthetic $\mathrm{N}$ solution) was tested by comparing BR and ANR for each treatment.

Furthermore, regression analysis was used to test for the effect of initial loading ratio of the biochar and clinoptilolite on plant availability of $\mathrm{N}$ by comparing BR and ANR for clinoptilolite and biochar separately. The statistical analysis was conducted using the statistical software R version 3.2.1 (R Core Team, 2015). 


\subsection{Results}

Biomass yield and $\mathrm{N}$ uptake were significantly lower for the control compared to the N-enriched materials in all ANOVA comparisons ( $\mathrm{p}<0.05$ after Holm correction), which indicated that application of enriched biochar and clinoptilolite increased both biomass and $\mathrm{N}$ uptake (Figure 5.1). For both biomass and $\mathrm{N}$ uptake, the largest means were obtained with CL45 for clinoptilolite, BH45 for biochar and S45 for the synthetic solution treatment. Among all treatments, nutrient-enriched clinoptilolite at a low initial loading ratio (CL) showed the highest BR and ANR (Figure 5.2). Enriched biochar treatments (BL and BH) resulted in the lowest BR and ANR.

We investigated the effects of initial loading ratio on BR and ANR for biochar and clinoptilolite enriched at low and high initial loading ratios. Figure 5.2 shows that clinoptilolite enriched at a low initial loading ratio resulted in higher BR and ANR compared to clinoptilolite enriched at a high initial loading

ratio ( $\mathrm{p}<0.0001$ for both $B R$ and ANR). Biochar enriched at a high initial loading ratio resulted in higher $\mathrm{BR}$, but the difference between the low and high initial loading ratios for biochar was not significant $(p=0.10)$. For ANR, the difference between the low and the high initial loading ratios was small, but statistically significant $(\mathrm{p}=0.034)$.

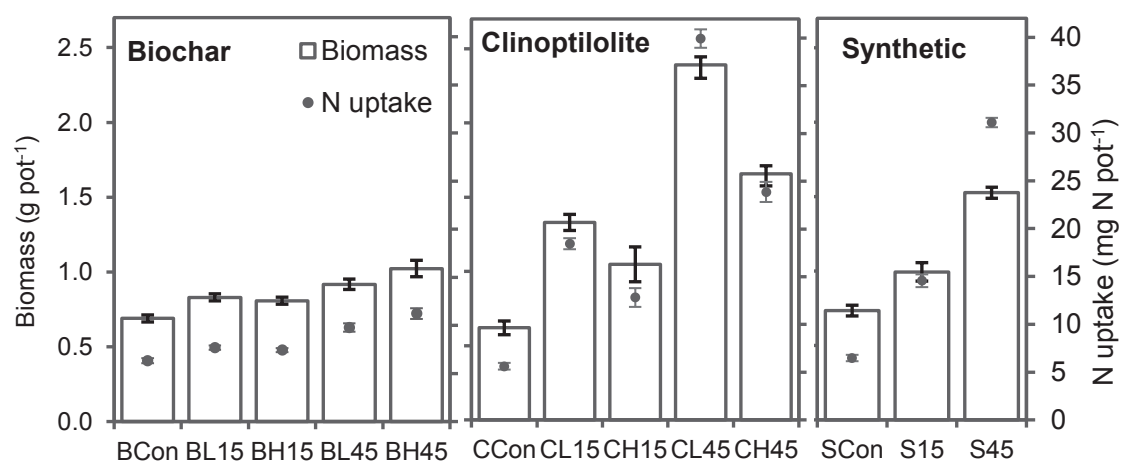

Figure 5.1 Biomass yield (g pot ${ }^{-1}$ ) and $\mathrm{N}$ uptake (mg $\mathrm{N}$ pot ${ }^{-1}$ ) of ryegrass after 70 days of plant growth in all treatments as a result of 0,15 and $45 \mathrm{mg} \mathrm{N}^{-1}$ pot $^{-1}$ nitrogen application levels using nutrient-enriched clinoptilolite (CL: low initial loading ratio; $\mathrm{CH}$ : high initial loading ratio), biochar (BL: low initial loading ratio and $\mathrm{BH}$ : high initial loading ratio) and synthetic nitrogen (S). Error bars indicate standard errors $(n=4)$. 

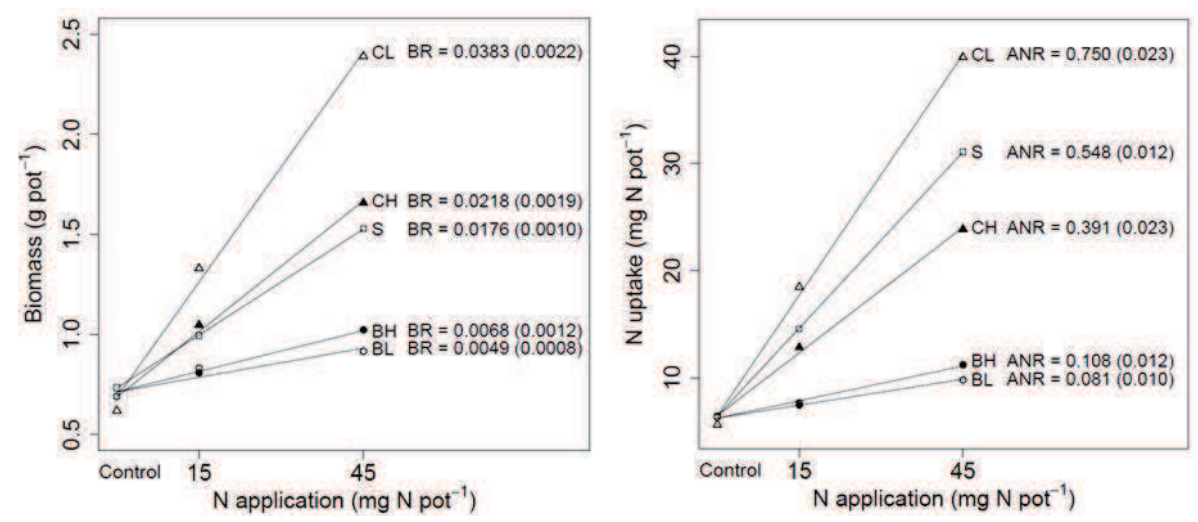

Figure 5.2 Biomass response (BR) and b) apparent $\mathrm{N}$ recovery (ANR) as a result of different treatments using nutrient-enriched clinoptilolite (CL: low initial loading ratio; $\mathrm{CH}$ : high initial loading ratio), biochar (BL: low initial loading ratio and $\mathrm{BH}$ : high initial loading ratio) and synthetic nitrogen (S). Standard errors in brackets $(n=4)$.

We found a strong negative correlation between RMR and $N$ uptake $\left(R^{2}=0.82\right.$, Figure 5.3). Treatments with a low $\mathrm{N}$ uptake resulted in a high RMR of around 0.70 , while the lowest RMR was around 0.45 for both clinoptilolite enriched at a low initial loading ratio and synthetic $\mathrm{N}$ application. For all $\mathrm{N}$-enriched biochar treatments, the mean RMR values ranged between 0.57 and 0.66 , which were higher than for the treatment in which clinoptilolite was enriched at a low initial loading ratio.

\subsection{Discussion}

\section{Effects of enriched sorbents on plant growth and $\mathbf{N}$ uptake}

The application of enriched clinoptilolite and biochar resulted in a higher biomass yield and $\mathrm{N}$ uptake compared to the control treatments (Figure 5.1) and this indicated that $\mathrm{N}$ from enriched sorbents was available to plants. Nutrientenriched clinoptilolite at a low initial loading ratio (CL) resulted in more than a twofold increase in yield and more than a threefold increase in nitrogen uptake at $15 \mathrm{mg} \mathrm{N}$ pot $^{-1} \mathrm{~N}$ application when compared to the control (untreated) clinoptilolite treatment (Figure 5.1). The increases were even greater at $45 \mathrm{mg} \mathrm{N}^{-1} \mathrm{~N}$ application, with almost a fourfold and sixfold increase in yield and nitrogen uptake respectively. This clearly showed that $\mathrm{N}$ from nutrient-enriched clinoptilolite was 


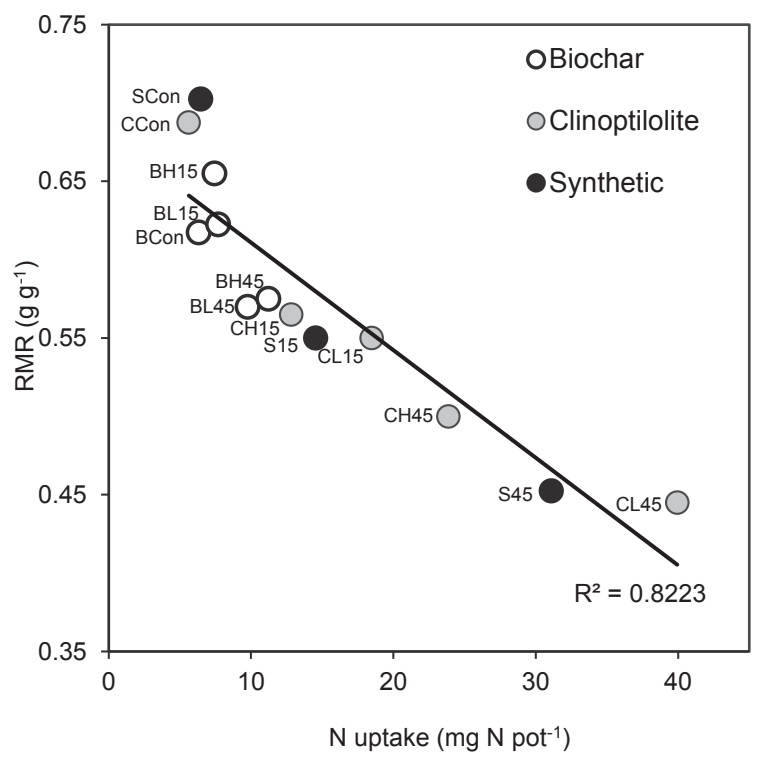

Figure 5.3 Root-to-mass ratio and $\mathrm{N}$ uptake of ryegrass per pot after 70 days of plant growth in all treatments as a result of different nitrogen applications at 15 and $45 \mathrm{mg} \mathrm{N}^{-\mathrm{N}^{-1}}$ using nutrient-enriched clinoptilolite (C) and biochar (B) and synthetic nitrogen (S); Con: control treatments; L: low initial loading ratio; $\mathrm{H}$ : high initial loading ratio.

available to the grass. These findings were in line with studies that report nitrogenloaded zeolite to be a good source of $\mathrm{N}$ (Ganrot et al., 2008) and urineenrichedclinoptilolite to be as effective as chemical fertiliser in preliminary pot trials (Beler-Baykal et al., 2011; Kocatürk \& Baykal, 2012).

Enrichment of biochar resulted in a small, but statistically significant increase in grass biomass yield and $\mathrm{N}$ uptake compared to the control (untreated) biochar application (Figure 5.1). Taghizadeh-Toosi et al. (2012a) report a two to threefold increase in leaf dry matter yields, and a twofold increase in root dry matter yields after application of ${ }^{15} \mathrm{~N}$ enriched biochar when compared to treatments receiving untreated biochar. In another study, Taghizadeh-Toosi et al. (2012b) investigated the plant availability of $\mathrm{N}$ in ruminant urine-treated biochar in pot experiments with ryegrass. They found that plant growth is not affected, but the $\mathrm{N}$ uptake in plant tissues increases, indicating that the adsorbed $\mathrm{N}$ is plant available. In the present study, less than a twofold increase was found for both enriched biochar treatments and this meant that only a small proportion of the $\mathrm{N}$ with which biochar had been enriched had become available to the plants. This could be due to a high retention of 
$\mathrm{N}$ on biochar which limits the availability of $\mathrm{N}$ to the plants through desorption. Many researchers have reported a high retention of nitrogen on the surface of biochar, even when using $\mathrm{KCl}$ extraction for desorption, which should replace $\mathrm{NH}_{4}{ }^{+}$ ions with $\mathrm{K}^{+}$and result in high desorption ratios. Hina et al. (2014) found that the amount of $\mathrm{NH}_{4}-\mathrm{N}$ desorbed is only 11-18 \% of $\mathrm{NH}_{4}-\mathrm{N}$ from enriched biochar with 2 $M \mathrm{KCl}$ extraction. Sarkhot et al. (2013) report a desorption ratio of 9-22\% of $\mathrm{NH}_{4}-\mathrm{N}$ from manure-enriched biochar with $0.001 \mathrm{CaCl}_{2}$ extraction, whereas TaghizadehToosi et al. (2012b) report this ratio to be as low as 3-13\% of the total $\mathrm{N}$ on enriched biochar with $1 \mathrm{M} \mathrm{KCl}$ extraction. Jassal et al. (2015) also report that only a small proportion of $\mathrm{N}\left(0.2-0.4 \mathrm{mg} \mathrm{N} \mathrm{g}^{-1}\right.$ biochar) is able to be released from $\mathrm{N}$ enriched biochar with a surface concentration of 2.9-48.7 $\mathrm{mg} \mathrm{N} \mathrm{g}^{-1}$ biochar.

The difference in $\mathrm{N}$ availability between the clinoptilolite and biochar treatments may be attributed to the different sorption mechanisms of ammonium on biochar and clinoptilolite during enrichment which subsequently affects the release of $\mathrm{N}$ from sorbents after soil incorporation. Ammonium is sorbed onto the clinoptilolite surface mainly through ion exchange and can subsequently can be released slowly through desorption (Kithome et al., 1998; Hedström, 2008; Beler-Baykal et al., 2011; Cyrus \& Reddy, 2011; Kocatürk \& Baykal, 2012). For biochar, some researchers report a strong relationship between cation exchange capacity and $\mathrm{NH}_{4}-\mathrm{N}$ sorption capacity (Hale et al., 2013; Cheng et al., 2014; Wang et al., 2015a), but other sorption mechanisms have been suggested, such as adsorption of $\mathrm{NH}_{3}$ on the biochar surface by acidic functional groups (Taghizadeh-Toosi et al., 2012b), chemisorption of $\mathrm{NH}_{3}$ (Petit et al., 2010), physical entrapment of $\mathrm{NH}_{3}$ in pores (Spokas et al., 2012; Jassal et al., 2015) and co-sorption of $\mathrm{NH}_{4}{ }^{+}$with soluble organic matter (Sarkhot et al., 2013), which can cause a strong retention of nitrogen on the biochar surface. Clinoptilolite and biochar samples used in this study had different cation exchange capacities: Up to $210 \mathrm{cmol}_{\mathrm{C}} \mathrm{kg}^{-1}$ for clinoptilolite and $42.3 \mathrm{cmol}_{\mathrm{c}} \mathrm{kg}^{-1}$ for biochar. This difference in cation exchange capacity may indicate that cation exchange plays an important role for ammonium removal by clinoptilolite; however other mechanisms may be involved for biochar to remove ammonium which subsequently affects $\mathrm{N}$ release from sorbents when they are used as $\mathrm{N}$ fertilisers.

Figure 5.2 shows that nutrient-enriched clinoptilolite application resulted in a higher BR and ANR with clinoptilolite enriched at a low initial loading ratio (CL) compared to synthetic fertiliser application. This was a somewhat unexpected result as synthetic solution contains ammonium nitrate as an immediately available form 
of nitrogen. Therefore higher nitrogen availability would be expected with synthetic fertiliser as compared to the other forms of nitrogen used in this study. The reasons for this observation can only be speculated upon; it could be attributed to $\mathrm{N}$ losses in the synthetic fertiliser application, such as i) nitrogen leaching from the upper pot to the lower pot during watering events and removal of that $\mathrm{N}$ during refreshing of the nutrient solution in the lower pot, and ii) ammonia volatilisation, as some of the $\mathrm{N}$ in the synthetic solution is ammonium and ammonium sorption on the quartz is likely to be limited and there is a chance that some of the ammonium has volatilised as ammonia. No tests were conducted for any losses in the synthetic $\mathrm{N}$ treatment, however the relatively low ANR value of 0.45 in a nutrient-limited system seemed to indicate that losses could be substantial in the synthetic fertiliser. Clinoptilolite has been widely reported to increase plant $\mathrm{N}$ uptake and decrease losses of $\mathrm{N}$ from soil in several studies (Ferguson \& Pepper, 1987; Perrin et al., 1998; Reháková et al., 2004; Tsadilas \& Argyropoulos, 2006; Liu \& Lal, 2015) and it may potentially prevent losses by retaining the nutrients as a slow release fertiliser.

When selecting a sorbent material for removing nutrients from the liquid fractions of digestate, one of the most important factors is the effectiveness of the enriched sorbents if the sorbent material is to be used as a fertiliser after the nutrient removal process. The findings from this pot experiment indicated that digestate-enriched clinoptilolite resulted in better plant growth compared to enriched biochar. However further research is necessary to observe the effects of enriched biochar on plant growth in a long-term experiment.

\section{Effects of initial loading ratio of sorbents on plant growth and $\mathbf{N}$ uptake}

A significant effect of initial loading ratio was found on plant growth with the enriched clinoptilolite treatments. An increasing initial loading ratio resulted in decreasing BR and ANR (Figure 5.2). This might have been due to the different desorption behaviour of clinoptilolite enriched at different initial loading ratios. Initial loading ratio influences the final amount of ammonium retained on the clinoptilolite surface, and increasing the loading ratios results in increasing ammonium concentrations (Kocatürk et al.; Beler Baykal et al., 2009). In our study, the $\mathrm{N}$ content of clinoptilolite enriched at a high initial loading ratio was almost two times greater than at the low initial loading ratio (Table 5.1). Differences in 
desorption from clinoptilolite with different amounts of ammonium on the surface have been found previously by Dimova et al. (1999), who report a decrease of approximately $10 \%$ in the amount of ammonium desorbed from clinoptilolite, with a $30 \%$ increase in enrichment of clinoptilolite. Our results were in line with their results to explain different desorption behaviours of clinoptilolite when it has a higher $\mathrm{N}$ content. This may also explain the limited release of $\mathrm{N}$, hence less availability to plants from clinoptilolite enriched at a higher initial loading ratio.

For biochar, the effect of initial loading ratio was statistically significant only for ANR. Contrary to clinoptilolite, increasing the initial loading ratio resulted in higher ANR, which may indicate that more $\mathrm{N}$ was released from biochar enriched at a high initial loading ratio. As discussed earlier, in literature biochar has been reported to strongly retain $\mathrm{NH}_{4}-\mathrm{N}$, which allows biochar to release only a small proportion of $\mathrm{N}$ from the biochar surface. Even so, the desorption behaviour of biochar was found to be different with different amounts of $\mathrm{N}$ transferred onto the biochar surface, and a higher desorption from the biochar surface with an increasing $\mathrm{N}$ content in biochar (Sarkhot et al., 2013; Hina et al., 2014) and therefore an increasing initial loading ratio.

Initial loading ratio is an important factor when designing a system to remove nutrients by sorption processes since it affects the removal efficiency and amount of nutrients sorbed by sorbents (Kocatürk et al.; Beler Baykal et al., 2009). In this study we found that initial loading ratio is an important factor, including when the enriched sorbents are to be used as a fertiliser, since it affects the availability of $\mathrm{N}$. This information is important when clinoptilolite and biochar are to be used both for the treatment of the liquid fraction of digestate and as fertilisers after the enrichment process.

\section{Root-to mass ratio (RMR)}

A higher biomass allocation to the roots than to the leaves can be observed under low and limiting nitrogen levels (Wilson, 1988; Poorte \& Nagel, 2000) and therefore a lower root-to-total biomass ratio indicates increasing nitrogen availability (Pérez-Harguindeguy et al., 2013). The data presented in Figure 5.3 shows that a strong negative correlation $\left(R^{2}=0.82\right)$ was also found between $R M R$ and $\mathrm{N}$ uptake. Clinoptilolite enriched at a low initial loading ratio (CL45) and synthetic (S45) treatment resulted in a similarly low RMR. This observation supported our findings discussed above, that both treatments led to similar $\mathrm{N}$ 
availability although they resulted in different $\mathrm{N}$ uptake. In contrast to nutrientenriched clinoptilolite, enriched biochar resulted in a high RMR as a result of invariably low $\mathrm{N}$ availability in all $\mathrm{N}$ application levels.

In conclusion, our results revealed that: i) $\mathrm{N}$ sorbed to clinoptilolite and biochar was available to plants, ii) the availability of $\mathrm{N}$ sorbed to clinoptilolite was higher than the availability of $\mathrm{N}$ sorbed to biochar, and iii) initial loading ratio had a significant effect on $\mathrm{N}$ availability and thereby on the performance of the sorbents as a fertiliser.

Our study highlights the importance of the choice of sorbent material to remove nutrients from the liquid fraction of digestate if the enriched sorbent is to be used as a fertiliser following the removal process. We found that both enriched clinoptilolite and biochar were able to increase biomass yield and $\mathrm{N}$ uptake, but clinoptilolite resulted in much higher BR and ANR compared to enriched biochar. However, further research in a long-term experiment is crucial to observe the effects of enriched biochar on plant growth. We also found that initial loading ratio is an important parameter that not only affects the nutrient removal efficiency from the liquid fraction of digestate, but also affects the availability of $\mathrm{N}$ and thereby the efficiency of the enriched material when used as a fertiliser. This information is important when selecting a sorbent as a nutrient carrier for the treatment of the liquid fraction of digestate if the enriched material is to be applied on soil as a fertiliser.

\section{Acknowledgements}

This work has been conducted as a part of a PhD thesis project supported by the Agricultural Transformation by Innovation (AgTraIn) Erasmus Mundus Joint Doctoral Programme (funded by the Education, Audiovisual and Culture Executive Agency) and supported by the EU project FP7 KBBE.2011.1.2-02 FERTIPLUS "Reducing mineral fertilisers and agro-chemicals by recycling treated organic waste as compost and bio-char" project no. 289853, co-funded by the European Commission, Directorate General for Research and Innovation, within the $7^{\text {th }}$ Framework Programme of RTD, Theme 2 - Biotechnologies, Agriculture and Food. We would like to thank Peter Kuikman, Jaap Nelemans and Popko Bolhuis for their contributions to the greenhouse experiments. We would also like to thank Rota Mining Co. for providing clinoptilolite samples, and Andrew Ross and Evert Jan Dijk for providing the data on biochar samples. 


\section{Chapter 6 \\ General Discussion}

N. Pelin Kocatürk 


\subsection{Introduction}

The treatment of liquid fraction of digestate with the intention to recover nutrients is necessary in areas with high livestock density due to practical and environmental problems. The nutrients contained in the liquid fraction of digestate can be concentrated through a range of technologies and processes to produce marketable end-products, which would help to reduce nutrient losses (Drosg et al., 2015). In this thesis, I aimed to assess the use of sorbent materials, namely biochar and clinoptilolite, to recover plant nutrients from the liquid fraction of digestate resulting from anaerobic digestion of animal manure, and to assess the further use of these nutrient-enriched materials as fertiliser. In Chapters 2-5, I investigated the effects of i) initial loading ratio, and ii) combining sorbents, on the nutrient removal efficiency from the liquid fraction of digestate, iii) activation, or preconditioning of sorbents, and iv) $\mathrm{N}$ fertiliser efficiency of nutrient-enriched biochar and clinoptilolite.

In this chapter, I summarise the main findings of my thesis and I discuss these findings in a broader context.

\subsection{The use of clinoptilolite and biochar for nutrient recovery from liquid fraction of digestate}

\section{Nutrient removal efficiency of clinoptilolite and biochar}

Clinoptilolite has been known as an efficient cation exchanger which has been used for wastewater treatment (Beler Baykal \& Guven, 1997; Hedström, 2008) as well as for nutrient recovery from human urine, which has much higher nutrient concentrations compared to domestic wastewater (Ganrot et al., 2007; Kocatürk \& Baykal, 2012; Allar \& Beler Baykal, 2015). The initial loading ratio has been suggested to be an important design parameter in column sorption experiments with clinoptilolite for nutrient recovery from human urine and defined as 'the initial amount of ammonium $\mathrm{N}$ in the liquid divided by the amount of sorbent in the system', which affects nutrient removal efficiency (Beler Baykal et al., 2009).

In Chapter 2, I found that the removal efficiency of ammonium, potassium and orthophosphate from the liquid fraction of digestate was significantly affected by 
the initial loading ratio. Increasing initial loading ratios resulted in increasing removals (concentration of nutrients on clinoptilolite) but decreasing removal efficiencies of clinoptilolite. These results were similar to those of Beler Baykal et al., (2009) who reported increased ammonium and potassium removal, but decreasing efficiencies, from source-separated human urine.

In Chapter 4, I investigated the effects of initial loading ratio on nutrient removal by biochar for the first time in literature. I observed similar effects of initial loading ratio on biochar (holm oak wood pyrolysed at $650^{\circ} \mathrm{C}$ ) as on clinoptilolite. Increasing the initial loading ratio resulted in higher removals with lower efficiencies to remove ammonium and orthophosphate from the liquid fraction of digestate. However, untreated biochar did not remove potassium from the liquid fraction of digestate, but did release potassium due to its high potassium content. Potassium release from wood biochar into aqueous solutions was also reported in earlier studies (Wu et al., 2011; Angst \& Sohi, 2013).

In Chapter 5, I found that an increasing initial loading ratio resulted in decreasing biomass response (BR) and apparent $\mathrm{N}$ recovery (ANR) for enriched clinoptilolite when it was used as $\mathrm{N}$ fertiliser. However, I observed the opposite effect of initial loading ratio with biochar, and ANR increased with an increasing initial loading ratio. The differences in plant availability of $\mathrm{N}$ from clinoptilolite and biochar enriched at different initial loading ratios can be related to different release behaviours. Dimova et al. (1999) reported a smaller amount of ammonium desorption with increasing initial amount of ammonium on clinoptilolite surface, whereas for biochar Sarkhot et al. (2013) and Hina et al. (2014) reported a higher desorption with increasing $\mathrm{N}$ content in biochar.

Considering the data from Chapters 2, 4 and $\mathbf{5}$, it can be stated that initial loading ratio is an important parameter that not only affects the nutrient removal efficiency from the liquid fraction of digestate, but also affects the availability of $\mathrm{N}$ and thereby the efficiency of the enriched material when used as a fertiliser. From the practical point of view, initial loading ratio is an important parameter affecting the efficiency of the sorbent material, as well as the degree of concentration of nutrients on the sorbent material; both are important factors when selecting a sorbent. Lower initial loading ratios resulted in high removal efficiencies (Chapter 2 and 4). However, this would also result in a lower concentration of nutrients on biochar and clinoptilolite. In order to make the treatment process economically attractive, a greater increase in concentration or weight reduction would be 
required. Nevertheless, if the nutrient-enriched clinoptilolite and biochar are to be applied on soil as a fertiliser, it is also important to consider the availability of the recovered form of nutrients.

\section{Combining biochar and clinoptilolite for enhanced nutrient removal}

Biochar has not only been suggested as a sorbent for ammonium and phosphate removal but also as an effective sorbent to remove organic contaminants from various wastewaters due to its porous structure and large surface area (Chen et al., 2011; Ahmad et al., 2014; Mohan et al., 2014; Wang et al., 2015b). Therefore, combining biochar and clinoptilolite may represent a complementary solution for nutrient recovery considering the specialised nature of biochar for ammonium, phosphate and organic matter adsorption, and the efficiency of clinoptilolite as a cation exchanger with high selectivity for ammonium and potassium. In Chapter 4, I found that combining biochar with clinoptilolite did not improve the efficiency of clinoptilolite to remove ammonium, orthophosphate, total $\mathrm{N}$ and dissolved organic carbon except for total P. Furthermore, I found that the combination of biochar and clinoptilolite decreased potassium removal efficiency compared to clinoptilolite alone. Therefore use of clinoptilolite and biochar sorbents in combination is not a reasonable option for nutrient recovery from liquid fraction of digestate from a system efficiency point of view.

\section{Improving nutrient removal by pre-treatment of clinoptilolite and biochar}

Preconditioning of clinoptilolite with sodium chloride has been found to improve the effective exchange capacity of clinoptilolite and its performance in ion exchange applications (Inglezakis et al., 2001; Inglezakis, 2005). In Chapter 2, however, no effect of preconditioning was found on the total ammonium and potassium removal from the synthetic solutions, where only ammonium and potassium were present as cations, as well as from the liquid fraction of digestate where other species of cations were also present. In the literature, contradictory results were reported regarding the effects of preconditioning on the exchange capacity. Inglezakis et al. (2001) reported that the cation exchange capacity could be improved with $\mathrm{NaCl}$ (up to $0.4 \mathrm{M} \mathrm{NaCl}$ ) preconditioning, whereas Semmens \& Martin (1988) reported that 
the total exchange capacity was not affected by preconditioning. A reason for the lack of an effect of preconditioning on the total exchange capacity could be high ammonium concentrations in both the synthetic solution and liquid fraction of digestate which caused a very large difference in ammonium concentrations between the solid and liquid phase. Therefore, a large difference between the concentration gradients in the solid and liquid phase can result in most of the exchangeable cations on the clinoptilolite surface being replaced by ammonium to a similar degree in both natural forms of clinoptilolite and preconditioned clinoptilolite. Further studies are needed to explore the effects of preconditioning at different initial ammonium concentrations.

Newly produced biochars have a low capacity for adsorbing cations due to the presence of fewer oxygen-containing functional groups (Cheng et al., 2014). Chemical activation of biochar has been suggested to increase the oxygencontaining functional groups (Xue et al., 2012). In Chapter 3, I found that ammonium removal from synthetic solutions was improved by chemical activation with sulfuric acid and sodium hydroxide. This could be due to the cations being replaced with $\mathrm{H}^{+}$and $\mathrm{Na}^{+}$as a result of $\mathrm{H}_{2} \mathrm{SO}_{4}$ and $\mathrm{NaOH}$ treatments, which allow $\mathrm{NH}_{4}{ }^{+}$ions to exchange as they are more competitive than hydrogen and sodium ions. Ammonium removal was higher from the liquid fraction of digestate where other cation species, as well as dissolved organic molecules were present. The higher removal of ammonium from digestate was likely due to co-adsorption of ammonium and dissolved organic matter (Lehmann et al., 2002; Sarkhot et al., 2013). Activation of biochar with sulfuric acid and sodium hydroxide enabled potassium removal, whereas untreated and hydrogen peroxide-treated biochar released potassium into the liquid fraction of digestate. However, the potassium removal was still rather low from the liquid fraction of digestate, and potassium remained in the activation media which cannot be reused.

Fourier transform infrared (FTIR) photoacoustic spectroscopy revealed that orthophosphate removal was related to oxygen-containing functional groups such as carboxyl. However, this was not the case for ammonium removal from liquid fraction of digestate. The positive correlation found between the oxygen-containing functional groups and orthophosphate removal could be due to cation bridging (Lin et al., 2012; Qian et al., 2013).

Overall, preconditioning of clinoptilolite did not seem to improve removal of ammonium and potassium, whereas removal of nutrients could be improved by 
activation of biochar. However, preconditioning and chemical activation of sorbents are resource demanding processes. Such pre-treatment processes may only be relevant where the resources are available at low cost or the savings on costs by improving removal (including savings due to volume reduction) are bigger than the costs of pre-treatment.

\section{Fertiliser efficiency of digestate-enriched biochar and clinoptilolite}

An important aspect of concentrating nutrients on a sorbent is the costeffectiveness of the sorbent material. In addition, it is important that nutrients can be released from the enriched sorbent if the product is to be applied to soil as fertiliser. Clinoptilolite is known to act as a slow-release fertiliser as it can desorb nutrients following nutrient enrichment (Kithome et al., 1998; Ganrot et al., 2007; Kocatürk \& Baykal, 2012). Biochar is also reported to release nutrients subsequent to enrichment (Hale et al., 2013; Sarkhot et al., 2013; Hina et al., 2014). In Chapter $\mathbf{5}$, I found that $\mathrm{N}$ sorbed to clinoptilolite and biochar from liquid fraction of digestate was available to plants and both enriched biochar and clinoptilolite were able to increase biomass yield and $\mathrm{N}$ uptake. However, clinoptilolite resulted in much higher biomass and $\mathrm{N}$ uptake compared to enriched biochar. As mentioned earlier, initial loading ratio was also an important parameter affecting the availability of $\mathrm{N}$, and thereby affecting the efficiency of enriched material when used as an $\mathrm{N}$ fertiliser.

The differences in the availability of $\mathrm{N}$ between the enriched clinoptilolite and biochar can be due to different sorption mechanisms of ammonium on biochar and clinoptilolite during enrichment, which subsequently affect the release of $\mathrm{N}$ from sorbents after soil incorporation. The enrichment of clinoptilolite with ammonium occurs mainly through ion exchange, and ammonium can subsequently be released through desorption (Kithome et al., 1998; Hedström, 2008; Beler-Baykal et al., 2011; Cyrus and Reddy, 2011; Kocatürk and Baykal, 2012). Nevertheless, other sorption mechanisms have been suggested for biochar, such as adsorption of $\mathrm{NH}_{3}$ on the biochar surface by acidic functional groups (Taghizadeh-Toosi et al., 2012b), chemisorption of $\mathrm{NH}_{3}$ (Petit et al., 2010), physical entrapment of $\mathrm{NH}_{3}$ in pores (Spokas et al., 2012; Jassal et al., 2015) and co-sorption of $\mathrm{NH}_{4}{ }^{+}$with soluble organic matter (Lehmann et al., 2002; Sarkhot et al., 2013), which can cause a strong retention of nitrogen on the biochar surface. 
The results highlight the importance of the choice of sorbent material to remove nutrients from the liquid fraction of digestate if the enriched sorbent is to be applied in the soil as $\mathrm{N}$ fertiliser (Chapter 5). Further research of the long-term effects of fertilisation with enriched sorbents is needed to fully understand the interactions between the sorbents, treatments, and their individual and their combined effects on soil quality and fertility.

\section{Practical implications of nutrient recovery with biochar and clinoptilolite}

\section{Clinoptilolite}

In Chapter 2, the nutrient removals achieved from the liquid fraction of digestate ranged from 9.05 to $20.58 \mathrm{mg} \mathrm{NH}_{4}-\mathrm{N} \mathrm{g}^{-1}$ for ammonium, from 4.62 to 12.07 $\mathrm{mg} \mathrm{K} \mathrm{g}{ }^{-1}$ for potassium, and from 0.26 to $0.95 \mathrm{mg} \mathrm{PO}_{4}-\mathrm{P} \mathrm{g}^{-1}$ for orthophosphate for varying initial loading ratios (L10-L52). In Chapter 4, clinoptilolite alone columns showed higher removal efficiencies compared to biochar alone. Combining clinoptilolite with biochar only improved total $\mathrm{P}$ removal efficiency, whereas ammonium and orthophosphate removal efficiency remained unaltered, and potassium removal efficiency decreased. In Chapter 5, I found that the plant availability of $\mathrm{N}$ in digestate-enriched clinoptilolite was much higher than that of enriched biochar.

Nutrient removal efficiencies from digestate using clinoptilolite can be as high as $89 \%$ for ammonium, $78 \%$ for potassium and $77 \%$ for orthophosphate (Chapter 2), which can be considered high efficiencies in practice. Apparent $\mathrm{N}$ recovery by the plants was as high as 0.75 when enriched clinoptilolite was applied as fertiliser (Chapter 5). These results indicate a superior performance of clinoptilolite as a sorbent material to remove and recover nutrients from the liquid fraction of digestate, and subsequently to apply it as a nutrient-enriched fertiliser compared to biochar. As indicated earlier, the plant availability of the recovered form of nutrients is also very important when selecting a treatment technology for digestate, and clinoptilolite seems to be an efficient material in both areas.

In spite of the high removal efficiencies by clinoptilolite resulting in low ammonium, phosphate and potassium concentrations in the treated digestate, the increase in the concentration of nutrients from the liquid fraction of digestate on the enriched clinoptilolite appears to be rather modest. A greater reduction in weight 
and volume would be desirable, but the economy depends mostly on the price of clinoptilolite, operation costs and costs of transport. A simple calculation is as follows: $194 \mathrm{Kg}$ of clinoptilolite would be needed to process $1 \mathrm{Mg}$ of liquid fraction of digestate if the $\mathrm{NH}_{4}-\mathrm{N}$ concentration of the liquid fraction of digestate were 4000 $\mathrm{mg} \mathrm{L}^{-1}$, and $20.58 \mathrm{mg} \mathrm{NH}_{4}-\mathrm{N}$ were removed per g clinoptilolite (as the highest $\mathrm{NH}_{4}-\mathrm{N}$ removal reported in Chapter 2). The price of clinoptilolite is approximately $€ 150$ $\mathrm{Mg}^{-1}$ including the transport cost to Denmark, the Netherlands or Belgium (Rota Mining Co., 2016), where treatment of digestate is necessary due to intensive livestock production. It follows that the cost of clinoptilolite would be approximately $€ 29 \mathrm{Mg}^{-1}$ digestate. However this estimated cost may be different in practice as the operational costs are not included here and the cost for clinoptilolite may be lower in large amounts. The costs of the existing treatment technologies in practice such as evaporation, membrane separation and ammonia stripping are in the range of $€ 11-13 \mathrm{Mg}^{-1}$ (Drosg et al., 2015). However, mineral concentrates, the end-product of membrane processes are in the liquid form and prone to $\mathrm{N}$ losses (mainly through ammonia volatilisation) when applied in the soil as fertiliser, which also reduces $\mathrm{N}$-use efficiency by the plants (Klop et al., 2012). The use of clinoptilolite does not seem to be economically feasible for recovering nutrients from liquid fraction of digestate. However the high fertiliser value of digestateenriched clinoptilolite and the nature of clinoptilolite to slowly release nutrients are superior compared to the end-products of the other treatment technologies.

\section{Biochar}

In Chapter 3 the highest ammonium and orthophosphate removal with untreated biochar was $4.74 \mathrm{mg} \mathrm{NH}_{4}-\mathrm{N} \mathrm{g}^{-1}$ and $1.38 \mathrm{mg} \mathrm{PO}_{4}-\mathrm{P}$ g-1 biochar, respectively. These removals could be improved up to $10.40 \mathrm{mg} \mathrm{NH}_{4}-\mathrm{N} \mathrm{g}^{-1}$ and 2.02 mg $\mathrm{PO}_{4}-\mathrm{P} \quad \mathrm{g}^{-1}$ with $\mathrm{NaOH}$-activated biochar and $\mathrm{H}_{2} \mathrm{SO}_{4}$-activated biochar, respectively. On the other hand, potassium removal was not possible with untreated biochars due to high potassium content of the biochars used, and only minor potassium removal (1.22 $\mathrm{mg} \mathrm{K} \mathrm{g}^{-1}$ ) was achieved with $\mathrm{H}_{2} \mathrm{SO}_{4}$-activated biochar. In Chapter 4, the highest ammonium and orthophosphate removal achieved from the liquid fraction of digestate was $8.61 \mathrm{mg} \mathrm{NH}_{4}-\mathrm{N} \mathrm{g}^{-1}$ and $1.95 \mathrm{mg} \mathrm{PO}_{4}-\mathrm{P} \mathrm{g}^{-1}$ biochar, respectively, when the columns were designed and run with the highest initial loading ratio. In Chapter 5, pot experiments resulted in an apparent $\mathrm{N}$ recovery of 
approximately 0.11 when enriched biochar was used as fertiliser, which is much lower compared to enriched clinoptilolite (apparent $\mathrm{N}$ recovery is 0.75 for clinoptilolite).

Biochar samples used in this thesis (produced by pyrolysing holm oak wood at $650{ }^{\circ} \mathrm{C}$ ) were not as efficient as clinoptilolite for removing nutrients from liquid fraction of digestate, and as $\mathrm{N}$ fertiliser following the enrichment. However, it is important to bear in mind that feedstock type and pyrolysis conditions, i.e. pyrolysis temperature, presence of oxygen, pyrolysis rate (slow or fast) can have a large effect on the characteristics of biochar such as surface area, CEC, and $\mathrm{pH}$, which are related to the effectiveness of biochar for sorption processes (Mukherjee et al., 2011; Spokas et al., 2012; Clough et al., 2013; Hollister et al., 2013; Gai et al., 2014; Jassal et al., 2015). Novak and Busscher (2012) indicated that the quality of biochars can vary, and different biochars can react differently in soils. Therefore, they state that one type of biochar type will not resolve all issues in all soils. Designing a biochar with specific chemical and physical properties targeting specific problems is often a better option (Novak \& Busscher, 2012; Novak et al., 2014).

In recent years, many studies have been published attempting to explain the mechanisms involved in the ability of biochar to remove nutrients. As discussed through Chapters 3-5, the mechanisms responsible for nutrient retention reported in the literature vary. Possible mechanisms reported for ammonium removal are: cation exchange with cations such as $\mathrm{Ca}^{2+}, \mathrm{Mg}^{2+}, \mathrm{K}^{+}, \mathrm{Na}^{+}$in biochar (Hale et al., 2013; Sarkhot et al., 2013; Zeng et al., 2013; Cui et al., 2016), chemical reactions with (oxygen-containing) surface functional groups (Kizito et al., 2015; Wang et al., 2015a, 2015c; Cui et al., 2016), surface area-dependent physical diffusion and physical entrapment of $\mathrm{NH}_{4}{ }^{+}$in biochar pores (Clough et al., 2013; Kizito et al., 2015), co-adsorption with soluble organic matter (Lehmann et al., 2002; Sarkhot et al., 2013) and struvite $\left(\mathrm{MgNH}_{4} \mathrm{PO}_{4} \cdot 6 \mathrm{H}_{2} \mathrm{O}\right)$ precipitation on biochar (Cui et al., 2016). Orthophosphate removal has been explained by phosphate adsorption to $\mathrm{MgO}$ on the biochar surface (Yao et al., 2011), precipitation reactions between phosphate and $\mathrm{Ca}^{+}$and $\mathrm{Mg}^{+}$ions (Wang et al., 2015c), anion exchange with surface hydroxyl groups (Sarkhot et al., 2013) and electrostatic interaction of phosphate anions with charged hydroxide surfaces (Chen et al., 2011). Our understanding of the mechanisms responsible for nutrient removal by biochar is still limited, and therefore the answer to the question: 'what is the most efficient biochar type to remove nutrients from liquid fraction of digestate?' is not straightforward. 
Answering this question was not the objective here, however, my thesis demonstrates that biochar has the potential to recover nutrients from liquid digestate, and this potential can be enhanced by activation processes. Continuing research in this field is necessary to improve our understanding of what constitutes biochar with desirable characteristics in the context of agronomic and environmental management applications. 


\section{Chapter 7 \\ Conclusions and Outlook}

N. Pelin Kocatürk 


\subsection{Main Conclusions}

This thesis demonstrates that clinoptilolite and biochar are able to remove nutrients from the liquid fraction of digestate resulting from anaerobic digestion of animal manure; and both enriched clinoptilolite and biochar act as $\mathrm{N}$ fertilisers. My conclusions based on the specific objectives of the thesis are:

- Preconditioning of clinoptilolite with sodium chloride does not increase total ammonium and potassium removal from the liquid fraction of digestate.

- Initial loading ratio is an important design parameter in sorption processes to determine the amount of nutrient removal and nutrient removal efficiency.

- Increasing initial loading ratio results in increasing removal of ammonium, potassium and orthophosphate by clinoptilolite, but the removal efficiency concomitantly decreases.

- Initial loading ratio affects ammonium and orthophosphate removal and potassium release by biochar: Increasing initial loading ratio results in higher ammonium and orthophosphate removal and potassium release. Removal efficiency is also influenced and increasing initial loading ratio results in lower removal efficiency.

- Initial loading ratio also affects the plant availability of the recovered nitrogen in digestate-enriched clinoptilolite and biochar.

- Chemical activation of biochar increases ammonium and orthophosphate removal compared to untreated biochar, and enables potassium removal from the liquid fraction of digestate.

- Clinoptilolite alone shows higher removal efficiencies compared to biochar alone, and combining clinoptilolite with biochar only improves total $\mathrm{P}$ removal efficiency.

- Biochar cannot be used on its own as a sorbent for potassium and it decreases the potassium removal efficiency of clinoptilolite when they are used in combination.

- Both enriched clinoptilolite and biochar act as $\mathrm{N}$ fertilisers, but clinoptilolite results in much higher plant growth than biochar. 


\subsection{Perspectives, outlook and further research}

Nutrient recovery from liquid fraction of digestate is gaining more and more importance due to environmental regulations in many countries concerning manure digestate management, especially in areas with high livestock density, and considering depletion of the global natural reserves of phosphorus and potassium. Considering the high energy demands for the production of nitrogen fertilisers, recovery of nitrogen is also of high importance. A range of possible technologies can be applied for nutrient recovery from the liquid fraction of digestate. In some cases ion exchange is used after membrane separation or evaporation in digestate treatment, but it has not been applied alone as a single treatment process. This thesis confirms that sorption with clinoptilolite and biochar can be a promising technology to recover nutrients from the liquid fraction of digestate. Using biochar and clinoptilolite increases the concentration of nutrients and thereby decreases volume, which allows for savings on storage, transport and application of the voluminous liquid fraction of digestate. The end-product of this technology is nutrient-enriched clinoptilolite and biochar which can be directly applied to soils as fertiliser. Concentrating nutrients on clinoptilolite and biochar, and subsequently applying them as fertiliser can provide a win-win scenario as a result of combining the fertiliser effect with their soil improving properties. Besides, slow nutrientrelease properties of sorbents can reduce nutrient losses to the environment. As compared to direct land application of liquid fraction of digestate, concentrating nutrients on clinoptilolite and biochar, and subsequently applying them as fertilisers may provide benefits in terms of:

- Reduction of digestate volume and volume-related costs such as storage and transport;

- Reduction of nutrient losses to the environment;

- Efficient use of nutrients by plants due to the slow nutrient-releasing nature of sorbents;

- Improvement in soil quality, in areas where the combined soil-improving properties of biochar and clinoptilolite can be beneficial.

Nevertheless, cost is an important factor when selecting a technology for nutrient recovery, and the concentration of nutrients on clinoptilolite and biochar is 
only moderate. Therefore, improvement of the technology is needed. For clinoptilolite, it does not seem possible to improve cation exchange capacity and, thus, the level of nutrient concentration. However, improvement of nutrient removal of biochar is possible and other techniques can be investigated such as chemical and thermal activation in combination.

I end this thesis with a list of research subjects which I find relevant and interesting for future research:

- Desorption experiments on the desorption behaviours of enriched (loaded) biochar and clinoptilolite which mimic the nutrient release from enriched sorbents as fertilisers;

- Testing the plant availability of $\mathrm{P}$ from digestate-enriched biochar and clinoptilolite;

- Testing the plant availability of K from digestate-enriched clinoptilolite;

- Long-term pot and field experiments to test the fertiliser efficiency of enriched biochar and clinoptilolite separately and together, and to observe their interactions with different soils;

- Liquid fraction of digestate is a complex solution with many anions, cations and dissolved organics which makes it difficult to understand the mechanisms behind nutrient removal. Therefore, sorption experiments with simple aqueous solutions at various $\mathrm{pH}$ levels could be insightful to understand the effects of biochar on the removal of one anion or cation at a time. I believe that understanding the mechanistic aspects of nutrient removal with biochar would allow us to get one step closer to creating a bespoke biochar for the specific purpose of nutrient recovery. 


\section{References}

Ahmad M, Rajapaksha AU, Lim JE et al. (2014) Biochar as a sorbent for contaminant management in soil and water: a review. Chemosphere, 99, 1933.

Allar AD, Beler Baykal B (2015) Stagewise processing of yellow water using clinoptilolite for nitrogen and phosphorus recovery and higher residual quality. Water Science \& Technology, 71, 1869.

Allar AD, Beler-Baykal B (2013) Phosphorus Recovery from Source Separated Human Urine upon Processing with Clinoptilolite. Proceedings of the Water Environment Federation, 2013, 117-124.

Ames LLJ (1960) The cation sieve properties of clinoptilolite. American Mineralogist, 45, 689-700.

Angst TE, Sohi SP (2013) Establishing release dynamics for plant nutrients from biochar. GCB Bioenergy, 5, 221-226.

Antil RS, Janssen BH, Lantinga EA (2009) Laboratory and greenhouse assessment of plant availability of organic $\mathrm{N}$ in animal manure. Nutrient Cycling in Agroecosystems, 85, 95-106.

Asada T, Ohkubo T, Kawata K, Oikawa K (2006) Ammonia Adsorption on Bamboo Charcoal with Acid Treatment. Journal of Health Science, 52, 585589.

Ban ZS, Dave G (2004) Laboratory studies on recovery of $n$ and $p$ from human urine through struvite crystallisation and zeolite adsorption. Environmental Technology, 25, 111-121.

Bekiaris G, Peltre C, Jensen LS, Bruun S Using FTIR-photoacoustic spectroscopy for phosphorus speciation analysis of biochars (In preparation).

Beler Baykal B, Guven DA (1997) Performance of clinoptilolite alone and in combination with sand filters for the removal of ammonia peaks from domestic wastewater. Water Science and Technology, 35, 47-54.

Beler Baykal B, Kocatürk NP, Allar AD, Sari B (2009) The effect of initial loading on the removal of ammonium and potassium from source-separated human urine via clinoptilolite. Water Science and Technology, 60, 2515-2520.

Beler-Baykal B, Oldenburg M, Sekoulov I (1996) The use of Ion Exchange in Ammonia Removal under Constant and Variable Loads. Environmental Technology, 17, 717-726.

Beler-Baykal B, Allar AD, Bayram S (2011) Nitrogen recovery from sourceseparated human urine using clinoptilolite and preliminary results of its use as fertilizer. Water science and technology: a journal of the International Association on Water Pollution Research, 63, 811-7.

Carey DE, McNamara PJ, Zitomer DH (2015) Biochar from Pyrolysis of Biosolids for Nutrient Adsorption and Turfgrass Cultivation. Water Environment 
Research, 87, 2098-2106.

Chen B, Chen Z, Lv S (2011) A novel magnetic biochar efficiently sorbs organic pollutants and phosphate. Bioresource Technology, 102, 716-723.

Cheng C-H, Lehmann J, Engelhard MH (2008) Natural oxidation of black carbon in soils: Changes in molecular form and surface charge along a climosequence. Geochimica et Cosmochimica Acta, 72, 1598-1610.

Cheng C-H, Lin T-P, Lehmann J et al. (2014) Sorption properties for black carbon (wood char) after long term exposure in soils. Organic Geochemistry, 70, 53-61.

Chia HC, Downie A, Munroe P (2015) Characteristics of Biochar: Physical and Structural Properties. In: Biochar for Environmental Management. Routledge.

Christel W, Bruun S, Magid J, Jensen LS (2014) Phosphorus availability from the solid fraction of pig slurry is altered by composting or thermal treatment. Bioresource Technology, 169, 543-551.

Christensen ML, Christensen K V., Sommer SG (2013) Solid-Liquid Separation of Animal Slurry. In: Animal Manure Recycling, pp. 105-130. John Wiley \& Sons, Ltd, Chichester, UK.

Clough T, Condron L, Kammann C, Müller C (2013) A Review of Biochar and Soil Nitrogen Dynamics. Agronomy, 3, 275-293.

Cui X, Hao H, Zhang C, He Z, Yang X (2016) Capacity and mechanisms of ammonium and cadmium sorption on different wetland-plant derived biochars. Science of The Total Environment, 539, 566-575.

Cyrus JS, Reddy GB (2011) Sorption and desorption of ammonium by zeolite: Batch and column studies. Journal of environmental science and health. Part A, Toxic/hazardous substances \& environmental engineering, 46, 408-414.

Dijk EJ (2015) Chemical oxidation of biochar and its nutrient retention properties. Wageningen University.

van Dijk KC, Lesschen JP, Oenema 0 (2016) Phosphorus flows and balances of the European Union Member States. Science of the Total Environment, 542, 1078-1093.

Dimova G, Mihailov G, Tzankov T (1999) Combined filter for ammonia removal part I: Minimal zeolite contact time and requirements for desorption. Water Science and Technology, 39, 123-129.

Drosg B, Fuchs W, Al Seadi T, Madsen M, Linke B (2015) Nutrient Recovery by Biogas Digestate Processing, IEA Bioenergy.

Dutch Standards (1997) NEN-EN 1484:1997 en. Water analysis - Guidelines for the determination of total organic carbon (TOC) and dissolved organic carbon (DOC).

Eldridge S, ChengRong C (2010) Greenwaste biochar potentially reduces nitrogen fertiliser losses. In: Proceedings of the 19th World Congress of Soil Science: Soil solutions for a changing world, pp. 100-103. Brisbane.

Erdem E, Karapinar N, Donat R (2004) The removal of heavy metal cations by natural zeolites. Journal of colloid and interface science, 280, 309-14. 
Farkaš A, Rožić M, Barbarić-Mikočević Z (2005) Ammonium exchange in leakage waters of waste dumps using natural zeolite from the Krapina region, Croatia. Journal of Hazardous Materials, 117, 25-33.

Feilberg A, Sommer SG (2013) Ammonia and Malodorous Gases : Sources and Abatement Technologies. Animal Manure Recycling: Treatment and Management, 153-175.

Ferguson GA, Pepper IL (1987) Ammonium Retention in Sand Amended with Clinoptilolite1. Soil Science Society of America Journal, 51, 231.

Fuchs W, Drosg B (2013) Assessment of the state of the art of technologies for the processing of digestate residue from anaerobic digesters. Water Science and Technology, 67, 1984-1993.

Gai X, Wang H, Liu J, Zhai L, Liu S, Ren T, Liu H (2014) Effects of Feedstock and Pyrolysis Temperature on Biochar Adsorption of Ammonium and Nitrate. PLOS ONE, 9, e113888.

Ganrot Z, Dave G, Nilsson E (2007) Recovery of N and P from human urine by freezing, struvite precipitation and adsorption to zeolite and active carbon. Bioresource Technology, 98, 3112-3121.

Ganrot Z, Slivka A, Dave G (2008) Nutrient Recovery from human Urine using pretreated Zeollite and struvite Precipitation in Combination with freezingthawing and Plant Availability Tests on common Wheat. Clean-Soil Air Water, 36, 45-52.

Ghafoori E, Flynn PC (2007) Optimizing the logistics of anaerobic digestion of manure. Applied biochemistry and biotechnology, 137-140, 625-37.

De Graaff MS, Temmink H, Zeeman G, Buisman CJN (2011) Energy and phosphorus recovery from black water. Water Science and Technology, 63, 2759-2765.

Guo X, Zeng L, Li X, Park H (2007) Removal of Ammonium from RO Permeate of Anaerobically Digested Wastewater by Natural Zeolite. Separation Science and Technology, 42, 3169-3185.

Günay A, Arslankaya E, Tosun I (2007) Lead removal from aqueous solution by natural and pretreated clinoptilolite: adsorption equilibrium and kinetics. Journal of hazardous materials, 146, 362-71.

Hale SE, Alling V, Martinsen V, Mulder J, Breedveld GD, Cornelissen G (2013) The sorption and desorption of phosphate-P, ammonium-N and nitrate-N in cacao shell and corn cob biochars. Chemosphere, 91, 1612-1619.

Halim AA, Aziz HA, Johari MAM, Ariffin KS (2010) Comparison study of ammonia and COD adsorption on zeolite, activated carbon and composite materials in landfill leachate treatment. Desalination, 262, 31-35.

Hartmann H, Ahring BK (2006) Strategies for the anaerobic digestion of the organic fraction of municipal solid waste: An overview. Water Science and Technology, 53, 7-22.

Hedström A (2008) Adsorption and desorption of ammonium by clinoptilolite adsorbent in municipal wastewater treatment systems. Journal of Environmental Engineering and Science, 7, 53-61. 
Henriksen K, Berthelsen L, Matzen R (1998) Separation of Liquid Pig Manure by Flocculation and Ion Exchange Part 1: Laboratory Experiments. Journal of Agricultural Engineering Research, 69, 115-125.

Hina K, Hedley M, Camps-Arbestain M, Hanly J (2014) Comparison of Pine Bark, Biochar and Zeolite as Sorbents for NH4+ -N Removal from Water. Clean Soil, Air, Water, 42, 1-6.

Hjorth M, Nielsen AM, Nyord T, Hansen MN, Nissen P, Sommer SG (2009) Nutrient value, odour emission and energy production of manure as influenced by anaerobic digestion and separation. Agronomy for Sustainable Development, 29, 329-338.

Hjorth M, Christensen KV, Christensen ML, Sommer SG (2010) Solid-liquid separation of animal slurry in theory and practice. A review. Agronomy for Sustainable Development, 30, 153-180.

Hollister CC, Bisogni JJ, Lehmann J (2013) Ammonium, Nitrate, and Phosphate Sorption to and Solute Leaching from Biochars Prepared from Corn Stover ( L.) and Oak Wood ( spp.). Journal of Environment Quality, 42, 137.

Inglezakis VJ, Zorpas AA (eds.) (2012) Handbook of Natural Zeolites. BENTHAM SCIENCE PUBLISHERS.

Inglezakis VJ (2005) The concept of "capacity" in zeolite ion-exchange systems. Journal of Colloid and Interface Science, 281, 68-79.

Inglezakis VJ, Hadjiandreou KJ, Loizidou MD, Grigoropoulou HP (2001) Pretreatment of natural clinoptilolite in a laboratory-scale ion exchange packed bed. Water Research, 35, 2161-2166.

International Biochar Initiative (2016) Terms and Definitions, http://www.biochar-international.org/definitions (Date accessed: 02.03.2016).

International Organization for Standardization (2003) ISO 15681-1:2003, Water quality - Determination of phosphate and total phosphorus by flow analysis (CFA and FIA), Part 1: Method by flow injection analysis (FIA).

International Organization for Standardization (2005) ISO 11732:2005, Water quality -Determination of ammonium nitrogen - Method by flow analysis (CFA and FIA) and spectrometric detection.

Ippolito JA, Spokas KA, Novak JM, Lentz RD, Cantrell KB (2015) Biochar Elemental Composition and Factors Influencing Nutrient Retention. In: Biochar for Environmental Management, pp. 139-163. Routledge.

Janssen BH (1990) A double-pot technique as a tool in plant nutrition studies. In: Plant Nutrition - Physiology and Applications, pp. 759-763. Springer Netherlands, Dordrecht.

Jassal RS, Johnson MS, Molodovskaya M, Black TA, Jollymore A, Sveinson K (2015) Nitrogen enrichment potential of biochar in relation to pyrolysis temperature and feedstock quality. Journal of Environmental Management, 152, 140-144.

Jensen LS (2013a) Animal Manure Fertiliser Value , Crop Utilisation and Soil Quality Impacts. Animal Manure Recycling: Treatment and Management, 
295-328.

Jensen LS (2013b) Animal Manure Residue Upgrading and Nutrient Recovery in Biofertilisers. Animal Manure Recycling, 271-294.

Jorgensen T., Weatherley L. (2003) Ammonia removal from wastewater by ion exchange in the presence of organic contaminants. Water Research, 37, 1723-1728.

Jørgensen K, Jensen LS (2009) Chemical and biochemical variation in animal manure solids separated using different commercial separation technologies. Bioresource technology, 100, 3088-96.

Karadag D, Koc Y, Turan M, Armagan B (2006) Removal of ammonium ion from aqueous solution using natural Turkish clinoptilolite. Journal of Hazardous Materials, 136, 604-609.

Kithome M, Paul JW, Lavkulich LM, Bomke a. a. (1998) Kinetics of Ammonium Adsorption and Desorption by the Natural Zeolite Clinoptilolite. Soil Science Society of America Journal, 62, 622.

Kizito S, Wu S, Kipkemoi Kirui W, Lei M, Lu Q Bah H, Dong R (2015) Evaluation of slow pyrolyzed wood and rice husks biochar for adsorption of ammonium nitrogen from piggery manure anaerobic digestate slurry. The Science of the total environment, 505, 102-12.

Klop G, Velthof GL, Van Groenigen JW (2012) Application technique affects the potential of mineral concentrates from livestock manure to replace inorganic nitrogen fertilizer. Soil Use and Management, 28, 468-477.

Kocasoy G, Sahin V (2007) Heavy metal removal from industrial wastewater by clinoptilolite. Journal of environmental science and health. Part A, Toxic/hazardous substances \& environmental engineering, 42, 2139-46.

Kocatürk NP, Baykal BB (2012) Recovery of Plant Nutrients from Dilute Solutions of Human Urine and Preliminary Investigations on Pot Trials. Clean - Soil, Air, Water, 40, 538-544.

Kocatürk N, Bruun S, Zwart K, Jensen L Nutrient recovery from the liquid fraction of digestate by clinoptilolite. (Submitted).

Kocatürk NP, Georgios B, Clément P, Jensen LS, Zwart K, Bruun S Chemical activation of biochar for enhanced nutrient removal from liquid manure digestate. (Submitted).

Kocatürk NP, Zwart K, Bruun S, Jensen LS, Sørensen H, Brussaard L Efficiency of digestate-enriched clinoptilolite and biochar as nitrogen fertilisers. (Submitted).

Koon JH, Kaufman WJ (1975) Ammonia wastewaters removal by from municipal ion exchange. Journal Water Pollution Control Federation, 47, 448-465.

Lebuf V, Accoe F, Elsacker S Van et al. (2013) Inventory, Techniques for nutrient recovery from digestate. Repor - ARBOR Interreg IVB project.

Lehmann J, Joseph S (2015) Biochar for Environmental Management. Routledge.

Lehmann J, da Silva JPJ, Rondon M et al. (2002) Slash-and-char-a feasible alternative for soil fertility management in the central Amazon. In: Proceedings of the 17th World Congress of Soil Science, pp. 1-12. American 
Chemical Society, Washington D.C.

Lin Y, Munroe P, Joseph S, Kimber S, Van Zwieten L (2012) Nanoscale organomineral reactions of biochars in ferrosol: An investigation using microscopy. Plant and Soil, 357, 369-380.

Lin L, Lei Z, Wang L et al. (2013) Adsorption mechanisms of high-levels of ammonium onto natural and NaCl-modified zeolites. Separation and Purification Technology, 103, 15-20.

Lin H, Zheng Q, Dong Y, Jin X, Zhang X, Liu Q (2015) Effect of modification and regulation on physicochemical properties of clinoptilolite, as well as nitrogen and phosphates removal performance. The Canadian Journal of Chemical Engineering, 93, 825-831.

Liu R, Lal R (2015) Potentials of engineered nanoparticles as fertilizers for increasing agronomic productions. The Science of the total environment, 514, 131-9.

Milan Z, Sánchez E, Weiland P, De Las Pozas C, Borja R, Mayari R, Rovirosa N (1997) Ammonia removal from anaerobically treated piggery manure by ion exchange in columns packed with homoionic zeolite. Chemical Engineering Journal, 66, 65-71.

Mohan D, Sarswat A, Ok YS, Pittman CU (2014) Organic and inorganic contaminants removal from water with biochar, a renewable, low cost and sustainable adsorbent--a critical review. Bioresource technology, 160, 191202.

Mukherjee A, Zimmerman AR, Harris W (2011) Surface chemistry variations among a series of laboratory-produced biochars. Geoderma, 163, 247-255.

Møller H (2000) Solid-liquid separation of livestock slurry: efficiency and cost. Bioresource Technology, 74, 223-229.

Møller HB, Sommer SG, Ahring BK (2002) Separation efficiency and particle size distribution in relation to manure type and storage conditions. Bioresource Technology, 85, 189-196.

Møller HB, Hansen JD, Sorensen CAG (2007) Nutrient Recovery by Solid-Liquid Separation and Methane Productivity of Solids. Transactions of the ASABE, 50, 193-200.

Møller J, Boldrin A, Christensen TH (2009) Anaerobic digestion and digestate use: accounting of greenhouse gases and global warming contribution. Waste management \& research : the journal of the International Solid Wastes and Public Cleansing Association, ISWA, 27, 813-824.

Möller K, Müller T (2012) Effects of anaerobic digestion on digestate nutrient availability and crop growth: A review. Engineering in Life Sciences, 12, 242257.

Nguyen ML, Tanner CC (1998) Ammonium removal from wastewaters using natural New Zealand zeolites. New Zealand Journal of Agricultural Research, 41, 427-446.

Novak JM, Busscher WJ (2012) Selection and Use of Designer Biochars to Improve Characteristics of Southeastern USA Coastal Plain Degraded Soils. 
In: Advanced Biofuels and Bioproducts, pp. 69-96.

Novak JM, Cantrell KB, Watts DW, Busscher WJ, Johnson MG (2014) Designing relevant biochars as soil amendments using lignocellulosic-based and manure-based feedstocks. Journal of Soils and Sediments, 14, 330-343.

Novozamsky I, Houba VJG, Temminghoff E, Der LJJ van (1984) Determination of "total" N and "total" P in a single soil digest. Netherlands Journal of Agricultural Science, 32, 322-324.

Oh S-Y, Seo Y-D (2015) Sorption of halogenated phenols and pharmaceuticals to biochar: affecting factors and mechanisms. Environmental Science and Pollution Research, 951-961.

Pantelopoulos A, Magid J, Jensen LS (2016) Thermal drying of the solid fraction from biogas digestate: Effects of acidification, temperature and ventilation on nitrogen content. Waste Management, 48, 218-226.

Pérez-Harguindeguy N, Díaz S, Garnier E et al. (2013) New handbook for standardised measurement of plant functional traits worldwide. Australian Journal of Botany, 61, 167-234.

Perrin TS, Drost DT, Boettinger JL, Norton JM (1998) Ammonium loaded clinoptilolite: a slow release nitrogen fertilizer for sweet corn. Journal of Plant Nutrition, 21, 515-530.

Petit C, Kante K, Bandosz TJ (2010) The role of sulfur-containing groups in ammonia retention on activated carbons. Carbon, 48, 654-667.

Poorte H, Nagel O (2000) The role of biomass allocation in the growth response of plants to different levels of light, $\mathrm{CO} 2$, nutrients and water: A quantitative review. IMF Occasional Papers, 27, 595-607.

Paavola T, Rintala J (2008) Effects of storage on characteristics and hygienic quality of digestates from four co-digestion concepts of manure and biowaste. Bioresource Technology, 99, 7041-7050.

Qian T, Zhang X, Hu J, Jiang H (2013) Effects of environmental conditions on the release of phosphorus from biochar. Chemosphere, 93, 2069-2075.

R Core Team (2015) R: A Language and Environment for Statistical Computing.

Reháková M, Čuvanová S, Dzivák M, Rimár J, Gaval'ová Z (2004) Agricultural and agrochemical uses of natural zeolite of the clinoptilolite type. Current Opinion in Solid State and Materials Science, 8, 397-404.

Rehl T, Müller J (2011) Life cycle assessment of biogas digestate processing technologies. Resources, Conservation and Recycling, 56, 92-104.

Rico C, Rico JL, Tejero I, Muñoz N, Gómez B (2011) Anaerobic digestion of the liquid fraction of dairy manure in pilot plant for biogas production: Residual methane yield of digestate. Waste Management, 31, 2167-2173.

Ross A (2016) Personal communication. Faculty of Engineering, University of Leeds, Leeds, UK.

Sakadevan K, Bavor HJ (1998) Phosphate adsorption characteristics of soils, slags and zeolite to be used as substrates in constructed wetland systems. Water Research, 32, 393-399.

Sánchez E, Milá Z, Borjat R, Weiland P, Rodriguez X (1995) Piggery waste 
treatment by anaerobic digestion and nutrient removal by ionic exchange. Resources, Conservation and Recycling, 15, 235-244.

Sarkhot D V, Ghezzehei TA, Berhe AA (2013) Effectiveness of biochar for sorption of ammonium and phosphate from dairy effluent. Journal of Environmental Quality, 42, 1545-1554.

Semmens MJ, Martin WP (1988) The influence of pretreatment on the capacity and selectivity of clinoptilolite for metal ions. Water Research, 22, 537-542.

Shackley S, Sohi S, Brownsort P, Carter S (2010) An assessment of the benefits and issues associated with the application of biochar to soil. Edinburgh, 1-132 pp.

Sigurnjak I, Michels E, Crappe S, Buysens S, Tack FMG, Meers E (2016) Utilization of derivatives from nutrient recovery processes as alternatives for fossilbased mineral fertilizers in commercial greenhouse production of Lactuca sativa L. Scientia Horticulturae, 198, 267-276.

Spokas KA, Novak JM, Venterea RT (2012) Biochar's role as an alternative Nfertilizer: ammonia capture. Plant and Soil, 350, 35-42.

Sørensen P, Jensen L (2013) Nutrient Leaching and Runoff from Land Application of Animal Manure and Measures for Reduction. Animal Manue Recycling: Treatment and Management, 195 - 210.

Taghizadeh-Toosi A, Clough TJ, Sherlock RR, Condron LM (2012a) A wood based low-temperature biochar captures NH3-N generated from ruminant urine$\mathrm{N}$, retaining its bioavailability. Plant and Soil, 353, 73-84.

Taghizadeh-Toosi A, Clough TJ, Sherlock RR, Condron LM (2012b) Biochar adsorbed ammonia is bioavailable. Plant and Soil, 350, 57-69.

Takaya CA, Fletcher LA, Singh S, Anyikude KU, Ross AB (2016) Phosphate and ammonium sorption capacity of biochar and hydrochar from different wastes. Chemosphere, 145, 518-527.

Tchobanoglous G, Burton FL, Stensel HD (2003) Wastewater Engineering: Treatment and Reuse. Metcalf \& Eddy, Inc., Vol. 4. 1819 pp.

Teglia C, Tremier A, Martel J-L (2011a) Characterization of Solid Digestates: Part 1, Review of Existing Indicators to Assess Solid Digestates Agricultural Use. Waste and Biomass Valorization, 2, 43-58.

Teglia C, Tremier A, Martel JL (2011b) Characterization of solid digestates: Part 2 , assessment of the quality and suitability for composting of six digested products. Waste and Biomass Valorization, 2, 113-126.

Temminghoff EEJM, Houba VJG (2004) Plant Analysis Procedures (eds Temminghoff EEJM, Houba VJG). Springer Netherlands, Dordrecht.

Tsadilas CD, Argyropoulos G (2006) Effect of Clinoptilolite Addition to Soil on Wheat Yield and Nitrogen Uptake. Communications in Soil Science and Plant Analysis, 37, 2691-2699.

United States Environmental Protection Agency (2016) Nutrient Pollution.

Vaneeckhaute C, Meers E, Michels E, Ghekiere G, Accoe F, Tack FMG (2013) Closing the nutrient cycle by using bio-digestion waste derivatives as synthetic fertilizer substitutes: A field experiment. Biomass and Bioenergy, 55, 175-189. 
Vázquez-Rowe I, Golkowska K, Lebuf V et al. (2015) Environmental assessment of digestate treatment technologies using LCA methodology. Waste Management, 43, 442-459.

Velthof GL, Hou Y, Oenema O (2015) Nitrogen excretion factors of livestock in the European Union: A review. Journal of the Science of Food and Agriculture, 95, 3004-3014.

Walsh JJ, Jones DL, Edwards-Jones G, Williams AP (2012) Replacing inorganic fertilizer with anaerobic digestate may maintain agricultural productivity at less environmental cost. Journal of Plant Nutrition and Soil Science, 175, 840-845.

Wang B, Lehmann J, Hanley K, Hestrin R, Enders A (2015a) Adsorption and desorption of ammonium by maple wood biochar as a function of oxidation and $\mathrm{pH}$. Chemosphere, 138, 120-126.

Wang Z, Han L, Sun K et al. (2015b) Sorption of four hydrophobic organic contaminants by biochars derived from maize straw, wood dust and swine manure at different pyrolytic temperatures. Chemosphere, 144, 285-291.

Wang Z, Guo H, Shen F et al. (2015c) Biochar produced from oak sawdust by Lanthanum (La)-involved pyrolysis for adsorption of ammonium (NH4+), nitrate (NO3-), and phosphate (P043-). Chemosphere, 119, 646-653.

Wilson JB (1988) A review of evidence on the control of shoot:root ratio, in relation to models. Annals of Botany, 61, 433-449.

Wojdyr M (2010) Fityk: a general-purpose peak fitting program. Journal of Applied Crystallography, 43, 1126-1128.

Wu H, Yip K, Kong Z, Li CZ, Liu D, Yu Y, Gao X (2011) Removal and recycling of inherent inorganic nutrient species in mallee biomass and derived biochars by water leaching. Industrial and Engineering Chemistry Research, 50, 12143-12151.

Xing W, Ngo HH, Kim SH, Guo WS, Hagare P (2008) Adsorption and bioadsorption of granular activated carbon (GAC) for dissolved organic carbon (DOC) removal in wastewater. Bioresource Technology, 99, 86748678.

Xu G, Sun J, Shao H, Chang SX (2014) Biochar had effects on phosphorus sorption and desorption in three soils with differing acidity. Ecological Engineering, 62, 54-60.

Xue Y, Gao B, Yao Y, Inyang M, Zhang M, Zimmerman AR, Ro KS (2012) Hydrogen peroxide modification enhances the ability of biochar (hydrochar) produced from hydrothermal carbonization of peanut hull to remove aqueous heavy metals: Batch and column tests. Chemical Engineering Journal, 200-202, 673-680.

Yao Y, Gao B, Inyang M, Zimmerman AR, Cao X, Pullammanappallil P, Yang L (2011) Biochar derived from anaerobically digested sugar beet tailings: Characterization and phosphate removal potential. Bioresource Technology, 102, 6273-6278.

Yao Y, Gao B, Chen J, Yang L (2013) Engineered biochar reclaiming phosphate 
from aqueous solutions: Mechanisms and potential application as a slowrelease fertilizer. Environmental Science and Technology, 47, 8700-8708.

Zarebska A, Nieto DR, Christensen K V, Sotoft LF, Norddahl B (2015) Ammonium Fertilizers Production from Manure: A Critical Review. Critical Reviews in Environmental Science and Technology, 45, 1469-1521.

Zeng Z, Zhang S, Li T et al. (2013) Sorption of ammonium and phosphate from aqueous solution by biochar derived from phytoremediation plants. Journal of Zhejiang University. Science. B, 14, 1152-61. 


\section{Summary}

The increasing number of biogas plants over the last decades has brought the need to improve techniques to handle digestate, the by-product of anaerobic digestion in biogas plants. Separation of digestate into liquid and solid fractions is often applied in centralised biogas plants, which necessitates the subsequent distribution of nutrients. The liquid fraction of digestate can be used as fertiliser in agricultural crop production systems and the most common practice of utilising the liquid fraction of digestate is direct field application in the vicinity of the biogas plant. However, direct application may result in practical problems such as need for high storage volume, and environmental problems as a result of nutrient losses in the environment. To overcome such problems, recovery and concentration of nutrients from the liquid fraction may be a desirable option which, would also result in recovery of nutrients whose natural reserves are being depleted such as phosphorus and potassium. In this thesis I propose the use of sorbents i.e. biochar and clinoptilolite to concentrate nutrients and subsequently the application of digestate-enriched biochar and clinoptilolite as fertiliser. Therefore the overall objective of this thesis is to investigate the use of clinoptilolite and biochar to recover plant nutrients from the liquid fraction of digestate resulting from anaerobic digestion of animal manure and investigate the plant-availability of the recovered form of nutrients.

In Chapter 1 (General Introduction), I summarised the motivation for this thesis, the objectives and experimental approach.

In Chapter 2, I investigated the use of clinoptilolite as a sorbent to recover nutrients from the liquid fraction of digestate. I found no effect of preconditioning on the total ammonium and potassium removal from the liquid fraction of digestate. I also found that the removal efficiency of ammonium, potassium and orthophosphate from the liquid fraction of digestate was significantly affected by the initial loading ratio; and increasing initial loading ratios resulted in increasing removals (concentration of nutrients on sorbent) but decreasing efficiencies of clinoptilolite to remove nutrients from the liquid fraction of digestate.

In Chapter 3, I studied the chemical activation of biochar by treating the biochar with deionised water, hydrogen peroxide, sulfuric acid and sodium hydroxide solutions to investigate the effects of activation on oxygen-containing functional 
groups, and ammonium, orthophosphate and potassium removal from the liquid fraction of digestate. I found that ammonium, potassium and orthophosphate removal from liquid fraction of digestate was improved by chemical activation. FTIR photoacoustic spectroscopy revealed that orthophosphate removal was related to oxygen-containing functional groups. However, no strong correlation was found between the oxygen-containing functional groups and ammonium removal from liquid fraction of digestate.

In Chapter 4, I investigated the effects of initial loading ratio on the ammonium, potassium, orthophosphate removal efficiency by biochar from the liquid fraction of digestate. I observed similar effects of initial loading ratio on the biochar (holm oak wood pyrolysed at $650{ }^{\circ} \mathrm{C}$ ) as for clinoptilolite. I also investigated the effect of the combination of clinoptilolite and biochar on the nutrient removal efficiency and found that combining biochar with clinoptilolite did not improve the efficiency of clinoptilolite to remove ammonium, orthophosphate, total $\mathrm{N}$ and dissolved organic carbon except for total P; and decreased potassium removal efficiency compared to clinoptilolite alone.

In Chapter 5, I tested nutrient enriched biochar and clinoptilolite as nitrogen fertilisers with a pot experiment using the double-pot technique with ryegrass. I found that $\mathrm{N}$ sorbed to clinoptilolite and biochar from liquid fraction of digestate was available to plans and both enriched biochar and clinoptilolite were able to increase biomass yield and $\mathrm{N}$ uptake. However, clinoptilolite resulted in much higher biomass and $\mathrm{N}$ uptake compared to enriched biochar. I demonstrated that the initial loading ratio was an important parameter that not only affected the nutrient removal efficiency from the liquid fraction of digestate, but also affected the availability of $\mathrm{N}$ and thereby the efficiency of the enriched material when used as a fertiliser.

In Chapter 6 (General Discussion), I synthesised the main findings of my research chapters and discuss their implications.

I concluded this thesis with a general conclusion in Chapter 7 (Conclusions and outlook) with a reflection on the findings of this thesis in the context of practical applicability of biochar and clinoptilolite for digestate treatment. I finalised this chapter with reflecting on the relevance of my main conclusions for future research.

In conclusion, this thesis confirms that sorption with clinoptilolite and biochar can be a promising technology to recover nutrients from liquid fraction of digestate. Using biochar and clinoptilolite provides concentration of nutrients and, thereby, 
volume reduction which allows for savings on storage, transport and application of the voluminous liquid fraction of digestate. The end-products are digestate-enriched clinoptilolite and enriched biochar can act as $\mathrm{N}$ fertilisers. 


\section{Resumé}

Det stigende antal biogasanlæg i de seneste årtier har forårsaget behov for at forbedre teknikker til at håndtere digestat, biproduktet af anaerobisk udrådning i biogasanlæg. Adskillelse af digestat i flydende og faste fraktioner anvendes ofte i biogasanlæg, hvilket forårsager fordeling af næringsstoffer. Den flydende fraktion af digestat kan anvendes som gødning i landbruget og den mest almindelige praksis ved at udnytte den flydende fraktion af digestat er direkte udbringning i nærheden af biogasanlægget. Dog kan direkte udbringning medføre praktiske udfordringer, såsom behovet for opbevaring og miljømæssige problemer som følge af næringsstoftab til vandmiljøet. For at overvinde sådanne udfordringer kan recirkulering og opkoncentrering af næringsstoffer fra den flydende fraktion være en ønskelig mulighed, som også kunne føre til genanvendelse af næringsstoffer, hvis naturlige reserver udtømmes såsom fosfor og kalium. I denne afhandling foreslår jeg brugen af sorbenter dvs. biochar og clinoptilolit til at opkoncentrere næringsstoffer og efterfølgende anvendelse af digestat -beriget biochar og clinoptilolit som gødning på landbrugsjord. Det overordnede formål med denne afhandling er derfor at undersøge brugen af clinoptilolit og biochar til at recirkulere plantenæringsstoffer fra den flydende fraktion af digestat som følge af anaerob udrådning af husdyrgødning og undersøge tilgængelighed af den genanvendte form af næringsstoffer.

I kapitel 1 (Generel introduktion), har jeg sammenfattet motivation for denne afhandling, formål og den eksperimentelle tilgang.

I kapitel 2, har jeg undersøgt brug af clinoptilolit som sorbent til at recirkulere næringsstoffer fra den flydende fraktion af digestat. Jeg fandt ingen effekt af forbehandling på den totale ammonium og kalium fjernelse fra den flydende fraktion af digestat. Derudover fandt jeg at effektiviteten af fjernelse af ammonium, kalium og orthophosphat fra den flydende fraktion af digestat var signifikant påvirket af det initiale forhold af digestat og næringsstof; og at stigende initiale forhold resulterede i øget fjernelse (koncentration af næringsstof på sorbent), men faldende effektivitet af clinoptilolit til at fjerne næringsstoffer fra den flydende fraktionen af digestat. 
I kapitel 3, studerede jeg kemisk aktivering af biochar ved behandling af biochar med deioniseret vand, hydrogenperoxid, svovlsyre og natriumhydroxid opløsninger for at undersøge effekterne af aktivering af oxygenholdige funktionelle grupper, og ammonium, orthophosphat og kalium fjernelse fra den flydende fraktion af digestat. Jeg fandt, at ammonium, kalium og orthophosphat fjernelse fra den flydende fraktion af digestat blev øget ved kemisk aktivering. FTIR fotoakustisk spektroskopi viste, at orthophosphat fjernelse var relateret til oxygenholdige funktionelle grupper. Ingen stærk korrelation mellem oxygenholdige funktionelle grupper og ammonium fjernelse fra den flydende fraktion af digestat blev fundet.

I kapitel 4, undersøgte jeg effekterne af det initiale forhold af digestat og næringsstof på ammonium, kalium og orthophosphat fjernelse ved tilførsel af biochar fra den flydende fraktion af digestat. Jeg observerede sammenlignelige effektiviteter af det initiale forhold af digestat og næringsstof for biochar (egetræ pyrolyseret ved $650 \stackrel{\circ}{\circ}$ ) som for clinoptilolit. Jeg undersøgte også effekten af kombinationen af clinoptilolit og biochar for fjernelseseffektivitet af næringsstoffer, og fandt at ved at kombinere biochar med clinoptilolit ikke forbedrede effektiviteten af clinoptilolit til at fjerne ammonium, orthophosphat, total $\mathrm{N}$ og opløst organisk kulstof, undtagen for total $\mathrm{P}$; og at dette reducerede kalium fjernelseseffektivitet i forhold til clinoptilolit alene.

I kapitel 5, testede jeg næringsstof-beriget biochar og clinoptilolit som kvælstofgødning i et potteforsøg ved dobbelt-potte teknik med rajgræs. Jeg fandt, at $\mathrm{N}$ bundet til clinoptilolit og biochar fra den flydende fraktion af digestat var tilgængeligt for planterne, og både beriget biochar og clinoptilolit var i stand til at øge udbyttet af biomasse og $\mathrm{N}$ optagelse. Men clinoptilolit resulterede i langt højere biomasse og $\mathrm{N}$-optagelse i forhold til beriget biochar. Jeg viste yderligere, at det initiale forhold af digestat og næringsstof var en vigtig parameter ikke kun til i forhold til fjernelseseffektivitet af næringsstof fra den flydende fraktion af digestat, men at det også påvirkede tilgængeligheden af $\mathrm{N}$ og dermed effektiviteten af det berigede materiale som anvendelse til gødning.

I kapitel 6 (Generel diskussion), kombinerede jeg de vigtigste resultater af min forskning og diskuterede deres konsekvenser.

Jeg konkluderede denne afhandling med en generel konklusion i kapitel 7 (Konklusioner og outlook) med en refleksion over resultaterne af denne afhandling i forhold til praktisk anvendelse af biochar og clinoptilolit til behandling af digestat. 
Jeg afsluttede dette kapitel med refleksion over relevansen af mine vigtigste konklusioner for fremtidig forskning.

Afslutningsvis, denne afhandling bekræfter at sorption med clinoptilolit og biochar kan være en lovende teknologi til at recirkulere næringsstoffer fra den flydende fraktion af digestat. Anvendelse af biochar og clinoptilolit giver en opkoncentrering af næringsstoffer og dermed reducerer digestatets volumen hvilket muliggør besparelser på opbevaring, transport og anvendelse af den omfangsrige flydende fraktion af digestat. Restprodukterne er digestat-beriget clinoptilolit og biochar som kan anvendes som $\mathrm{N}$ gødning. 


\section{Acknowledgements}

It has been a long journey between two countries, getting used to two environments in more than four years, moving back and forth, 'doing a joint PhD' together with all practical, academic and administrative formalities, and finally I am there... As it has been such a long journey, there have been many people contributing to it and making the journey a unique experience for me. I would like to take the opportunity to acknowledge some of them while knowing not all of them could be addressed here.

To start with, I would like to thank my supervisors Lars Stoumann Jensen, Lijbert Brussaard, Kor Zwart and Sander Bruun who have been very supportive and patient during my $\mathrm{PhD}$ experience. You guided me through all the way, even in times I did not realize I needed your guidance! I will miss our Skype meetings (which I called 'All Star meetings') where I could take the opportunity to learn from all of you. More specifically, Lars, I will miss your guidance which directed me in a more determined way rather than my own floating in thoughts way during the entire PhD. It has always been challenging to find availability in your calendar, but this has certainly led me to a better time and project management. Knowing I could always rely on your thorough feedback allowed me for sharpening my scientific skills with self-criticism. Sander, I have really enjoyed our discussions, which most of the time created a bigger curiosity and many more questions to be answered after leaving your office. I could easily do another $\mathrm{PhD}$ about the ideas we have been discussing about! Lijbert, thank you for your guidance towards science and academia. You helped me a lot structuring my academic thinking and writing. Kor, you have always given me encouragement and contributed to my independency as a researcher. I will miss our discussions, where we tried to 'make chocolate' out of our results. I would also like to thank Peter Kuikman who was not my supervisor, but a true mentor during my work at Alterra. Peter, I appreciate your encouragement and support to feel and present myself as an independent researcher.

I would like to thank our secretaries Lisbeth (UCPH) and Marnella (WUR) who were always smiling and helpful! Many thanks to the laboratory crew at both University of Copenhagen (UCPH) and Wageningen University (WUR). Ea, thanks a lot for being a helpful and dedicated colleague in the first place and later on becoming a dear friend of mine as a result of spending many hours to analyse my 
uncountable number of samples. Many thanks to Anja, Lene for being helpful. As for the Soil Quality Lab at WUR, I would like to give my special thanks to Jaap who shared a part of his limitless knowledge with me during my lab work in Wageningen. I have appreciated a lot the general attitude of 'never say no' of Soil Quality lab technical staff whenever I asked for a help. I would like to thank Andre, Gerlinde, Miranda, Monique, Johan, Popko and Willeke, Erna, for their patience and assistance. Many thanks to the technicians and staff members who helped me with the greenhouse experiments.

One may realize at some stage(s) of her/his academic life that statistics is an important discipline and it takes a lot of practice. I have been grateful to Johannes, Walter, Helle and Sander for their help whenever I was in trouble with statistics in general and more specifically with $\mathrm{R}$.

During these 4.5 years I had the pleasure of experiencing two working environments in Copenhagen and Wageningen. In both places I have been extremely lucky to have great colleagues and friends who crossed my way! To start with, I would like to thank all my colleagues at UCPH. I would also like to express my gratitude to my dear friends Aga, Anne, Clément, Eliza, George, Guillaume, Laetitia, Ludo, Mette, Petros, Sean, Thanos, Viktor, Wibke who made Copenhagen a second home for me and were there in all good and difficult times!

2.5 years after I started my $\mathrm{PhD}$, I had to move to my second institute where I enjoyed working with great people. Thanks to all my colleagues at Soil Quality Department. Angie, Bastian, Janna, Joana, Mart, Valentina, Walter, Tatiana, Wei, Xinxin, special thanks for good times. I felt like my third home was Wageningen, and I owe this feeling to meeting many great people who lived in this amazing university town. Andre, Aranka, Armando, Cata, Kris, Noora, Samet, Vicente and Yunus, thanks for the great times!

Special thanks goes to Eliza for helping me with the design of my thesis cover, and to Sean and Samet for proofreading my thesis.

I would like to express my gratitude to AgTraIn Consortium and programme coordinator Andreas de Neergaard, for giving me the great opportunity to be a part of AgTraIn family and supporting my PhD project which I have been feeling excited about from the very first day that I saw the advertisement on AgTraIn website. I would also like to acknowledge FERTIPLUS Project which supported the $4^{\text {th }}$ year of my PhD work. 
Even though doing a joint $\mathrm{PhD}$ is very rewarding, it can sometimes become challenging to work with four supervisors and in two countries. It certainly takes some time to get used to a new working environment and a new laboratory while working on the same $\mathrm{PhD}$ project. In addition, a joint degree can only be earned after fulfilling the requirements of both universities, which means bigger workload than fulfilling requirements in only one institute. Therefore, I wished to reflect on this matter by including a proposition in my $\mathrm{PhD}$ thesis. However, I could not include it since I already had enough number of propositions. Here, I would like to take the opportunity to include this proposition, hoping that it would somehow create awareness and help future joint PhD students:

"Joint degree PhD students who have to fulfill academic and administrative requirements at more than one institute should be given more time and resources compared to non-joint degree PhD students."

I would like to thank my former supervisor Bilsen Beler Baykal for believing in me from the very beginning of my master studies and supporting me like a mother... Many thanks to my dear cousins Özgur abla, Özlem abla, Ayşenur and Gizem, and friends in Turkey: Büşra, Arzu, Ayșe, Batıkan and Can for giving me the courage to start this journey, and being there whenever I needed your support!

I would like to give many thanks to my family who always believed in me... Sevgili ailem, sizlere duyduğum sevgiyi, bunca yıldır bir türlü alıșamadığım özlemi ve sonsuz minnetimi ifade etmenin bir yolu olsa keşke... Canım babacığım, yanımda olduğunu bilmek beni her zaman güçlü ve mutlu kıldı. Beni her koşulda destekleyeceğini bilerek, seçimlerimi hep özgürce ve heyecanla yaptım. İşte bu nedenle olsa gerek, seçimlerimden ötürü mutluluk duydum. Bu zorlu doktora yolunu seçerken de beni en çok destekleyen sen oldun! Beni özgür bir birey olarak yetiştirirken gösterdiğin sevgi, emek ve hoşgörü için sonsuz teşekkür ederim... Canım Asiye ablacığım, senin iyi niyetin, kocaman yüreğinle verdiğin desteğin ve her zaman sergilediğin olumlu yaklaşımın sayesinde, çıktığım yolculuklardan mutlulukla dondum ve bir sonraki maceraya ilerledim. Yaşamıma öyle bir incelikle dokundun ki, yaşamımdaki her şey güzelleşti... Canım Ahmetciğim, aramızdaki yaş farkının artık yalnızca sayılarla farkedilebileceği günlerden bu yana bana bir dost ve sırdaş oldun. Heyecanlarımı ve korkularımı paylaştığım canım kardeșim, bu yola çıkarken de en büyük destekçilerimden birisi sendin! Kopenhag'a ve Wageningen'e taşınırken benimle gelip, her defasinda değișen hayatıma şahitlik ettiğin ve o ilk günlerin heyecanına eşlik ettiğin için ne kadar teşekkür etsem azdır... 
Finally, my deepest gratitude goes to Johannes! My dear fiancé and soon to be my husband... I cannot thank you enough for all the encouragement and support that you have given me since we met! You have made this difficult path much easier, especially whenever we had to move from one country to another, back and forth... With you, it has always felt like home! Your patience helped me to find strenght whenever I freaked out about the magnitude of the challenges. Your love helped me whenever I needed to remember that life is a wonderful experience! Thank you!

Thanks to everyone who has been a part of this unique experience for me! 


\section{Curriculum Vitae}

Nazlı Pelin Kocatürk was born on the 24th of August, 1983, in Istanbul, Turkey. In June 2006, she completed her bachelor's degree in Forest Industry Engineering at Istanbul University, Turkey. In the last year of her bachelor's programme, she realised her interest in environmental engineering.

In September 2006, she began her Master's degree in Environmental Sciences and Engineering at Istanbul Technical University. Her MSc thesis, Removal of nutrients from separately collected

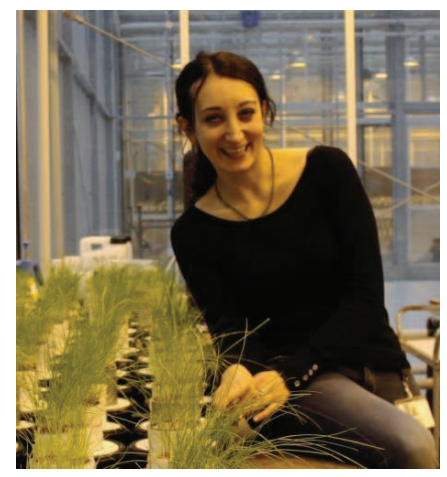
human urine with clinoptilolite and their recovery for agricultural reuse, developed her interest for the topic of nutrient removal and recovery from waste, and the use of sorption processes in environmental engineering.

In 2011, she was accepted to Erasmus Mundus Joint Doctorate Programme Agricultural Transformation by Innovation (AgTraIn). She conducted her research between September 2011 and April 2014 at the Department of Plant and Environmental Sciences, University of Copenhagen, Denmark. In 2014, she moved to the Netherlands to continue her PhD project at the Department of Soil Quality, Wageningen University.

In addition to her $\mathrm{PhD}$ project, she also worked as a researcher between September 2014 and September 2015 at Alterra WUR, where she contributed to Fertiplus Project, co-funded by the European Commission. 


\section{List of publications}

Kocatürk NP, Baykal BB (2012) Recovery of Plant Nutrients from Dilute Solutions of Human Urine and Preliminary Investigations on Pot Trials. Clean - Soil, Air, Water, 40, 538-544.

Beler Baykal B, Kocatürk NP, Allar AD, Sari B (2009) The effect of initial loading on the removal of ammonium and potassium from source-separated human urine via clinoptilolite. Water Science and Technology, 60, 2515-2520. 


\section{PE\&RC Training and Education Statement}

With the training and education activities listed below the $\mathrm{PhD}$ candidate has complied with the requirements set by the C.T. de Wit Graduate School for

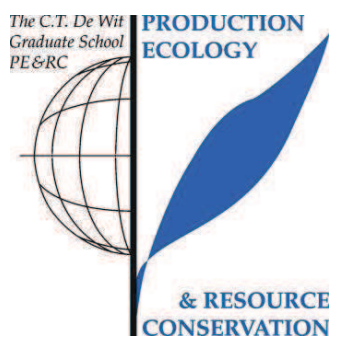
Production Ecology and Resource Conservation (PE\&RC) which comprises of a minimum total of 32 ECTS (= 22 weeks of activities)

\section{Review of literature (6 ECTS)}

- Biogas digestate recycling as crop fertilizer (2013)

\section{Writing of project proposal (4.5 ECTS)}

- Biogas digestate recycling as crop fertilizer (2013)

\section{Post-graduate courses (14 ECTS)}

- Introductory course to doctorate research within agricultural development, food chains and innovation; AgTraIn (2011)

- Plant nutrition in terrestrial ecosystems-acquisition and turnover; University of Copenhagen (2012)

- Stable isotopes in ecosystem research; University of Lorraine (2012)

- Chemistry of liquid waste; Aarhus University (2012)

- Statistical methods for biosciences; University of Copenhagen (2013)

\section{Deficiency, refresh, brush-up courses (12 ECTS)}

- The carbon dilemma; Wageningen University (2012)

- Nutrient management; Wageningen University (2012)

\section{Competence strengthening / skills courses (3 ECTS)}

- The essentials of scientific writing and presenting; Wageningen University (2014)

- How to write grant proposals; University of Copenhagen, Wageningen University (2015)

- Career lab for PhD students; University of Copenhagen (2015) 
PE\&RC Annual meetings, seminars and the PE\&RC weekend (1.2 ECTS)

- PE\&RC First year weekend (2012)

- WGS: PhD Workshop carousel (2014)

Discussion groups / local seminars / other scientific meetings (3.4 ECTS)

- Nordic Association of Agricultural Sciences meeting (2011)

- Agricultural transformation by innovation annual scientific meetings (20112012)

- Annual PhD student conference of Department of Plant and Environmental Sciences; University of Copenhagen (2013)

- Fertiplus Science Camp meetings (2013-2015)

International symposia, workshops and conferences (8 ECTS)

- Ramiran Conference; poster presentation; Versailles, France (2013)

- ManuResource Conference; oral presentation; Bruges, Belgium (2013)

- Biochar Research Symposium; oral presentation; DTU Risø, Denmark (2013)

- Organic Matter Management and Compost Use for Horticulture; oral presentation; Murcia, Spain (2015)

- FIRe joint scientific meeting; oral presentation; Neudietendorf, Germany (2015)

Lecturing / supervision of practical's / tutorials (4.2 ECTS)

- Applied plant nutrition $(2012,2013)$

- Environmental chemistry in biological systems $(2012,2013)$ 


\section{Funding}

This research was financially supported by the Agricultural Transformation by Innovation (AgTraIn) Erasmus Mundus Joint Doctorate Programme funded by the Education, Audiovisual and Culture Executive Agency (EACEA) and the EU FP-7 FertiPlus Project (grant no. 289853).

Cover design by Elisavet Papageorgiou

Thesis printed by Proefschriftmaken.nl || Digiforce Vianen 